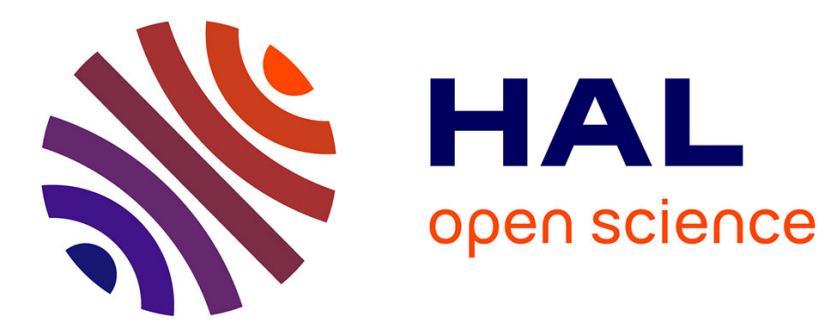

\title{
Epidemiology and Evolution of Fungal Pathogens in Plants and Animals
}

Pierre Gladieux, Edmond Byrnes, Gabriela Aguileta, Matthew C. Fisher, Joseph Heitman, Tatiana Giraud

\section{- To cite this version:}

Pierre Gladieux, Edmond Byrnes, Gabriela Aguileta, Matthew C. Fisher, Joseph Heitman, et al.. Epidemiology and Evolution of Fungal Pathogens in Plants and Animals. Genetics and Evolution of Infectious Disease, Elsevier, pp.59-132, 2011, 978-0-12-384891-8. 10.1016/B978-0-12-384890-1.000042. hal-02333038

\section{HAL Id: hal-02333038 \\ https://hal.science/hal-02333038}

Submitted on 6 Jun 2020

HAL is a multi-disciplinary open access archive for the deposit and dissemination of scientific research documents, whether they are published or not. The documents may come from teaching and research institutions in France or abroad, or from public or private research centers.
L'archive ouverte pluridisciplinaire HAL, est destinée au dépôt et à la diffusion de documents scientifiques de niveau recherche, publiés ou non, émanant des établissements d'enseignement et de recherche français ou étrangers, des laboratoires publics ou privés. 


\title{
4 Epidemiology and Evolution of Fungal Pathogens in Plants and Animals
}

\author{
Pierre Gladieux ${ }^{1}$, Edmond J Byrnes III' ${ }^{2}$, Gabriela \\ Aguileta $^{1}$, Matthew C Fisher ${ }^{3}$, Joseph Heitman ${ }^{2}$ and \\ Tatiana Giraud ${ }^{1, *}$ \\ ${ }^{1}$ Ecologie, Systématique et Evolution, UMR 8079, Bâtiment 360, Univ. \\ Paris-Sud, F-91405 Orsay, France; UMR 8079, CNRS, F-91405 Orsay, France, \\ ${ }^{2}$ Department of Molecular Genetics and Microbiology, Duke University \\ Medical Center, Durham, North Carolina, United States of America, \\ ${ }^{3}$ Department of Infectious Disease Epidemiology, School of Public Health, \\ Imperial College London, St. Mary's Hospital, Norfolk Place, London W2 \\ $1 P G, U K$
}

\section{s0010 4.1 Introduction}

p0030 Although parasitism is one of the most common lifestyles among eukaryotes, population genetics on parasites lag far behind those on free-living organisms, probably because they are rarely conspicuous in the environment, do not possess the visible morphologic or behavioral variation used in the early studies of population genetics, and are less charismatic than the macrofauna. However, the advent of molecular markers offers great tools for studying key processes of parasite biology, such as dispersal, mating systems, host adaptation, and patterns of speciation. Population genetics studies have also valuable practical applications, for instance for studying the evolution of drug resistance or new virulence. Another reason to study epidemiology and evolution in parasites is that they display a huge diversity of life cycles and lifestyles, thus providing great opportunity for comparative studies to test pathogen-specific questions or general issues about evolution. Nevertheless, the field of parasitology has yet to attract more evolutionary biologists. This is especially true for fungal parasites, despite their importance in crop diseases, and even in animal and human diseases. Furthermore, despite their obvious common interests there are few connections so far between scientists working on fungal parasites versus other parasites.

* E-mail: tatiana.giraud@u-psud.fr 
Approximately 100,000 species of fungi have been described so far (1.5 million fungal species are estimated to exist; Hawksworth, 1991), of which a high percentage obtain nutrients by living in close association with other organisms, mainly plants. Many fungi are pathogenic and can have important impact on human health or lead to severe economic losses due to infected crops or to animal diseases. Fungal species parasitizing animals and plants are found interspersed with saprophytes and mutualists in fungal phylogenies (Berbee, 2001; James et al., 2006), suggesting that transitions between these life-history strategies have occurred repeatedly within the fungal kingdom.

p0040 True fungi belong to the opisthokont clade, as do animals. The two major groups that have been traditionally recognized among the true fungi are the Ascomycota, including the yeasts and filamentous fungi, with several important model species (e.g., Saccharomyces cerevisiae, Neurospora crassa), and the Basidiomycota, including the conspicuous mushrooms, the rusts and the smuts. Ascomycota and Basidiomycota have been resolved as sister taxa (Lutzoni et al., 2004; James et al., 2006) and they have been called the Dikaryomycota (Schaffer, 1975). The dikarya contain the majority (ca. 98\%) of the fungal species, including most of the human and plant pathogens. Basal to the Dikarya branch there are several other fungal groups. The Glomeromycota, mycorrhizal mutualists, are united within a clade with the dikarya (James et al., 2006). The Zygomycota are common in terrestrial and aquatic ecosystems, but they are rarely noticed by humans because they are of microscopic size. Some fungi among the Zygomycota are pathogens of animals (including humans), plants, amoebae, and other fungi (mycoparasites). Zygomycota branch at the base of the clade containing the dikarya and the Glomeromycota. The Chytridiomycota are defined as fungi with flagellated cells and were long thought to be the sister group of all the other true fungi, nonflagellated. However, recent phylogenies suggested that the chytrids may in fact be polyphyletic, representing early diverging lineages having retained the ancestral flagellum (James et al., 2006). Chytrids also encompass plant and animal pathogens. Microsporidia are obligate endoparasitic, protist-like organisms with highly reduced morphology and genomes; they have recently been proposed to belong to the fungi, as the most basal group (James et al., 2006). Oomycetes have long been considered as fungi but were recently recognized to belong to the distant Stramenopiles (Keeling et al., 2005). These filamentous organisms however share many morphologic and physiologic characteristics with fungi and continue to be studied by mycologists. They also contain plant pathogens, such as Plasmopara viticola, responsible for the grape mildew, and Phytophthora species, causing devastating emerging diseases, in particular on trees. Some oomycetes are pathogens on fishes or amphibians. We will therefore also consider oomycetes in this chapter.

p0045 Most fungi have been dependent on other organisms for their resources through much of their evolutionary history, in particular, fungal pathogens. During the past century, however, many new fungal diseases have emerged. This is probably due to human activities that have completely modified the ecosystems on earth at a global scale (e.g., climate warming, widespread deforestation, habitat fragmentation and urbanization, changes in agricultural practices, global trade) (Kareiva et al., 2007). 
Of these, the intensification and globalization of agriculture as well as the increase in international trade and travel have broken down many natural barriers to dispersal causing an unprecedented redistribution of many organisms (Kolar and Lodge, 2001). Concomitantly, there is growing evidence that these global changes play a key role in the emergence of infectious diseases in humans (Tatem et al., 2006), wildlife (Daszak et al., 2000), domestic animals (Cleaveland et al., 2001), and plants (Anderson et al., 2004).

p0050 To understand how new diseases emerge, and more generally to understand the spread and maintenance of diseases, it is essential to study dispersal, mating systems, host adaptation, and mechanisms of speciation. The advent of molecular markers offers great tools for studying these key processes of parasite biology (Criscione et al., 2005; Giraud et al., 2008a). Molecular markers, together with mathematical modeling and experiments, have also been instrumental to unravel the mechanisms of fungal speciation (Giraud et al., 2008b). The recent development of full genome sequencing, especially among fungi because they have small genomes (Galagan et al., 2005), has allowed comparative genomics to begin drawing inference on the mechanisms of pathogenicity (Aguileta et al., 2009).

p0055 In this chapter, we will thus describe the main pathogenic fungi, parasitizing humans, animals, and plants, and having important consequences on human health or human activities. We will focus on some examples of recent emerging fungal diseases on humans, animals, and plants. We will then review (1) the modern molecular tools used for epidemiology and population genetics of fungal pathogens, the types of markers most useful, and the different types of analyses that can be performed to unravel their mating systems and dispersal; (2) the criteria used for species delimitation in fungi and the mechanisms of fungal speciation that have been elucidated to date; (3) the recent advances in fungal genomics, in particular the insights that have been gained so far regarding the pathogenic lifestyles; and (4) the relationship between mating and pathogenesis in fungi.

\section{s0015 4.2 Major Human and Animal Pathogenic Fungi}

p0060 Each of the four major fungal phyla has representatives that cause serious disease in both humans and a vast range of other animals. Although less prevalent than plant pathogens, the animal pathogens pose serious threats to entire animal populations and continue to cause serious morbidity and mortality among immunocompromised patients and otherwise healthy individuals worldwide. In many cases, the incidence of disease is increasing due to a rise in susceptible hosts, while at the same time the treatment options have remained limited in comparison to other classes of pathogens. A major factor influencing treatment is that, unlike bacteria and viruses, the fungi are eukaryotic siblings to the animals. These issues cause major obstacles in the search and development of new antimicrobials that target fungi without causing major toxic side effects against animal metabolism. Here we summarize the morbidity and mortality associated with several of the major classes of human and animal pathogenic fungi. 


\subsubsection{Ascomycetes: The Candida Species Complex, Aspergillus fumigatus, Pneumocystis, the Dimorphic Fungi, and Others}

p0065 Within the fungal kingdom, the ascomycetes harbor the majority of fungal pathogens that afflict humans. Among these, Candida species are the most common causes of invasive fungal infections in humans. Infections can range from readily treatable mucocutaneous disorders, although these may be acute in AIDS-infected patients, to severe invasive disease that can result in significant morbidity and mortality, most often occurring in patients with immune system suppression (Pappas et al., 2003, 2009). Candidemia is the fourth most common cause of nosocomial bloodstream infections in the USA (Wisplinghoff et al., 2004), with similar levels in many other developed countries. It has been estimated that the attributable mortality of invasive candidiasis is approximately $15-25 \%$ for adults and $10-15 \%$ for the pediatric population (Morgan et al., 2005; Zaoutis et al., 2005), with one study reporting mortality rates reaching levels $>45 \%$ (Gudlaugsson et al., 2003).

p0070 Another of the major causes of human fungal infections is the filamentous pathogen, A. fumigatus and other closely related Aspergillus species. Aspergillosis, primarily invasive aspergillosis, is an emerging disease in the immunocompromised population (Walsh et al., 2008). The spores are widely prevalent in all environments, and are readily inhaled, causing both respiratory and disseminated disease in immunocompromised patients. There is a particularly high incidence of aspergillosis among stem cell and solid organ transplant recipients (Paterson and Singh, 1999; Marr et al., 2002a,b). Additionally, infected patients often have long and costly hospitals visits (Dasbach et al., 2000), making this disease a major concern, particularly in hospital settings.

p0075 A group of pathogenic fungi in humans that cause serious disease in both healthy and immunocompromised individuals are the dimorphic fungi. The name dimorphic stems from the common feature that all of these pathogens grow in a filamentous mold form in the environment, and based on changes in temperature grow as yeast at mammalian host temperatures and in the infected host (Rappleye and Goldman, 2006). This class of fungi includes the primary pathogens Histoplasma capsulatum, Coccidioides immitis, and Coccidioides posadasii, as well as species that more often infect immunocompromised individuals, including Blastomyces dermatitidis, Sporothrix schenckii, Paracoccidioides brasiliensis, and Penicillium marneffei (Fraser et al., 2007; Reis et al., 2009; Sharpton et al., 2009). All of these species (except S. schenckii and H. capsulatum) are known as "endemic mycoses". These are pathogenic fungi that have restricted ranges and tend to be associated with specific ecologic niches. For instance, C. immitis and C. posadasii are associated with the Lower Sonoran Life Zone-low hot deserts found only in northern, central, and southern America. Within these regions, the fungus exists as mycelia in sandy soils, as well as infections in small desert mammals such as kangaroo rats (Dipodomys) (Rippon, 1988). Human infection occurs as a consequence of the inhalation of arthroconidia, which can then undergo a temperature-determined dimorphic transition into septate spherules that disseminate throughout the body via hematogenous spread, causing a severe and life-threatening 
disease in a variable proportion of individuals. In common with Coccidioides, other endemic dimorphic mycoses inhabit recognizable ecologic niches that are often associated with animals. For instance, $P$. marneffe $i$ is the only pathogenic species of Penicillium from the highly speciose biverticilliate clade, and exhibits a highly constrained distribution to the wet tropics of Southeast Asia (Vanittanakom et al., 2006). Within this region, the pathogen is found infecting a high proportion of the tropical bamboo rat species Rhizomys and Cannomys, and is a key HIV-associated mycosis across the region. Although the route of human infection has yet to be confirmed, it is likely to stem from the inhalation of airborne conidia whereupon a thermally regulated dimorphic transition to a fission arthroconidium form occurs. Dissemination throughout the body causes significant pathologic effects with involvement documented for most of the major body organs (Vanittanakom et al., 2006).

p0080 Although the incidence of HIV-associated mycoses has decreased since the establishment of highly active antiretroviral therapy (HAART), pneumocystis infections are another of the major human pathogens infecting immunosuppressed hosts, with high incidences observed in the AIDS-infected and stem cell transplant recipient populations (Cushion, 2004). Infections result in a severe pneumonia, and are predominantly caused by Pneumocystis jirovecii, a widely prevalent species known to principally infect mammalian lung cells (Calderon, 2010). Research in this group of pathogens is difficult because axenic in vitro cultivation remains elusive. Culturing techniques are currently limited to growth in mammalian tissue culture cell lines (Cushion and Walzer, 1984a,b).

\section{s0025 4.2.2 Basidiomycetes: The Pathogenic Cryptococcus Species Complex}

p0085 Cryptococcus neoformans and Cryptococcus gattii comprise the pathogenic Cryptococcus species complex. They are related basidiomycete yeast species that are common fungal pathogens of both humans and animals. The two species are distinguished in that $C$. neoformans is prevalent, ubiquitous worldwide, largely associated with pigeon guano, and a common cause of meningitis in immunocompromised hosts (Perfect, 1989; Casadevall and Perfect, 1998; Carlile et al., 2001). C. gattii is generally geographically restricted to tropical and subtropical regions, associated with trees, and commonly infects immunocompetent hosts, although cases in immunocompromised patients also occur (Kwon-Chung and Bennett, 1984a,b; Sorrell, 2001). It is estimated that the two sibling species diverged $\sim 37.5$ million years ago, which may explain the observed differences in ecology and host range (Kwon-Chung et al., 2002). Additionally, the "tropical" status of C. gattii has been recently challenged by the occurrence of an outbreak that began in 1999, initially on Vancouver Island, Canada at latitude $49.28^{\circ}$. This emerging infection has since expanded into mainland British Columbia and the Pacific Northwest region of the USA (Kidd et al., 2004; Fraser et al., 2005; MacDougall et al., 2007; Upton et al., 2007; Byrnes et al., 2009b; Datta et al., 2009).

p0090 C. neoformans can be further subdivided into two serotypes (A and D) based on unique antigenic profiles and sequence divergence (Kwon-Chung and Varma, 
2006; Bovers et al., 2008). This distinction is clinically relevant, as serotype A strains cause the vast majority of infections globally, with high incidences in the AIDS and transplant populations (Casadevall, 1998; Blankenship et al., 2005; Singh et al., 2008). Overall, $>99 \%$ of AIDS-related infections and $>95 \%$ of overall cases are attributable to serotype A (Casadevall, 1998). The global burden of disease is significant, with a recent report documenting almost 1 million annual cases with over 620,000 attributable mortalities, resulting in approximately onethird of all deaths in AIDS patients (Park et al., 2009). While less prevalent globally, C. gattii has also been a significant cause of morbidity and mortality, with high incidences in humans and animals reported in North America, Australia, Southeast Asia, and South America (Sukroongreung et al., 1996; Chen et al., 2000; Sorrell, 2001; Lizarazo et al., 2007; MacDougall et al., 2007; Galanis and MacDougall, 2010). Thus, the Cryptococcus species complex remains a global health concern for both humans and a wide range of domestic, agrarian, and wild mammals.

\subsubsection{Globally Emerging Fungal Infections in Wildlife Species}

p0095 While fungi are recognized as serious pathogens to their human hosts, it is also becoming clear that fungal pathogens have the capacity to cause severe disease in wildlife species. Notably, several of the fungi that are currently causing impacts on biodiversity were not previously recorded as pathogens. This illustrates not only the vast pool of undescribed fungal taxa, but also the capability of any branch of the fungal tree to give rise to serious pathogens. For instance, globally spreading chytridiomycosis in amphibians stems from a basal fungal lineage that was never before found to infect vertebrates (Fisher and Garner, 2007; Voyles et al., 2009). Similarly, Nosema ceranae, another microsporidian basal fungal lineage, has been discovered as a contributing agent for the currently mysterious declines in honeybee colonies (Klee et al., 2007). More recently, a new fungal infection of bats called white-nose syndrome (WNS) has swept though the northeastern USA since 2008 , causing the deaths of $>1$ million bats and extirpating some well-known cave roosts (Blehert et al., 2008). The etiologic agent has been described as an ascomycete fungus Geomyces destructans, related to the human skin-infecting fungus Geomyces pannorum (Meteyer et al., 2009). These fungi exemplify the wide range of disease syndromes that are attributable to fungi, and the breadth of hosts that they are able to infect.

\section{s0035 4.3 New and Emerging Mycoses}

\section{s0040 4.3.1 Evolution and Emergence of Pathogenic C. gattii Genotypes in the Pacific Northwest}

p0100 As of 1999, C. gattii emerged as a primary pathogen in northwestern North America, including both Canada and the USA (Kidd et al., 2004, 2005; Fraser et al., 2005; MacDougall et al., 2007; Bartlett et al., 2008; Byrnes et al., 2009b; 
Byrnes and Heitman, 2009; Galanis and MacDougall, 2010). This outbreak now spans a large geographic range, with levels of infection as high or higher than anywhere else globally, with an annual incidence on Vancouver Island of approximately 25 cases/million (Galanis and MacDougall, 2010). The only two reports with higher overall levels are one examination of native Aboriginals in the Northern Territory of Australia, and a study conducted in the central province of Papua New Guinea (Fisher et al., 1993; Seaton, 1996; Galanis and MacDougall, 2010). Specifically, C. gattii is classified into four discrete molecular types (VGI-VGIV), with molecular types VGI and VGII as the two most frequent causes of illness in otherwise healthy individuals (Byrnes and Heitman, 2009). Infections due to VGI have been reported at high rates among populations in Australia, while the levels of VGII infection are high in the Pacific Northwest, where $\sim 95 \%$ of all cases are attributable to this molecular type (Sorrell, 2001; Fraser et al., 2003, 2005; Bovers et al., 2008; Byrnes and Heitman, 2009). The appearance of $C$. gattii in North America is startling because this is the first major emergence in a temperate climate (MacDougall and Fyfe, 2006; Kidd et al., 2007b). To examine the evolutionary aspects of this unprecedented emergence, efforts were undertaken to study the molecular epidemiology and characteristics of isolates collected from humans, animals, and the environment. These efforts have and will continue to shed light onto several key features of this outbreak, while other contributing factors remain elusive.

p0105 The first efforts to elucidate the molecular types of the isolates collected in the Vancouver Island area revealed that two genotypes, now known as VGIIa/major and VGIIb/minor, are responsible for the vast majority of cases (Kidd et al., 2004; Fraser et al., 2005). C. gattii was identified in the number of environments including several tree species, the air, soil, seawater, and freshwater (Kidd et al., 2007a,b; Bartlett et al., 2008). These studies then led to questions surrounding the properties of the common genotypes in the region. The VGIIa/major genotype was found to be highly virulent in a murine model of infection (Fraser et al., 2005). In addition, the examination of the isolates, particularly the discovery of a homozygous VGIIa/ major diploid and the molecular characterization of the genome and mating-type locus, led to the hypothesis that same-sex mating was involved in this $\alpha$ only outbreak (Fraser et al., 2005). Together, these efforts showed that $C$. gattii VGII was now endemic in much of the region, and that the genotype responsible for the majority of cases is highly virulent in animal models of infection and also possibly in humans.

p0110 The next question in the field became focused on a possible expansion of the outbreak zone and the molecular and phenotypic characterizations of virulent isolates.

p0115 In 2007 and 2008, the first reports of C. gattii in the Pacific Northwest of the USA were published. The report of Upton and colleagues (2007) illustrated the first confirmed case of the Vancouver Island outbreak VGIIa/major in the USA (2006) from a patient in Puget Sound, Washington. Additionally, in 2005, MacDougall and colleagues discovered an increased number of outbreak-related cases on the mainland of British Columbia and related C. gattii VGII genotypes in the USA, including one later recognized as a VGIIc/novel isolate. Shortly thereafter, studies 
by Byrnes et al. documented a large cohort of clinical and veterinary cases from the VGIIa/major outbreak genotype in both Washington and Oregon (Byrnes et al., 2009a,b). These studies also reported VGIIb/minor in the USA, and importantly, defined a novel VGIIc genotype that was unique to Oregon and observed in both human and animal cases (Byrnes et al., 2009b).

p0120 Recent phenotypic examinations have also begun to address several key aspects of the outbreak genotypes. Studies in the mouse model revealed that $C$. gattii isolates from the outbreak induced less protective inflammation than $C$. neoformans, indicating that $C$. gattii may thrive in immunocompetent hosts by evading or suppressing the protective immune responses that normally limit $C$. neoformans disease progression (Cheng et al., 2009). Another unique feature of the outbreak VGIIa/major genotype is its ability to proliferate at high levels within macrophages as well as the ability to form highly tubular mitochondria after intracellular parasitism (Ma et al., 2009). These unique features were also shown to be positively correlated with murine virulence (Ma et al., 2009). Recently, it had also been shown that the VGIIc/novel genotype shares similar intracellular proliferation rates, mitochondrial morphology, and murine virulence characteristics with the VGIIa/major genotype, further supporting the hypothesis that the genotypes seen in the region are uncharacteristically enhanced for virulence (Byrnes, Lewit, Li, et al., PLoS Pathogens 2010 in press).

p0125 Over the past decade, we have witnessed the emergence and expansion of a tropical/subtropical pathogen into a temperate climate, leading to the formation of a multidisciplinary $C$. gattii working group established to address the epidemiology, clinical features, and basic science questions surrounding this outbreak (Datta et al., 2009). Although the overall incidence remains low, little is currently known about how or why specific humans and animals become infected and may involve unique host factors, including possible genetic predispositions. In addition, the origins of the VGIIa/major and VGIIc/novel genotypes remain elusive. Substantial progress has been achieved in addressing the molecular epidemiology and expansion of the outbreak, and also the phenotypic characteristics that make these genotypes unique. However, many critical questions remain to be addressed in the future to understand the evolutionary dynamics of this unprecedented C. gattii emergence in the region of the world, including expanded environmental sampling, further phenotypic characterizations of associations with host animals and plants, and genome sequencing of more representative $C$. gattii mitochondrial and nuclear genomes.

s0045 The Global Emergence of the Amphibian Pathogen Batrachochytrium dendrobatidis

p0130 The ability of fungi to cause severe disease in nonhuman vertebrate species has been dramatically illustrated by global declines in amphibian biodiversity caused by the fungus Batrachochytrium dendrobatidis $(B d)$. Only discovered in 1997 (Berger et al., 1998) and named in 1999 (Longcore et al., 1999), Bd is a basal fungal lineage in the Chytridiomycota; these fungi are characteristically aquatic and 
unique from other fungi in that they have a motile, flagellate zoospore (James et al., 2006). Many species of chytrid have been described in aquatic environments and soils, as free-living or commensal organisms, and as parasites of algae, invertebrates, and fungi (Gleason et al., 2008). Of these, $B d$ is unique in that it is the only chytrid known to parasitize vertebrates, by infecting and developing within the keratinized epidermal cells of living amphibian skin (Pessier et al., 1999; Piotrowski et al., 2004). $B d$ is now known to be widespread in all continents except Antarctica (where amphibian hosts do not occur). A global-mapping project for this pathogen has shown that $B d$ infects over 350 species of amphibian, and has been implicated in driving the declines and extinctions of over 200 of these (http://www.spatialepidemiology.net/bd-maps/; Fisher et al., 2009).

p0135 Following the discovery that $B d$ was a driver of declines in amphibian species in Australia, the Americas, and Europe, much attention has been focused on finding out how $B d$ was being spread, and from where. In eastern Australia, prospective and retrospective sampling of amphibians has shown that populations were initially $B d$-negative prior to 1978 , followed by an expansion north and south from a center in southern Queensland; western Australia was $B d$-negative until mid-1985, whereupon the spread of disease was detected and documented (Berger et al., 1998). Mesoamerica has witnessed a rapid wave-like front of expansion from an apparent origin in Monteverde, Costa Rica, southward at estimated rates of 17-43 km/year, and has recently jumped the Panama Canal (Lips et al., 2008). The epidemic front of chytridiomycosis along the North-South transect of Central America has been predictable to the extent that researchers have been able to anticipate the arrival of $B d$ in uninfected regions, such as El Copé in Panama, and to document the collapse of the amphibian community upon arrival of the pathogen and the onset of chytridiomycosis (Lips et al., 2006).

p0140 Given these patterns of declines, where is the original source of $B d$ ? Answers to this question have been sought by attempting to identify geographic regions where $B d$ has had a long and stable association with host species, indicative of coevolution, as well as substantially increased levels of genetic diversity when compared against the various regional epizootics. One such study by Weldon et al. (2004) has identified Africa as a potential source of the panzootic. Histology on historical museum specimens showed that $B d$ has infected amphibians in Southern Africa since at least 1938, and the "Bd Out of Africa" hypothesis was coined to suggest that $B d$ was spread around the world via the extensive trade in the African clawed frog Xenopus laevis from the 1930s onward. However, the recently published molecular analysis by James et al. (2009) on global strains of the pathogen failed to find evidence that Africa contains more diversity than occurs in other regions, and in fact found that North American isolates of $B d$ were more highly diverse than elsewhere and that a single globalized lineage is causing the current panzootic. However, recent discovery that genotypes of $B d$ occur in the Japanese archipelago that appear basal to the panzootic lineage suggests that there may yet be other potential sources of $B d$ diversity (Goka et al., 2009). Therefore, the overarching question on the origin of $B d$ remains unanswered to date. What is clear, however, is that the global trade in amphibians is a potent force in spreading $B d$ into naïve 
populations and species. This statement is especially true for the so-called Typhoid Mary species such as $X$. laevis and the North American bullfrog Rana catesbeiana; these species carry $B d$ infections but rarely exhibit the disease, chytridiomycosis. They are also widely traded and are often highly invasive when introduced by accident or purpose into new environments (Fisher and Garner, 2007). Therefore, these two species constitute ideal vectors for introducing $B d$ into uninfected regions of the globe (Garner et al., 2006) and are likely a major source of new $B d$ infections when released into naïve environments.

p0145 Currently, it is not known whether the genome of $B d$ harbors the genes for mating and meiosis, although such genes have been found in the related Zygomycete lineage Phycomyces blakesleeanus (Idnurm et al., 2008). Importantly, all population genetic studies thus far have shown that $B d$ exhibits levels of heterozygosity that are consistent with a predominately asexual mode of reproduction. Of James' 17 sequenced polymorphic loci, 8 of these exhibited heterozygote excess. By anchoring the 17 sequenced loci to the genome-scaffolds, James et al. (2009) showed that levels of heterozygosity were not uniformly distributed across the genome, but were significantly reduced on the largest inferred chromosome where loss of heterozygosity $(\mathrm{LOH})$ had occurred. This pattern of $\mathrm{LOH}$ is not consistent with sexual reproduction and segregation, but rather with a model of chromosomespecific variation in mitotic (somatic) recombination, a process that is well documented in other fungi including the diploid pathogenic fungus Candida albicans that exhibits vegetative diploidy (Odds et al., 2007).

p0150 This model of asexual LOH driving the diversity of $B d$ isolates is not, however, consistent across all studied populations. For instance, $B d$ sampled from Sierra Nevada populations of the mountain yellow-legged frogs, Rana muscosa, showed that, while allelic diversity was still found to be low throughout the dataset, within some local populations genotypic diversity was high. In these "high diversity" populations no new alleles appeared to have been introduced, and no genotypes were shared between different infected populations. Thus, it was suggested that local recombination had occurred within introduced lineages infecting particular lakes (Morgan et al., 2007). These findings have two interpretations: either $B d$ has the potential for outcrossing that is largely unrealized due to population bottlenecks causing the loss of complementary mating types or that $\mathrm{LOH}$ can occur at variable rates in different populations, generating a spurious "signal" of genetic recombination. Recent efforts to sample more global isolates of $B d$ coupled to next-generation sequencing techniques are likely to reveal with greater clarity the mechanisms by which the $B d$ genome evolves.

p0155 Despite the apparent rapid spread of $B d$ and the high degree of genetic similarity between isolates, data is accumulating showing that genotypes differ significantly in their virulence. Fisher et al. (2010) showed that the sporangia of five isolates of $B d$ from the Balearic Island of Mallorca, all with identical genotypes, were similar in size, but differed significantly from those isolates recovered from amphibians in mainland Spain and the UK. When the virulence of a Mallorcan isolate of $B d$ (TF5a1) and a UK isolate of $B d$ (UKTvB) was assayed in Bufo bufo (Fisher et al., 2010), the Mallorcan strain of $B d$ was avirulent in comparison against the UK 
strain of the pathogen. Proteomic profiling of a global set of isolates showed that there was significant interisolate variation in patterns of protein expression. The amount of differentiation among isolates at neutral genetic markers and biologic (morphologic and proteomic) characters was greatest for morphologic traits, suggesting that these characters are under selection, and that this is possibly related to local environmental conditions (Fisher et al., 2009). These data suggest that, if $B d$ is able to generate functional diversity from a genetically depauperate genetic background via recombination, and thus increase its rate of adaptation to new environments, then the pathogen likely has the capacity to adapt to new climates and/or host species. This raises the possibility that $B d$ may increase its fitness to new environments and/or species combinations, and in this way change future patterns of disease in ways that parallel to those seen in other species of pathogenic fungi such as C. gattii.

\subsubsection{Origin of Human Pathogens: Cryptococcus and Candida from Saprobes Associated with Insects}

p0160 The origin and evolution of pathogens remain central questions in studies of both plant and animal diseases. One method to examine the likely origins of pathogens is to phylogenetically place the species into the context of closely related saprobic relatives. As mentioned earlier, Cryptococcus and Candida represent major classes of mammalian fungal pathogens, and in both cases their closest related species are associated with insects. Although these sibling species are less often studied than their medically relevant counterparts, they offer important insights into the evolution of the animal pathogens and how these pathogenic species might have arisen from insect-associated saprophytes.

p0165 Phylogenetic analyses indicate that the Cryptococcus species complex likely arose from the Tremella lineage and that it clusters closely with the Tremellales, Trichosporonales, Filobasidiales, and Cystofilobasidiales (Ergin et al., 2004; Rimek et al., 2004; Sampaio et al., 2004). Several of the species within these lineages are saprophytes that are commonly associated with insect debris, leading to the hypothesis that the pathogens emerged from an association within this environmental niche (Findley et al., 2009). In support of this hypothesis, C. gattii has been isolated from both insect frass and wasp nests, and $C$. neoformans has been isolated from honeybee hives, indicating that these animal pathogens may still in some cases act as an insect-associated saprophyte in the environment (Gezuele et al., 1993; Kidd et al., 2003; Ergin et al., 2004). While the evolutionary factors influencing the emergence of a mammalian pathogen from saprobes are still unclear, the support for this hypothesis of emergence based on phylogenetic and ecologic studies gives insights into the emergence of the pathogenic Cryptococcus species complex.

p0170 In addition to the studies mentioned earlier, interactions between Cryptococcus and insects have been further supported by the development of a well-validated insect model of pathogenesis in the model insect Galleria mellonella (Mylonakis et al., 2005; Fuchs and Mylonakis, 2006; London et al., 2006). Results from this 
system have been shown to correlate with the murine model of infection, and studies examining $C$. neoformans and $C$. gattii both show successful survival assays (Byrnes et al., 2009c; Findley et al., 2009; Velagapudi et al., 2009). Additionally, the pathogenic Cryptococcus species were shown to be more virulent than their nonpathogenic insect-associated relatives (Findley et al., 2009). This invertebrate model of infection is low-cost and poses fewer ethical issues, allowing for more facile, high-throughput analyses of virulence.

p0175 Studies in the Candida clade have shown several species to be associated with insects, particularly plant-associated beetles (Suh et al., 2004b, 2005, 2006, 2008). In most cases, these yeast species are xylose-fermenting, closely related to the pathogenic Candida species, and isolated from the insect gastrointestinal (GI) tract, leading to the hypothesis that this is a symbiotic relationship between the insects and fungi (Suh et al., 2003, 2004a,b, 2005, 2006; Suh and Blackwell, 2004, 2005; Nguyen et al., 2007). The large number of Candida taxa that are associated with a diverse range of host beetles also suggests that this phylogenetic lineage has a strong possibility of being involved in symbiotic insect associations (Suh et al., 2006). Recently, four novel species from the C. albicans/Lodderomyces clade were isolated from insect guts, with one, Candida blackwellae, the closest relative to C. albicans yet to be reported (Ji et al., 2009). Furthermore, Candida dubliniensis, a human pathogen, was isolated from seabird-associated ticks suggesting a possible reservoir and ecologic niche for this pathogen (Nunn et al., 2007).

p0180 Although the phylogeny and ecology of the clade are being uncovered, little is known about how several representative species from this lineage may have emerged and expanded into mammals. One commonality between the pathogenic mammalian and insect-associated species is that they are associated with the gut (Nguyen et al., 2006, 2007; Suh et al., 2006; Schulze and Sonnenborn, 2009; Tampakakis et al., 2009). While the environments are largely different, there may be common links between the insect and mammalian GI tracts that are important for survival and proliferation. An increase in number of studies examining the role of fungi in the human GI tract will also enhance the understanding of what roles the fungi, particularly the Candida clade, play in animal microbiomes.

\section{s0055 4.4 Plant Pathogenic Fungi}

p0185 Although several important fungal pathogens attack animals, land plants have probably been the main nutrient source of fungi through much of their evolutionary history, given the predominance of plant saprophytes, pathogens, and mycorrhizal species in fungi (Berbee, 2001; Berbee and Taylor, 2001; James et al., 2006). Collectively, fungi cause more plant diseases than any other group of plant pests (such as viruses or bacteria), with over 8000 species shown to cause disease. The life cycles of many of these are complex and involve two or more host plants. Plant diseases caused by fungi exhibit a huge diversity of symptoms. Pathogenic fungi can indeed be responsible for lesions on leaves or on flowers, stem cankers, root and fruit rot, or for sterilizing plants. 
p0190 Fungal pathogens are therefore a serious concern for agriculture, as they reduce crop yield and lower product quality by attacking cultivated plants and their products (seeds, fruits, grains). Nearly all crops have their pathogenic fungi, and often several of them, from cereals to corn, rice, potatoes, beans, peas, soybean, fruit trees (including coffee and cacao), and ornamental plants and trees. Some of the world's great famines and human suffering can be blamed on plant pathogenic fungi. Wheat crops of the Middle Ages were commonly destroyed when the grains became infected with a dark, dusty powder now known to be the spores of the fungus called bunt or stinking smut (Tilletia spp.). Epidemics caused by rust fungi have also been noted for millennia. These epidemics were recognized in ancient Greece and described in the writings of Aristotle and Theophrastus. The Romans held a religious ceremony/festival, the Robigalia, to appease the gods Robigo and Robigus, whom they believed responsible for the rust epidemics. Potato late blight, caused by the oomycete Phytophthora infestans, is the most important biotic constraint to potato production worldwide. It caused epidemics during the $1840 \mathrm{~s}$, because of which more than 1 million people died from starvation or famine-related diseases, and more than 1.5 million emigrated from Ireland. A more recent epidemic that resulted in large-scale famine was caused by a fungus responsible for brown spot of rice; 2 million people died of starvation during the great Bengal famine of 1942 . A related fungus, which attacks corn and causes southern leaf blight, resulted in a widespread epidemic in the USA in 1970; ca. 15\% of the total corn crop was lost, with yields in some states reduced to $50 \%$. In the USA alone, hundreds of millions of bushels of wheat have been lost in epidemic years due to stem rust (Puccinia graminis tritici). Rice blast, caused by the fungus Magnaporthe oryzae, is an important disease on rice, among many other diseases. It is found wherever rice is grown, it is always important, and it is always a threat. Coffee rust, caused by Hemileia vastatrix, caused epidemics on cultivated coffee in Ceylon (Sri Lanka, which was British at the time) in the nineteenth century. All exports of coffee from Ceylon had to be stopped; planters turned to tea in place of Arabian coffee, and tea became the social drink of the British (Staples, 2000). Scarcity of wheat caused by epidemics of wheat stem rust is the historical reason that the bread of central Europe is often made of rye and that cornbread is so popular in the southern US (Horsfall, 1983; Palm, 2001). The Botrytis gray mold is a common disease of greenhouse floral crops and all ornamental plants can be infected by powdery mildews. These are only few examples of the many pathogenic fungi devastating crops.

p0195 In addition to being agents of preharvest and postharvest diseases and rots, fungi produce highly toxic, hallucinogenic, and carcinogenic chemicals that not only affected the lives of millions of people historically, but also continue to be of problems today. In 2006, dozens of dogs perished in the USA from food tainted with aflatoxin, a chemical produced by several Aspergillus species. These fungi can grow on corn and fill the seed with the toxin that not only attacks the liver, but is one of the most carcinogenic substances known. Another example comes from the genus Fusarium, which contains numerous phytopathogenic species, F. culmorum and $F$. graminearum being particularly important pathogens of cereal crops in many areas of the world. They are responsible for head and seedling blight of small 
grains such as wheat and barley, ear and stalk rot of corn, and stem rot of carnation. Besides causing yield reduction, these Fusarium diseases come with the production of mycotoxins, which are highly toxic to both plants and animals, including humans (Desjardins et al., 1993).

p0200 Several methods are used in modern agroecosystems to control fungal pathogens, including spraying fungicides, creating resistant varieties, crop rotations, and a variety of cultural practices aimed at reducing plant infections. Fungicides and resistance can be very efficient at first, but are expensive, polluting, and often do not last. Fungi have indeed huge effective sizes, with millions of spores produced by a single diseased plant, great dispersal abilities, and several generations per year, enabling rapid adaptation. Fungicide breakdown often occurs within a few years, as does resistance resistance (Brown, 1994).

p0205 Pathogenic fungi are also widespread in natural ecosystems, with great impacts on the compositions of natural communities. Forest trees, for instance, are attacked by many pathogenic fungi. Armillaria root disease, causing branch dieback and crown thinning, is often one of the most important diseases of trees in temperate regions of the world, especially in native forests. The most infamous tree diseases include Dutch elm disease caused by Ophiostoma species, chestnut blight caused by Cryphonectria parasitica, and sudden oak death, ramorum leaf blight, and ramorum shoot blight all caused by the oomycete Phytophthora ramorum. These diseases have dramatic consequences on forest composition and their associated biota, with some tree species even disappearing from continents. For instance, the chestnut blight fungus caused the death of $80 \%$ of the native American chestnut trees throughout eastern forests from Maine to Georgia during the first half of the twentieth century. The Dutch elm disease fungus, Ophiostoma ulmi, has led to the destruction of American elm trees and has altered urban landscapes by killing ornamental elms across the country. It has been estimated that more than 77 million elms have died. Not only trees, but virtually all natural plants have their own pathogenic fungi. Examples include choke disease on grasses caused by Epichlö̈ species, anther smut disease on Caryophyllaceae caused by Microbotryum violaceum, and powdery mildew on many natural plants.

\section{s0060 4.5 New and Emerging Plant Diseases}

p0210 Fungi are also responsible for about 30\% of emerging diseases in plants (sensu lato, i.e., including oomycetes), which is 3 times more than for emerging diseases in humans or wildlife (Anderson et al., 2004). These patterns of fungal disease emergence in plants have elicited great concern for several reasons. First, epidemics caused by invasive pathogens have been repeatedly reported to alter natural ecosystems (Anderson et al., 2004; Desprez-Loustau et al., 2007). Well-documented examples of emergent diseases in natural plant communities include some of the ones mentioned earlier, such as the spread of Cryphonectria parasitica that eliminated the dominant chestnut forests throughout eastern North America at the end of the nineteenth century. The Dutch elm disease caused by Ophiostoma ulmi 
and O. novo-ulmi appeared in Europe around 1919, and the fungus was described in Holland in 1921; it was first found in the USA in Ohio in 1930 (Anagnostakis, 2001). Phytophthora cinnamomi that threatens native forests throughout Australia is also an emerging disease (Anderson et al., 2004; Desprez-Loustau et al., 2007). Many powdery mildews appear as invasive fungi (Kiss, 2005). Such dramatic diseases not only affect the host plants, but also the whole associated fauna, including insects, birds, and mammals.

p0215 Second, our primary food production is at risk due to emerging crop diseases; the most dramatic historical example being the Irish Potato Famine caused by $P$. infestans on cultivated potato in the beginning of the twentieth century (Birch and Whisson, 2001). Other examples of invasive fungi parasitizing crops include Plasmopara viticola, an oomycete causing the grapevine downy mildew, that has been introduced from North America to Europe in the past two centuries, Plasmopara halstedii, another oomycete causing sunflower downy mildew (Delmotte et al., 2008), the soybean rust in North America and the coffee rust in Asia and South America (Staples, 2000). Crop plants are in fact particularly susceptible to the emergence of new diseases because of the large-scale planting of genetically uniform varieties.

p0220 Third, epidemics on crop plants generate a huge production of potentially infectious spores (Brown and Hovmoller, 2002). In addition to spreading disease over agricultural areas, this high propagule pressure on surrounding areas may contribute to disease emergence in natural plant communities. Indeed, though nonhost resistance is quite durable, host shifts are known to occur (Stukenbrock and McDonald, 2008; Tellier et al., 2010), so epidemics of crop species may pose an undetected and poorly recognized danger to natural plant communities (Power and Mitchell, 2004).

p0225 There has been an increasing focus on identifying the factors that drive the emergence of new fungal diseases (Anderson et al., 2004; Thrall et al., 2006; Desprez-Loustau et al., 2007; Stukenbrock and McDonald, 2008). As mentioned earlier, introduction of pathogens in a new area is one of the most obvious causes. It has been estimated that between $65 \%$ and $85 \%$ of plant pathogens worldwide are alien in the location where they were recorded (Pimentel et al., 2001). The emergence of a new fungal disease following an introduction may be due to the reunification of a pathogen and a crop that had been introduced to new continents. This has been the case for instance for the potato late blight, rubber leaf blight, and coffee rust (Staples, 2000; Birch and Whisson, 2001; Desprez-Loustau et al., 2007). Fungal pathogens introduced into new continents have also been responsible for disease emergence in natural plant communities. Examples include the sudden oak death in North America caused by Phytophthora ramorum (Rizzo et al., 2005), the oak decline in Europe and Jarrah decline in Australia caused by Phytophthora cinnamomi (Hardham, 2005), the Dutch elm disease caused by Ophiostoma ulmi and O. novo-ulmi (Brasier, 2001), and the chestnut blight caused by Cryphonectria parasitica (Anagnostakis, 2001).

p0230 Horizontal gene transfer (HGT) (i.e., the exchange of specific genes between species that are normally reproductively isolated) has also been invoked to explain the emergence of new fungal diseases (Stukenbrock and McDonald, 2008). The 
most convincing example is a HGT between Phaeosphaeria nodorum and Pyrenophora tritici-repentis, both fungal pathogens of wheat with similar foliar symptoms worldwide. P. tritici-repentis is a very recently emerged pathogen, which was suggested to be due to the acquisition of a host-specific toxin gene by horizontal transfer from P. nodorum (Friesen et al., 2006).

p0235 Interspecific hybridization involves whole genomes, in contrast to HGTs. Hybridization is quite common in fungi, and can also lead to the emergence of new hybrid species (see Section 4.8). Transgressive traits in hybrids could even lead to the emergence of a disease on a new host that the hybrid would be able to parasitize while its parent species would not (Brasier, 2001; Olson and Stenlid, 2002; Stukenbrock and McDonald, 2008). In fact, this scenario has been suggested for some emerging fungal diseases, in particular the rusts caused by Melampsora spp. on poplar (Newcombe et al., 2000) and the diseased caused by a complex of Phytophthora species on alder in Europe (Ioos et al., 2006).

s0065

\subsection{Modern Molecular Epidemiologic Tools for Investigating Fungal Diseases}

p0240 To understand the dynamics of fungal diseases and the dynamics of emergence of new diseases, epidemiology is a necessary step. Epidemiology is indeed a discipline concerned with understanding the factors affecting the dynamics of disease in space and in time, with an emphasis on being quantitative and predictive. During the past decade, the integration of molecular biology into traditional epidemiologic research has revolutionized the discipline (Tibayrenc, 1998; Taylor et al., 1999a). This led to the development of a new field, molecular epidemiology, which addresses epidemiologic problems using "the various molecular methods that aim to identify the relevant units of analysis of pathogens involved in transmissible disease" (Tibayrenc, 2005). Increasingly sophisticated, sensitive, and reproducible detection methods have made studies of spatial patterns of disease, nosocomial infections, or disease outbreaks much more convincing and have provided unprecedented opportunities to track pathogen populations with particularly harmful characteristics in pathogenicity, virulence, or resistance to chemicals. Early adoption of molecular typing techniques to address applied questions in fungi of medical, veterinary, and agronomical relevance was soon cross-fertilized by the related field of molecular evolutionary genetics (Milgroom, 1996; Taylor et al., 1999b). However, in common with other microbial fields, a plethora of novel platforms and typing techniques was developed to study the molecular epidemiology of fungi during the 1990s. This multiplication may have, to some extent, confused rather than elucidated fungal epidemiology (Achtman, 1996; Urwin and Maiden, 2003). Fortunately, the list of esoteric acronyms for typing techniques (or YATMs, for yet another typing method; Achtman, 1996) eventually ceased to expand as research coalesced on those platforms that yielded unambiguous and portable data. Specifically, two methods in particular are now predominant in molecular epidemiologic studies of fungal pathogens: MLST, for multilocus strain typing (Maiden 
et al., 1998) and MLMT, for multilocus microsatellite typing (Fisher et al., 2001). The advantages of these two techniques as typing approaches are their portability and reproducibility (typing can be done in any molecular biology laboratory and generates identical results for identical DNA samples), their archiveability (results can be compiled by multiple contributors in publicly available web databases) and their amenability to high-throughput automation. The development of these methods, designed to be enduring, would not have been possible without the technologic advances that eased and reduced the cost of generating, determining, storing, and interpreting genetic data. Currently, new advances in next-generation high-throughput sequencing techniques mean that MLST and MLMT typing schemes are on the brink of being absorbed into whole-genome single nucleotide polymorphism (SNP)-typing platforms. However, the nature of MLST/MLMT typing schemes is such that older data will be incorporated into new schemes rather than discarded, as was previously the case.

p0245 MLST schemes compare nucleotide polymorphisms within regions of ca. 500 nucleotides from five to seven genes. Traditionally, the regions represent coding sequences of housekeeping genes, which are under purifying selection to retain function and persist in genomes. MLST was originally developed to facilitate studies of epidemiology in bacterial populations (Maiden et al., 1998). Mycologists were using a similar technique since the mid-1990s championed by J.W. Taylor and his associates, but it was lacking an acronym and more oriented toward the study of evolutionary features of fungal species than issues of epidemiology (Taylor et al., 1999a; Taylor and Fisher, 2003). The principle of an MLST scheme is simple: allelic variants, resulting from SNPs, are recorded as series of integers that together constitute a barcode called a strain sequence type (ST). The MLMT scheme is a direct extension of the MLST approach to microsatellite loci, which are short tandem repeats of 2-6 nucleotides. Allelic variants at ca. 5-15 microsatellite loci, here resulting from variation in the number of repeats of the microsatellite motif, are recorded as series of integers called microsatellite types (MT). Both MLST and MLMT have been greatly enhanced by the availability of complete fungal genomes that render the steps of isolation of new markers less cumbersome and more likely to succeed. This is particularly true for MLMT schemes, whose development is often hindered in fungi by the weak representation of microsatellite loci in fungal genomes, the low abundance of motifs with potentially high mutability (i.e., with high number of repeats), and the small size of genomes (Dutech et al., 2007).

p0250 The main use of fungal MLST is for diagnosis and species identification (Taylor and Fisher, 2003). Issues such as quarantine, selection of appropriate treatments and disease control measures, identification of significant sources of inoculum for epidemics, or nosocomial infections depend on a proper taxonomic assignment (Palm, 2001). Traditional methods based on phenotype or mating tests, if applicable, were laborious and compromised in their accuracy. Phylogenetic methods using genealogical concordance phylogenetic recognition (GCPSR) are progressively superseding previous approaches (Taylor et al., 2000; Giraud et al., 2008b). Gene-sequence data from studies using GCPSR can easily be converted to STs and stored in web databases accessible to the whole community of mycologists. Species 
recognition studies are also an elementary prerequisite to the design of an MLST scheme, as molecular epidemiology tools are based on the idea that pathogen populations form discrete entities that are stable enough to be identifiable. These entities, and their biologic relevance, are conditioned by evolutionary forces; hence, the usefulness of a preliminary exploration of species limits and population structure by evolutionary biologists (Tibayrenc, 2005). The delimitation of species, and therefore implicitly the design of a new MLST scheme, requires assembling a diverse collection of isolates on the basis of current knowledge on the ecology of the fungus and existing typing information (Urwin and Maiden, 2003). Clinical or field isolates can be quite readily collected, but even a modest sampling of environmental individuals of pathogenic fungi can turn out to be a very difficult task (Greene et al., 2000; Taylor and Fisher, 2003). Where fungi have been thoroughly sampled across their range and habitats and have provided a sufficient diversity of genotypes, MLST schemes can assist in dissecting the factors behind a disease outbreak. For instance, a recent MLST study of the chytrid fungus Batrachochytrium dendrobatidis (James et al., 2009), suggested as a principal cause for the worldwide decline of amphibians, found the global epidemic owes to the global dispersal of a single genotype. This data was used to argue that the observed low allelic diversity and high heterozygosity provide strong support that the fungus is a novel pathogen introduced into naïve host populations, over the alternative hypothesis that the species is an endemic pathogen whose emergence is due to recent changes in the environment. By contrast, an MLST study of Coccidioides immitis, the etiologic agent of coccidiomycosis revealed that the epidemic observed in California in the early 1990s was not due to the emergence of a virulent genotype but rather governed by the synchrony of environmental factors (Fisher et al., 2000). In this study, analyses of clinical isolates with MLST data revealed extensive genetic, genotypic diversity and a lack of significant association across loci, rejecting the hypothesis of aggressive clonal spread, and in conjunction with these elements, multivariate statistical treatment of environmental data showing that the number of cases of disease was best explained by the interaction between two climatic factors.

p0255 MLMT-based techniques are more useful in discriminating genotypes within species and inbred populations than among species, which make their use complementary to MLST. A primary reason is that the cross-species transferability of microsatellite appears lower in fungi than in other organisms (Dutech et al., 2007), which limits their utility to discriminate among species (with some exceptions, e.g,. Fisher et al., 2002; Matute et al., 2006). A second reason is that microsatellites typically have high mutation rates in fungi, even though they appear less polymorphic in this kingdom than in others (Dutech et al., 2007). Factors such as recent speciation, demographic bottlenecks, or selective sweeps associated with a lack of recombination can dramatically reduce variation at housekeeping genes and thus seriously hamper the discriminatory power of MLST schemes at the intraspecific level (Morehouse et al., 2003; Couch et al., 2005; Bain et al., 2007). In such cases where nucleotide variation is not sufficient to address questions at the intraspecific level, MLMT provide a powerful alternative (Fisher et al., 2004; Morgan et al., 2007). In a recent study Ivors et al. (2004) sequenced three housekeeping genes in outbreak isolates of Phytophthora ramorum, the etiologic agent of the devastating 
"sudden oak death" disease. This study showed that all sequences were identical among all isolates and therefore completely uninformative on the nature of epidemic. MLMT tools developed later (Prospero et al., 2004, 2007; Ivors et al., 2006) proved very useful in tracking the pathogen as it spread in the USA (Cooke, 2007; Prospero et al., 2007). Analyses of MLMT data provided evidence of a historical link between nursery and wild populations of the pathogen, and identified three common genotypes as the likely founders of the Californian epidemics (Mascheretti et al., 2008). The potential of MLMT as a tool to resolve interstrain differences even at fine-scale can also be useful to study basic features of the biology of fungi. For instance, in plant pathology it is critical to know the relative importance of ascospores, mycelium, and conidia in dispersal of fungi and whether the source of primary inoculum is soil, plant debris, infected seeds, other plants, etc. The most obvious application of this knowledge in disease management is to eliminate the source of inoculum by sanitation, debris, and weed management, or crop rotation (Milgroom and Peever, 2003). MLMT also provides a useful tool to infer the source and type of primary pathogen inoculum, which are often impossible to identify by direct observation or using the traditional epidemiologic approach of studying the distribution of disease foci (Douhan et al., 2002; Peever et al., 2004). A last original application of MLMT tools in fungi is in plant breeding efforts. Here, the basic idea is the use of a better representative of existing variation in pathogen populations to screen for resistant germplasms in order to assist in breeding plant varieties with more durable and effective resistance. Based on the assumption that variation at microsatellite markers can be used as a proxy for variation in pathogenicity traits, MLMT schemes have found use in selecting a core collection of pathogen genotypes that are more representative of extant genetic diversity than are a random sample of the local inoculum found in the immediate neighborhood of the nursery (Peever et al., 2000).

p0260 What biostatistical methods can be used to track genotypes and species using MLST and MLMT data? Many fungal species exhibit limited recombination in nature and form complexes of genetically related haplotypes (Taylor et al., 1999b). For these taxa, split decomposition (Huson and Bryant, 2006), statistical parsimony (Clement et al., 2000), or eBURST (Feil et al., 2004; Spratt et al., 2004) can provide a graphical representation of the relationships among genotypes and their prevalence (Morehouse et al., 2003; Urwin and Maiden, 2003; Couch et al., 2005; Fisher et al., 2005; Morgan et al., 2007). These network approaches can be used to infer the origin of particular isolates, provided that the species have sufficient host-specific or geographical population structure. Where population structures are highly recombining, however, network approaches are improper for epidemiologic tracking because recombination mixes genotypes at individual loci and renders multilocus genotypes unstable (Tibayrenc, 2005). Therefore, in recombining species, determining source populations requires comparing individual isolates in statistical settings that explicitly model the associations amongst loci. A number of Bayesian methods have been developed to produce robust assignments for organisms with extensive genetic recombination (Rannala and Mountain, 1997; Pritchard et al., 2000; Falush et al., 2003; Piry et al., 2004). An example of the utility of this approach is provided by Fisher et al., 2001 to identify the source populations for 
Coccidioides isolates recovered from patient treated outside the endemic area of Coccidioides sp. These methods can also be used to exclude possible sources. In one study, Bayesian tests were used to demonstrate that populations of Venturia inaequalis, the apple scab fungus, spreading in France on apple varieties harboring the $V f$ major resistance gene were not derived from local apple scab populations, but rather introduced from another region (Guérin et al., 2007).

p0265

Recent technologic developments have increased the rate of data generation and concomitantly greatly enhanced our understanding of fungal species and populations. The next step will be to increase the level of data sharing and to promote the development of curated Internet databases that can accommodate the incoming avalanche of SNP-diversity that is generated by next-generation sequencing schemes. Web-based community tools are still underdeveloped in fungi in comparison with other microbial pathogens, and an extensive sharing of data could allow more sophisticated spatio-temporal surveys of epidemics. Recent progress is illustrated by the development of an MLST-typing scheme for the fungal pathogen C. neoformans that integrates MLST-approaches with new scalable mapping technologies to ascertain regional and global patterns of spread (http://cneoformans.mlst.net/earth/ maps/) (Meyer et al., 2009). Such informatic technologies will in the future be integrated with next-generation sequencing and combined with the development of predictive models of disease spread to relate strain typing data with phenotypic traits, environmental data, and disease risk-assessment decision platforms.

\subsection{Population Genetics of Pathogenic Fungi}

p0270 Population genetics is also needed to understand fungal diseases. The genetic structure of a species refers to the amount and distribution of genetic variation within and among populations. Population genetics aims to understand the evolutionary processes that shape the genetic structures of species. For pathogenic fungi, population genetics questions are not simply of academic interest, as these questions have genuinely practical applications. Issues such as breakdown of plant resistance, resistance to fungicides, emergence and spread of virulent strains, or the design of tools for identification are related to the genetic structure of fungal populations. By providing an understanding of the processes that shaped the structure of a pathogen species in the past, population genetics offers the opportunity to forecast the emergence of genotypes, populations, or species with detrimental characteristics for human affairs (McDonald and Linde, 2002; Giraud et al., 2010), and also to inform practical attempts to bring fungal pathogens into durably effective human control (Williams, 2009). Currently, a great part of the research effort of population geneticists on fungal pathogens is devoted to fuel the development of risk-assessment models. Herein, we provide an overview of the tools available to understand three important components of population structure of fungal pathogens that are related to their evolutionary potential: the reproductive system, gene flow, and population subdivision. We also provide examples of case studies where the methods have been successfully applied to elucidate genetic structures in fungi. 


\subsubsection{Reproductive System}

p0275 Fungi present a striking diversity of life cycles, and studying their reproductive biology is a challenging task. However, this information is critical to assess the risk posed by pathogens and for the design of disease management strategies (McDonald and Linde, 2002). For instance, outcrossing promotes genetic exchange and can accelerate the spread of new mutations in combination with other beneficial alleles, which is critical in the context of an arms race between hosts (or the humans that breed or grow them) and pathogens. By contrast, selfing or asexual reproduction provides insurance of reproduction for species having a low probability of finding a mate, and these species can therefore invade distant territories more easily and/or more rapidly (Taylor et al., 2006). Asexual reproduction is also an expeditious way of multiplying rapidly favorable combinations of genes built by past selection (Otto, 2009) and a more efficient strategy of transmitting genes to the next generation. Indeed, an asexual parent transmits $100 \%$ of its genes to the next generation, against only $50 \%$ for a sexual parent, which is called "the twofold cost of sex" in anisogamous species (Bell, 1982). In the following, we briefly define the terminology used to qualify different aspects of fungal reproductive systems, and then we provide an overview of the methods available for their analysis, with some case studies among the fungal pathogens.

\section{s0080 Terminology}

p0280 Inconsistent use of key terms might be a cause of the slow integration of fungi in the field of evolution, and more generally unclear definitions of concepts are often an obstacle in the progress of science (Neal and Anderson, 2005). A proper identification of the key features of the reproductive system of fungal pathogens is also fundamental for the correct selections of appropriate models to study population structure (Giraud et al., 2008a). Three aspects of the fungal reproductive system can be distinguished: the reproductive mode, the breeding system, and the mating system.

p0285 Sexual reproduction is the process by which progeny is formed through the combination of two parental nuclei, generally involving syngamy and meiotic recombination (Schurko et al., 2009). In fungi, genes can be transmitted across generations through asexual, sexual, or mixed modes of reproduction ("mixed" referring to the alternation of sexual and asexual reproduction during the life cycle). Approximately one-fifth of described fungal species have been thought to be asexual, but population genetic studies have revealed that most show footprints of recombination, which is incompatible with strictly asexual reproduction (Taylor et al., 1999b). The difficulty in determining the reproductive mode mostly stems from the failure of morphologic observations of sexual structures. There is also the complication that fungal species often participate in both sexual and asexual reproduction, and therefore the same fungal species can display different reproductive modes in different places or at different times. It is often asserted that mitotic recombination via parasexuality can mix parental genomes and mimic the effect of 
sexual reproduction in fungi (Taylor et al., 1999b), but the importance of parasexuality in nature remains to be determined (but see Milgroom et al., 2009).

p0290 The term "breeding system" refers to the physiologic determinants of compatibility among individuals (Neal and Anderson, 2005). Mating compatibility in fungi is regulated strictly in the haploid stage by mating-type loci. For most species, the successful fusion of gametes can occur only between haploids carrying functionally different mating-type alleles, a phenomenon called heterothallism. Compatibility can be determined by alleles at a single locus (a condition termed bipolar heterothallism) or by alleles at two unlinked loci (a condition termed tetrapolar heterothallism). Some fungi are homothallic, meaning that they do not require genetic differences for mating compatibility.

p0295 The term "mating system" refers to the degree of genetic relatedness between mates. Outcrossing corresponds to the mating between cells derived from meioses in two different unrelated diploid genotypes, whereas inbreeding corresponds to the mating between related individuals. Inbreeding can be caused by selfing, the mating between meiotic products of the same diploid genotype. Three subcategories of selfing can be distinguished: intertetrad, intratetrad, and intrahaploid mating. Intertetrad mating refers to the union of cells derived from the same diploid individual but from different meiotic tetrads. Intratetrad mating refers to the union of cells derived from the same meiotic tetrad. Intrahaploid mating is allowed by homothallism, where genetic differences between pairing individuals are not required, permitting union between haploid mitotic descendants of the same meiotic product. We invite the reader to note that, contrary to persistent misconceptions in the fungal literature, the breeding system has little influence on the mating system. For instance, heterothallism does not prevent selfing, because any diploid individual is necessarily heterozygous at the mating-type locus (see Giraud et al., 2008 c, for more details), and homothallism may have been selected for more efficient outcrossing rather than for allowing intrahaploid mating, the latter having little advantage over asexuality while retaining some of the costs of sex (Billiard et al., 2010). Tetrapolarity is often suggested to promote outcrossing. If one considers biallelic breeding systems, it is true that tetrapolarity is less favorable to intratetrad mating than bipolarity, since the chance that any two siblings are compatible is $50 \%$ in a bipolar cross compared to only $25 \%$ in a tetrapolar cross (Hsueh et al., 2008). However, if gametes disperse before mating, these odds of compatibility within a progeny will be of little relevance. Whereas the breeding system cannot be determined without laboratory experiments, the mating system and reproductive mode of fungi cannot be inferred without analyzing patterns of genetic variation in natural populations.

\section{s0085 Analysis of the Reproductive System}

p0300 Following Milgroom (1996), we can distinguish three basic questions usually asked by fungal population geneticists: (1) Is population structure consistent with random mating? (2) Is there evidence for recombination? (3) What is the degree of relatedness between mates? In practice, answers to these questions are not independent 
and investigators often take the inability to reject a random mating hypothesis as an evidence for recombination.

p0305 The identification of populations and species is an essential prerequisite to the study of the reproductive mode and mating system. Hidden population subdivision or cryptic species within the units defined to perform analyses can indeed lead to erroneous conclusions on the reproductive biology of a fungus. This causes deviations from random mating or from random association among alleles. A wellknown example is the Wahlund effect, where the failure to detect population subdivision influences measures of inbreeding and association among alleles at different loci and leads to the same signal as inbreeding. Although they form a prerequisite to the study of reproduction, methods to analyze population subdivision generally do not provide a genuine assessment of the characteristics of the mating system (Gao et al., 2007), and therefore specific analyses are needed.

p0310 The most immediate consequence of asexual reproduction is the occurrence of repeated identical genotypes. The ratio of the number of multilocus genotypes found over the sample size can give an idea as to the rate of asexual reproduction, ranging from zero for a completely clonal population to one for a sexually reproducing population. Many populations of plant pathogens actually fall between the two extremes, having annual sexual cycles and asexual epidemic phases that amplify clones (Milgroom, 1996). One approach to analyzing the reproductive biology of these pathogens is to include a single representative of each multilocus genotype (an approach referred to as "clone correction"). However, one should ensure prior to clone correction that repeated genotypes do not simply result from insufficient discriminative power of the molecular markers assayed. This can be tested by calculating the likelihood that a multilocus genotype observed more than once in a sample is the result of sexual reproduction, given the observed allele frequencies and assuming random mating (Stenberg et al., 2003). The GENODIVE (Meirmans and Van Tienderen, 2004) and Genclone (Arnaud-Haond and Belkhir, 2007) programs offers user-friendly implementations of clone correction methods.

p0315 Under random mating, the frequency of multilocus genotypes is expected to be equal to the product of the allelic frequencies. Deviation from this expectation (or linkage disequilibrium) can hence serve as a test for random mating. A first approach is to analyze linkage disequilibrium between pairs of loci. The lack of association among pairs of loci in two isolated groups of the agent responsible for gray mold (Botrytis cinerea), for example, supported regular events recombination despite the absence of a sexual structure in field observations (Giraud et al., 1997). The existence of linkage equilibrium was also taken as evidence for sexual reproduction in populations of the wheat pathogen Mycosphaerella graminicola in regions where the teleomorph is rare or absent (Chen and McDonald, 1996; Zhan et al., 2003). Another, more powerful approach is to analyze linkage disequilibrium over multiple loci. This forms the basis of the test based on the index of association ( $I_{\mathrm{A}}$; Maynard-Smith et al., 1993). The $I_{\mathrm{A}}$ statistic relies on the variance of the number of differences among individual allelic profiles. This variance is higher than expected if mating is nonrandom due to an excess of very close and very large distances among individuals. The statistical significance of the $I_{\mathrm{A}}$ statistic can be 
established using the program MultiLocus, by comparing the observed value of the statistics to the distribution obtained from datasets for which alleles at each locus are resampled without replacement to simulate the effect of random mating (Agapow and Burt, 2001). This procedure has been applied to investigate the reproductive mode of Penicillium marneffei, the causal agent of biverticilliate mycosis in mammals. Analyses revealed very high and significant values of the $I_{\mathrm{A}}$ statistic (Fisher et al., 2005), providing one of the very rare cases of a fungus showing no evidence of recombination by population genetic criteria (Taylor et al., 2006). Another striking example of a fungus displaying a highly clonal population structure is provided by the European populations of the yellow rust of wheat (Puccinia striiformis f. sp. tritici). There are also several examples where the $I_{\mathrm{A}}$ suggested the existence of cryptic sexual reproduction in fungal pathogens in species where sex has not been observed in nature, such as the human pathogens Coccidioides immitis (Burt et al., 1996), Aspergillus nidulans (Pringle et al., 2005), and the alfatoxin producing A. flavus (Geiser et al., 1998).

p0320 Several tests for recombination or random mating were adapted from phylogenetic methods. A popular implementation of this approach is the parsimony tree length permutation test (PTLPT; Burt et al., 1996) that tests for random mating. The statistic used is the tree length, in number of steps, and the data are allelic profiles. The rationale for using PTLPT is that asexual populations produce few short, well-resolved genealogies, whereas the contrary is expected for recombining populations (Taylor et al., 1999b). The significance of the PTLPT can be assessed using the same method and program as the $I_{\mathrm{A}}$. Significance is calculated based on the proportion of trees in simulated datasets that are at least as long as those built from data. Other phylogenetic approaches search for the presence of recombination, based on sequence data. These tests exploit the predictions that in the absence of recombination, alleles at different regions are associated and all gene trees should therefore be congruent (Maynard-Smith, 1999) and have mutation (reversals, parallelisms, or convergence) as the sole possible cause of homoplasy (Hudson and Kaplan, 1985; Maynard-Smith and Smith, 1998). For instance, Matute et al. (2005) analyzed gene genealogies from eight regions to search for recombination in the pathogen Paracoccidioides brasiliensis. Incongruence among gene genealogies was examined by comparing the sum of the lengths of the most parsimonious trees inferred for each region to the sum of the length of trees obtained by permuting characters among regions (the incongruence length difference test; Farris et al., 1994). The null hypothesis of congruence for all isolated and all regions could be rejected, consistent with a lack of association among alleles, and thus with recombination. Another elegant application of methods inspired by phylogenetic analysis to search for recombination is provided by Couch et al. (2005). On the basis of a worldwide collection of isolates of the rice pathogen Magnaporthe oryzae, they investigated the reproductive mode of the fungus using a pairwise compatibility matrix for polymorphic sites built from the combination of nine sequence loci. A compatibility matrix is a visual representation of Hudson and Kaplan's four gamete test (Hudson and Kaplan, 1985) for all possible pairs of sites (the program SITES, available from Jody Hey's website at Rutgers University, can be used to 
perform such analyses). Incompatible sites are sites that support conflicting genealogies (and therefore introduce homoplasy in tree reconstructions) due to recombination or recurrent mutations. The finding of large blocks of incompatibility among loci from the same chromosome and from different chromosomes was interpreted as a sign of recombination on some, but not all, hosts of this pathogen.

p0325 In diploids or dikaryotic fungi, insights into the reproductive mode can be provided by the use of Wright's $F$-statistics (Halkett et al., 2005). $F$-statistics are hierarchical measures of the correlations of alleles within individuals and populations. A very informative $F$-statistic in this context is $F_{\text {IS }}$, a measure of the deviation from random mating. $F_{\text {IS }}$ corresponds to the identity of alleles within individuals relative to the identity of alleles randomly drawn from two different individuals within the same population (Balloux and Lugon-Moulin, 2002; De Meeus et al., 2006). The value of $F_{\text {IS }}$ can vary between -1 (all individuals being heterozygous) and +1 (all individuals being homozygous). Large negative values are expected for asexuals (Goyeau et al., 2007), and large positive values for selfers (Giraud, 2004). Several programs implement the calculation and test of $F_{I S}$ (e.g., Genodive, Meirmans and Van Tienderen, 2004; GenEPOP, Rousset, 2008b; Fstat, Goudet, 1995). For instance, the finding of $F_{\text {IS }}$ values nonsignificantly different from zero allowed Mboup et al. (2009) to conclude to the existence of sexuality in Chinese populations of $P$. striiformis f. sp. tritici, a fungus showing a highly clonal population structure in other regions of the world. In another application of this approach, James et al. (2009) revealed a significant excess of heterozygous genotypes for half of the loci surveyed (i.e., $F_{\text {IS }}<0$ ) in worldwide samples of the amphibian-killing fungus Batrachochytrium dendrobatidis, suggesting a predominantly asexual mode of reproduction. Another remarkable particularity of diploids is the "Meselson effect," where the absence of sex over long evolutionary times allows alleles at a single locus to become highly divergent within individuals as the two gene copies accumulate mutations independently in the absence of recombination (Birky, 1996; Welch and Meselson, 2000). Meselson effects have been evidenced in European populations of P. striiformis f. sp. tritici (Enjalbert et al., 2002; Mboup et al., 2009) and in Scutellospora castanea, an arbuscular mycorrhizal (nonpathogen) fungus (Kuhn et al., 2001).

p0330 A number of methods have also been developed to estimate the population recombination rate $(\rho)$ from haplotype data representing multiple positions in the genome (i.e., typically, moderate to large genomic dataset) (Hudson, 1987) and Wakeley (1997) developed moment estimators of the population recombination rate from the variance in pairwise differences. By making use of only a summary of the data, these methods are not computationally demanding at the expense of some loss in accuracy (Wall, 2000). Other methods use coalescent models to relate genetic variation in random population samples to the underlying recombination rate. Some approaches use conditioning on the complete dataset to obtain a maximum likelihood of the recombination rate (Griffiths and Marjoram, 1996; Kuhner et al., 2000; Nielsen, 2000; Fearnhead and Donnelly, 2001). These full likelihood methods have the advantage of making use of all of the information available in the data, but they become impractical for genomic regions of moderate size 
(Fearnhead and Donnelly, 2001). Hudson (2001), Fearnhead and Donnelly (2002), and McVean et al. (2002) proposed a "composite-likelihood" approach for estimating rates of recombination for large genomic regions. The principle of the compositelikelihood approach is to calculate likelihoods for subsets of data (pairs of sites or small genomic regions) and multiplying likelihoods obtained for each subset. A promising recent development is the approximate likelihood approach developed by Li and Stephens (2003). This approach relies on a "copying model" to represent haplotypes (Davison et al., 2009) and overcome several limitations of the approaches described earlier (see Li and Stephens [2003] for details). A population genomics study has recently been conducted to gain insights into the reproductive biology of the wild yeast Saccharomyces paradoxus. Tsai et al. (2008) analyzed DNA sequence variation on the third chromosome (containing the mating-type locus) among 20 isolates. By comparing estimates of population size obtained from the population mutation rate $\theta$ (Watterson, 1975) and from three distinct estimates of the population recombination rate $\rho$ (using methods of Wakeley, 1997; McVean et al., 2002; Li and Stephens, 2003), in addition to using estimates of the rates of mutation and recombination per base pair per generation from $S$. cerevisiae, the author inferred from this discrepancy that sexual reproduction occurs once every 1000-3000 generations in this species. They also estimated the frequency of intratetrad mating to be approximately $94 \%$. This was accomplished by comparing values of the population recombination rate for regions located near the matingtype locus and for the whole chromosome.

\section{s0090 4.7.2 Dispersal, Migration, and Gene Flow}

p0335 Dispersal is the movement of gametes or individuals. Parameters of dispersal can be estimated by: (1) direct methods, relying on direct observation of dispersing individuals at particular life-history stages, which provides a measure of actual dispersal; or (2) by indirect methods that use the changes in some characteristics of populations caused by movement of individuals and provide a measure of effective dispersal (Slatkin, 1985; Broquet and Petit, 2009). Because the movement of individuals obviously leads to movement of genes, the study of dispersal is tightly related to the study of gene flow (direct methods) and the monitoring of particular genotypes (indirect methods). The two types of methods are treated together here. We use the term "gene flow" synonymously with "migration," as is often the case in population genetics (though migrants that do not reproduce in a new environment do not contribute to gene flow).

p0340 Gene flow can be defined as the change (in gene frequency) due to movements of gametes, individuals, or groups of individuals (Slatkin, 1987). Implications of gene flow among populations and species are so manifold that it is difficult to provide a synthetic and concise overview. Generally speaking, gene flow can be regarded as either a constraining force that prevents adaptation to local conditions or a creative force that promotes evolution by spreading new genes and combinations within and between species (Slatkin, 1985, 1987). For fungal pathogens, in practical terms, some of the most unfortunate consequences of gene flow for human 
affairs include immigration of genotypes capable of defeating a resistance gene, exchanges of alleles allowing resistance to antifungal molecules (and more generally the spread of variants with increased pathogenicity), increase in population size which in turns increases the probability of accumulating mutations, and increase the efficacy of selection (and the possibility of selective sweeps). The degree of gene flow is also of central importance in the formation and maintenance of pathogen species. Humans have moved many pathogens far beyond their natural dispersal limits, and it is a safe bet that many pathogens are still transported among continents today (Yarwood, 1970; McDonald and Linde, 2002). These introductions likely have set the stage for the formation of reproductively isolated populations adapting to local hosts or environments (Giraud et al., 2010) or for secondary contacts followed by introgression or hybridization among species (Stukenbrock and McDonald, 2008). Gene flow is thus a critical target for disease management tactics. The objective is dual: first to set up or maintain barriers to gene flow among fungal pathogen populations, and second to prevent the emergence of new diseases. This requires a comprehensive understanding of transmission pathways and of the processes that govern gene flow in focal species, as well as the role of gene flow in species formation or maintenance. Three different aspects can be distinguished in analyses of gene flow and dispersal: rate and direction of gene flow, dispersal distance, and distribution of gene flow in time and in the genome.

\section{s0095 Rate and Direction of Gene Flow}

p0345 Pathogenic fungal species are often organized into discrete populations. Population genetics usually assumes a simple model of $n$ populations, each of which is equally likely to receive and give migrants to and from each of the other populations (the $n$-island model; Wright, 1931; Latter, 1973). Under this model, providing additional simplifying assumptions, a relationship between $N_{\mathrm{e}} m_{\mathrm{e}}\left(N_{\mathrm{e}}\right.$ being the effective size of each population; $m_{\mathrm{e}}$ being the effective migration rate between populations) and $F_{\mathrm{ST}}$ (a $F$-statistic that measures genetic differentiation among populations by quantifying the differences in allele frequencies between populations) can be derived: $F_{\mathrm{ST}} \approx 1 /\left(1+4 N_{\mathrm{e}} m_{\mathrm{e}}\right)$. The same type of relationships can be established from other measures of differentiation, using the same assumptions (Slatkin, 1985; Excoffier, 2007). This approach has been severely criticized by some authors (Bossart and Prowell, 1998; Whitlock and McCauley, 1999) who raised concerns about the unrealistic assumptions under the $n$-island model (constant population sizes, symmetrical migration at constant rates, no selection, and persistence for periods of time long enough to achieve migration-drift equilibrium), leaving only little quantitative information to be gained about gene flow from measures of population differentiation. Hence, although $N_{\mathrm{e}} m_{\mathrm{e}}$ was taken as an effective number of migrants in the original model, it is safer to interpret its value as the per-generation number of migrants that would characterize an idealized island system having the same $F_{\mathrm{ST}}$ value as the study system (Broquet and Petit, 2009). For the fungal pathogens. a major pitfall of estimating migration rates from allele frequency data is the assumption that the whole population has reached equilibrium between migration and 
genetic drift. However, many fungal pathogens have been introduced recently into new areas, or have recently invaded continents. Therefore, populations may not have had sufficient time to reach equilibrium. The time to reach a new equilibrium can be extremely long if population sizes are large and migration rates are low (Whitlock and McCauley, 1999). Even though they do not provide reliable estimates of rates of gene flow, measures of population differentiation can nonetheless be used to gain information on the history of dispersal. Several studies reported very low differentiation among samples of fungal pathogens of agricultural crops or forestry trees from different localities across a continent, including Fusarium verticillioides (Reynoso et al., 2009), M. graminicola (Linde et al., 2002), Venturia inaequalis (Tenzer and Gessler, 1999; Gladieux et al., 2008, 2010c), Gibberella zeae (Zeller et al., 2004), Phaeosphaeria nodorum (Keller et al., 1997), and Melampsora larici-populina (Barres et al., 2008). These patterns of weak population structure within continent are likely due to the superimposition of moderate to high levels of contemporary gene flow and relatively recent colonization. However, other pathogens of cultivated crops show highly significant differentiation within continents. For example, North American populations of the chickpea blight pathogen Ascochyta rabiei are highly differentiated, possibly due to restricted dispersal and possible selection by host cultivar combined with some life cycle characteristics conducive to differentiation (Peever et al., 2004; Giraud, 2006). High population differentiation is also a footprint of the "founder effect" that occurs following introduction in a new region. Such patterns have been evidenced for newly virulent populations of $V$. inaequalis spreading in northern France (Guérin et al., 2007), for populations of Mycosphaerella fijiensis spreading on banana plantations in Africa (Rivas et al., 2004), and for populations of several species that spread across continents (Salamati et al., 2000; Engelbrecht et al., 2004; Ordonez and Kolmer, 2007; Zhou et al., 2007; Zaffarano et al., 2009).

p0350 The coalescent theory (Kingman, 1982) relates patterns of common ancestry within a set of genes to the structure of the populations from which they were sampled. In coalescent models, patterns of relationships among genes are represented by a genealogy, and the structure of the population is represented by parameters such as population size, rates of population growth, or rates and directions of gene flow (as is relevant in the present section). Both the genealogy and the parameters are generally unknown, and one usually wants to estimate the parameters of the model. It is generally impossible to jointly consider all possible ancestral relationships and parameter values and to search for the combinations that maximize the probability of the model. Instead, approaches have been developed that simultaneously explore many relatively probable genealogies (loosely speaking, irrelevant genealogies are disregarded) and parameter values (see Stephens, 2008; Kuhner, 2009 for reviews). These approaches are collectively referred to as "coalescent genealogy samplers"; there are two families of such samplers: Markov chain Monte Carlo (MCMC) algorithms and important sampling algorithms. Several methods relying on coalescent genealogy samplers were designed to estimate, among other parameters, rates of gene flow between species or populations (Griffiths and Tavare, 1994; Wang et al., 1997; Beerli and Felsenstein, 1999, 2001; 
Nielsen and Wakeley, 2001; Hey and Nielsen, 2004, 2007). These methods offer the advantage of allowing less restrictive models than the more traditional methods presented earlier, and thus they accommodate complexities that are typical of real populations, such as nonsymmetrical gene flow. These methods have been successfully applied to infer the ancestral routes of colonization for several fungal globally distributed plant pathogens such as the wheat pathogens M. graminicola (Banke and McDonald, 2005) and P. nodorum (Stukenbrock et al., 2006), the barley scald pathogen Rhynchosporium secalis (Brunner et al., 2007; Zaffarano et al., 2009), and the apple scab pathogen $V$. inaequalis (Gladieux et al., 2008). Programs using coalescent genealogy samplers can also be applied to assess gene flow between welldefined species. The isolation-with-migration model implemented in the IMa programs (Hey and Nielsen, 2007) was used, for instance, to demonstrate unidirectional gene flow from Microbotryum lychnidis-dioicae into M. silenes-dioicae, respectively anther smut pathogens of the white and red campions (Gladieux et al., 2010b).

p0355 Additional information on historical migration routes can also be retrieved by examining the relationship between patterns of diversity and the putative history of introduction of the species in different regions from a source population. Under a model of serial founder effects, genetic variation is expected to decrease steadily from the earliest to the latest populations formed along the colonization route (Austerlitz et al., 1997; Ramachandran et al., 2005; Linz et al., 2007; Szpiech et al., 2008). The existence of such patterns has been uncovered for $V$. inaequalis, in which allelic richness tends to be lower in regions where apple has been introduced more recently, suggesting that the pathogen tracked its host during the spread of apple cultivation worldwide (Gladieux et al., 2008).

p0360 Methods based on coalescent genealogy samplers remain computationally demanding. For many datasets and models of population structure, they even remain computationally intractable. As a result, there is an increasing interest in developing alternative approaches that are faster and easier to implement, without loosing too much accuracy (Marjoram and Tavare, 2006; Stephens, 2008; Nielsen and Beaumont, 2009). The most promising approaches are rejection sampling and approximate Bayesian computation (Tavare et al., 1997; Li and Fu, 1999; Pritchard et al., 1999; Beaumont et al., 2002), composite-likelihood methods (Hudson, 2001), and product of approximate conditionals (Li and Stephens, 2003; Davison et al., 2009). These methods also potentially offer the advantage of being more easily tailored to the specificities of fungal pathogens, such as for life cycles with both sexual and asexual modes of reproduction, or histories of sequential introduction with exchanges of migrants among neighboring populations. Approximate Bayesian computation has been shown to be particularly powerful to determine the origin and routes of introduction of invading pest species (Miller et al., 2005; Cornuet et al., 2008; Guillemaud et al., 2010), and it is very likely that it will also provide important insights into the history of fungal pathogens.

p0365 A number of approaches have been developed for inferring recent gene flow by extracting information from the transient disequilibrium observed at individual multilocus genotypes of migrants or their recent descendants. These methods can serve as direct estimators of recent migration (Paetkau et al., 1995; Rannala and 
Mountain, 1997; Cornuet et al., 1999; Pritchard et al., 2000; Dawson and Belkhir, 2001; Anderson and Thompson, 2002; Gaggiotti et al., 2002; Gao et al., 2007) or even rates of recent gene flow (Wilson and Rannala, 2003). More details on these methods are given in Section 4.7.3. Such an approach was used, for instance, to estimate the frequency of cross host-species disease transmission and hybridization between two species of anther smut fungi (Gladieux et al., 2010b), or to demonstrate intercontinental dispersal and admixture of populations of the destructive dry rot fungus Serpula lacrymans, possibly linked to the development of worldwide shipping activity with wooden sea vessels (Kauserud et al., 2007). For pathogens with very little genetic variation and also with life cycles violating assumptions of the above-cited methods, approaches based on measures of the percentage of identity between isolates from recently colonized areas and putative source populations can also provide an easy-to-use and rapid method for the identification of migration routes. Hovmoller et al. (2008) used this approach, in combination with pathotyping, to demonstrate the foreign incursion of particular strains of the wheat yellow rust fungus in regions of North America, Australia, and Europe where severe epidemics have been observed in recent years.

s0100

p0370

\section{Dispersal Distance}

There is considerable interest in estimating the distance fungal pathogens disperse at agriculturally relevant scales, such as fields or production areas. This information can be inferred from patterns of genetic variation by fitting a model of isolation by distance (Wright, 1943, 1946; Kimura, 1953). A general formulation of isolation by distance models is the infinite lattice model (Malécot, 1951), in which individuals or populations are distributed on a lattice with spatially homogenous demographic parameters (i.e., homogenous population sizes or density and dispersal; Broquet and Petit, 2009; Guillot et al., 2009). The slope of the regression of differentiation statistics (e.g., $F_{\mathrm{ST}}$ ) onto the log-transformed geographic distance among individuals or populations allows estimation of the product of $D$, the population density, and $\sigma^{2}$, the second moment of dispersal distance (Rousset, 1997, 2000, 2008a; Vekemans and Hardy, 2004). For fungal pathogens that alternate asexual and sexual reproduction during their life cycle, these methods are not suitable due to the occurrence of repeated genotypes (Dutech et al., 2008). This specificity must be considered for correct inference of dispersal distance. Wagner et al. (2005) developed a weighting procedure that retains the spatial positions of all individuals but also applies a weighting to each genotype inversely proportional to its frequency. They also showed that variograms (i.e., plots of the semivariance in number of differences between genotypes against distance) are efficient tools to estimate the degree and extent of spatial genetic structure accounting for autocorrelation (which is the tendency that nearby observations to be more similar than distant ones). Variograms were used to study dispersal in the chestnut blight fungus (Cryphonectria parasitica), showing that asexual spores probably disperse over several hundred meters, which is a far larger spatial scale than previously thought (Dutech et al., 2008). 


\section{s0105 Distribution of Gene Flow in Time and Along the Genome}

p0375 The coalescent-based implementation of the isolation-with-migration model in the IM and IMa program (Nielsen and Wakeley, 2001; Hey and Nielsen, 2004, 2007) offers the opportunity to gain valuable insights into the history of gene flow between species. An interesting feature of the program is that counts and dates of migration events in sampled genealogies can be recorded during the course of the MCMC at stationarity for each locus to obtain the migration time distribution. IM was used to demonstrate that the wheat pathogen $M$. graminicola emerged in the Fertile Crescent at the time of wheat domestication following a series of introgressions from populations infecting three different uncultivated grasses (Stukenbrock et al., 2007). Estimates of the time of gene flow events indicated that populations from wheat and uncultivated grasses diverged in the face of gene flow but are now genetically isolated. This approach was also used to show that the species of anther smut fungi $M$. lychnidis-dioicae and M. silenes-dioicae initially diverged in allopatry without gene flow and exchanged genes only recently following secondary contact (Gladieux et al., 2010b). Gene flow between the two species of Microbotryum appeared restricted to four loci, supporting the view that genomes are mosaics with respect to interspecific gene flow, with some regions more or less permeable to genetic exchanges (Wu and Ting, 2004).

\section{s0110 4.7.3 Population Subdivision}

p0380 Fungal pathogens, like all organisms, are not homogenously distributed across the environment, which can lead to genetic structure. There are two main sources of population subdivision in fungal pathogens: geography and hosts. While some species have very broad host ranges (e.g., the amphibian pathogen $B$. dendrobatidis, $>350$ host species, Fisher et al., 2009; or the gray mold B. cinerea, $>235$ host species, Fournier et al., 2005; Staats et al., 2005), others display clear subdivisions that correspond to the host of origin of populations (e.g., Verticillium dahliae, Atallah et al., 2010; V. inaequalis, Gladieux et al., 2010a, or A. rabiei, Frenkel et al., 2010). Such host-specific divergence may evolve as a consequence of limited dispersal or of trade-offs in adaptation (Timms and Read, 1999; Giraud et al., 2006). Among pathogen species found on a single host, some species display clear geographically distinct populations (e.g., the mammalian pathogen Histoplasma capsulatum, Kasuga et al., 2003); or the white campion smut M. lychnidis-dioicae, Vercken et al., 2010), while others appear to have global distributions such as the human pathogen A. fumigates (Pringle et al., 2005; Rydholm et al., 2006). These patterns of geographical subdivision result from a complex interplay between contemporary and historical gene flow processes.

p0385 Understanding the origin of population subdivision is fundamental to our knowledge of the mechanisms responsible both for disease emergence and for the biodiversity of fungi. Four main approaches are available to analyze population subdivision: measures of differentiation, evolutionary trees, multivariate methods, and model-based clustering algorithms. 


\section{Measures of Differentiation}

p0390 Population subdivision can be assessed by calculating differentiation indices (e.g., $F_{\mathrm{ST}}$ ) between pairs of populations (see Section 4.7.2 for a detailed discussion). A more general framework to study population subdivision has been developed by Cockerham $(1969 ; 1973)$, who introduced the use of the analysis of variance (ANOVA) framework to decompose the total variance of gene frequencies into variance components associated to different subdivision levels (reviewed in Excoffier, 2007). Later, Cockerham's ANOVA of gene frequencies was extended to include information conveyed by the amount of differences (mutations) between alleles (the analysis of molecular variance, AMOVA; Excoffier et al., 1992). The AMOVA framework is widely used in population genetics studies of fungal pathogens. It is implemented in the ARLEQUiN (Excoffier et al., 2005) and GENETIC STUDIO packages (Dyer, 2009). The principle is to summarize population differentiation into $F$-statistics by partitioning molecular variance among the different hierarchically nested levels of sampling represented in a dataset (which can be localities, host species, regions, continents, etc.). The main drawback of this procedure is that the sampling units must be assigned into given hierarchical subdivisions by investigators, which may be a relevant issue. The main advantage is that it is a very fast way to get a summary representation of the differentiation existing among the different assumed levels of subdivision within a species. A useful application of the AMOVA procedure is for instance to determine whether the most important source of differentiation within a species is the host or the region of origin (e.g., see Morgan et al., 2007 or Gladieux et al., 2010c).

p0395 The issue of defining an a priori model of population arrangement can be sidestepped by using a multivariate graph-theoretic approach called population graphs (Dyer and Nason, 2004). The principle is to measure the genetic covariance relationships among all sampling units simultaneously and to represent these relationships graphically. Examples of application to fungal pathogens can be found in Guérin et al. (2007) and Fournier and Giraud (2008). Population graphs can be built using Genetic Studio (Dyer, 2009).

\section{s0120 Evolutionary Trees}

p0400 The most traditional approach to track population subdivision from genetic data is to build an evolutionary tree. Such trees are often improperly called "phylogenetic trees," though a phylogeny describes the pattern of ancestry among species, rather the pattern of genetic ancestry among pieces of DNA sampled within a species or a set of closely related species (Hey and Machado, 2003). Two main classes of evolutionary tree construction methods are available: (1) clustering methods use an iterative method (e.g., neighbor-joining) to combine samples in a hierarchical fashion, (2) searching methods that consider a range of possible trees and choose the ones that best fit the data according to an optimality criterion (such as maximum parsimony, maximum likelihood, or maximum Bayesian probability; Holder and Lewis, 2003). In practice, clustering methods are often used for data from multiple loci (typically, microsatellite markers) summarized by a matrix of distances among 
samples (Kalinowski, 2002), while searching methods are used for data from individual loci (typically, sequence data). Note that a very useful application of evolutionary trees based on sequence data is for species identification, but this approach is developed in Section 4.8, and we therefore focus on intraspecific subdivision here.

p0405 Evolutionary trees are appealing because they provide a graphical representation of the relationships among samples (Hey and Machado, 2003). When constructed from multilocus data, evolutionary trees can be very useful for exploratory data analysis or for visualizing the main subdivisions within a dataset. When interpreting an evolutionary tree, there are two main reasons to be cautious: (1) the stochastic variance in evolutionary trees (the problem being greater for evolutionary trees based on a single locus), and (2) the inadequacy of a bifurcating model when applied at the intraspecific level. The stochastic variance in evolutionary trees is due to the fact that different loci that have passed through the same demographic history, leading to evolutionary trees that vary widely in topology and branch lengths (Hey and Machado, 2003). The cause of this variance is that the processes that produce treelike relationships among gene copies (i.e., birth, death, and Mendelian reproduction, in a neutral model) and mutations are stochastic (Felsenstein, 2007). The other potential issue is that bifurcating models may not be appropriate to represent relationships at the intraspecific level. Several phenomena lead to violation of the assumptions underlying reconstruction methods and lead to poor resolution or inadequately portray genealogic relationships (reviewed in Posada and Crandall, 2001). These phenomena include low divergence among alleles, the persistence of an ancestral allele together with its descendants within a population, the existence of multiple descendants for a single allele, recombination among alleles through crossing-over, and exchanges of alleles (gene flow) between lineages. An alternative to tree-based approaches for representing relationships among samples is to use a network. Several methods of network reconstruction have been developed. Networks offer the advantage over evolutionary trees of being able to incorporate persistent ancestral nodes, multifurcations, and reticulations (Posada and Crandall, 2001). Examples in fungal pathogens can be found in Morgan et al. (2007) or Couch et al. (2005).

p0410 Another caveat for the use of evolutionary trees concerns the so-called population trees. The distance among populations is often represented as a tree in studies analyzing the population structure of fungal pathogens. However, this approach is questionable, as there is no reason to think that a model in which populations split from a common ancestor and subsequently do not mix represents the reality of population evolution.

\section{s0125 Model-Based Bayesian Clustering Algorithms}

p0415 The aim of model-based Bayesian clustering algorithms (or assignment methods) is to infer groups of individuals (called clusters or populations) that fit some genetic criteria that define them as distinct groups (Guillot et al., 2009). The use of a clustering method is an almost unavoidable step in every population genetic study. This field has been flourishing for a decade, and we will not give an extensive 
description of all the methods currently available. The most popular program is STRUCTURE (Pritchard et al., 2000; Falush et al., 2003). The method assumes a model in which there are $K$ clusters, each of which is characterized by a set of allele frequencies. Assuming Hardy-Weinberg and linkage equilibrium within clusters, the program simultaneously estimates allele frequencies in each cluster and then assigns every individual probabilistically to a single cluster ("no-admixture model"), or estimates the proportion of ancestry of every individual in every cluster ("admixture model"). It uses a variant of MCMC to approximate the probabilities of assigning individuals to clusters or membership proportions. The method has also been modified to allow for linkage of the loci (Falush et al., 2003). When using STRUCTURE, one usually wants to determine the number of clusters that is optimal for describing the population structure. The program does not estimate such an optimal number of clusters, but a heuristic method for selecting $K$ can be used, based on the rate of change in the log-probability of data between successive $K$ value (Evanno et al., 2005). Other Bayesian clustering programs can be used to obtain estimates of the optimal number of clusters based on various statistical methods (Dawson and Belkhir, 2001; Pella and Masuda, 2006; Corander and Tang, 2007; Huelsenbeck and Andolfatto, 2007), some of which are subject to debate (Durand et al., 2009; Guillot, 2009a,b). However, the biologic interpretation of any "best $K$ " estimate may not be straightforward (Pritchard et al., 2007) and should not be taken at face value. This is all the more true as there may be several different relevant $K$ numbers, in particular if the population structure is hierarchical. The best approach is therefore to provide a representation of several $K$ values and not a single "optimal" one. Departures from the structure of the model due to isolation by distance or inbreeding can lead to spurious signals of population structure and artificially increase the number of inferred clusters (Gao et al., 2007; Guillot et al., 2009). This issue is partially alleviated when using the INSTRUCT program (Gao et al., 2007), an extension of the approach implemented in STRUCTURE that eliminated the assumption of Hardy-Weinberg equilibrium within clusters and instead estimates individual membership on the basis of inbreeding or selfing rates. Last, we note that in case of poorly informative datasets (too few loci or individuals, or not enough differentiation among populations), group information such as host or region of origin of samples or geographic coordinates can be incorporated to achieve better results in analyzes of population subdivision (briefly reviewed in Hubisz et al., 2009).

\section{s0130 Multivariate Methods}

p0420 The principle of multivariate analyses, when applied to genetic variation among individuals or populations, is to extract and summarize multivariate genetic information into a few synthetic variables (Jombart et al., 2009). Methods such as principal component analysis have long been applied to population genetics questions (Cavalli-Sforza, 1966). They benefit from a renewed interest thanks to recent results of theoretical statistics and the development of software packages specifically devoted to the multivariate analysis of genetic data (Patterson et al., 2006; Jombart, 2008). Multivariate methods offer three main advantages. A first 
advantage is that they perform much faster than methods that are based on evolutionary trees or Bayesian clustering algorithms. The speed of analytical tools will become an increasingly important criterion of choice with the development of population genomics datasets of hundreds of markers for hundreds of individuals. A second advantage is that these methods make no assumption of population structure, such as Hardy-Weinberg or linkage equilibrium. This can be particularly useful for fungal pathogens with asexual or partially asexual modes of reproduction, for which Bayesian clustering algorithms present a high risk of producing spurious assignments (Falush et al., 2003). A principal component analysis was applied to investigate the origin of French populations of the chestnut blight fungus, a species in which high rates of asexual reproduction and may be also of intrahaploid sexual reproduction (allowed by homothallism) result in high frequencies of repeated multilocus genotypes (Dutech et al., 2010). Analyses revealed three distinct genetic lineages with separate geographic distributions, suggesting independent introduction events with limited gene flow among lineages descending from the three original groups of founding strains.

\section{s0135 4.7.4 Conclusion}

p0425 Empirical population genetics studies have revolutionized our understanding of fungal pathogen evolutionary biology. The distribution range of pathogens (in space and on hosts), their reproductive system, and transmission pathways are crucial features of pathogen biology that would have remained inaccessible based solely on phenotypic data and without the powerful inferential framework of population genetics. How could have we showed that "everything is not everywhere" and that many broadly distributed fungal pathogens are actually subdivided into populations constrained to small geographical areas? How could have we known that only very few fungal pathogens are ancient strictly asexual species and that the deuteromycota do not constitute a formal phylum of fungi? The upcoming flood of genomic data should galvanize investigations on central topics such as the evolution of reproductive systems (Heitman et al., 2007; Billiard et al., 2010), the acquisition of virulence to new hosts, resistance to disease control strategies (Stukenbrock and McDonald, 2008; Hogenhout et al., 2009; Morris et al., 2009; Giraud et al., 2010), and the evolution of reproductive isolation (Kohn, 2005; Taylor et al., 2006; Giraud et al., 2008b). However, this technologic leap should be accompanied by the development of population genetic models tailored to the specificities of fungal pathogens, such as the possibility of complex life cycles or nonpanmictic mating systems. There is still much to discover using population genetics. Most existing work has been focused on fungal species causing disease of humans, agricultural crops, or domesticated animals in the developed world (Taylor and Fisher, 2003; Morris et al., 2009). Studies are needed of pathogens from wild species in natural settings, from developing areas, and of nonpathogenic species that might be the pathogens of the future. 


\subsection{Species and Speciation in Pathogenic Fungi}

p0430 Understanding how the 1.5 million fungal species estimated to exist (Hawksworth, 1991) have arisen is of fundamental interest and has tremendous applied consequences for understanding emergent diseases on plants and animals (Giraud et al., 2010). We will briefly summarize here the main recent advances on fungal speciation, but more extensive reviews on speciation and species recognition in fungi have been written elsewhere (Taylor et al., 2000; Kohn, 2005; Giraud et al., 2008b).

\subsubsection{Species Concept Versus Species Criteria}

p0435 To study speciation, an obvious first step is to define species. The continual proposal of new species concepts may lead one to think that there is no general agreement about what species are. The apparently endless dispute about species concepts stems from the confusion between a species definition (describing the kind of entity that is a species) and species criteria (standard for judging or recognizing whether individuals should be considered members of the same species). Many so-called species concepts actually correspond to species criteria (i.e., practical means to recognize and delimit species) (Taylor et al., 2000; Hey, 2006; De Queiroz, 2007). The biological species concept (BSC) for instance emphasizes intersterility, the morphological species concept (MSC) emphasizes morphologic divergence, the ecological species concept (ESC) emphasizes adaptation to a particular ecologic niche, and the phylogenetic species concept (PSC) emphasizes nucleotide divergence. These species criteria correspond to the different events that occur during lineage separation and divergence, rather than to fundamental differences in what is considered to represent a species. To the contrary, it has been argued that all modern biologists agree on a common "species concept" or "species definition" that would be segments of evolutionary lineages that evolve independently from one another (de Queiroz, 1998).

p0440 One may wonder why there are conflicts over which species criterion we adopt. In fact, there are three main reasons why such criteria cannot be universal: (1) speciation is a temporally extended process, but one which varies tremendously in its pace among different types of organisms; (2) several modes of speciation can occur, during which the phenomena used for species recognition do not necessarily appear in the same chronologic order (Figure 4.1); and (3) characteristics of certain organisms render some criteria difficult to apply. The most useful criterion to apply to recognize species in nature thus necessarily depends on the type of organism, on its history of speciation, and on the degree of achieved divergence. Searching for a single species criterion that would be applicable to all cases thus appears fundamentally hopeless.

p0445 Until quite recently, the most commonly used species criterion for fungi has been the MSC. However, many cryptic species have been discovered within morphologic species, using the BSC (Anderson and Ullrich, 1978), or the genealogical concordance phylogenetic species recognition (GCPSR) (Taylor et al., 2000), an extension of the PSC. This latter species criterion uses the phylogenetic 


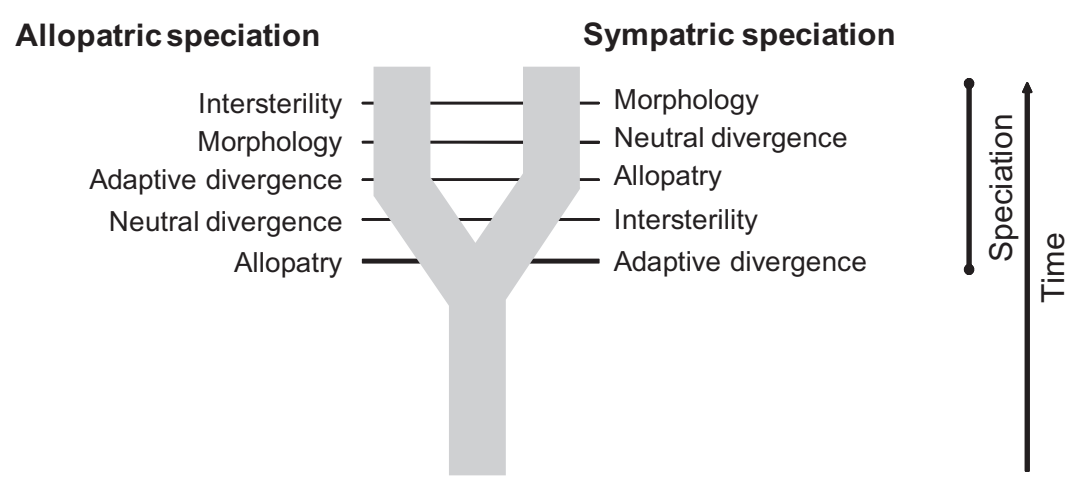

f0010 Figure 4.1 Schematic divergence of two species, in two hypothetical cases of respectively allopatric and sympatric speciation, with the progressive appearance of various criteria traditionally used to recognize species.

concordance of multiple unlinked genes to indicate a lack of genetic exchange, and thus evolutionary independence of lineages. Species can thus be identified that cannot be recognized using other species criteria due to the lack of morphological characters or incomplete intersterility. The GCPSR criterion has proved immensely useful in fungi, because it is more finely discriminating than the other criteria in many cases, or more convenient (e.g., for species that we are not able to cross), and is currently the most widely used within the fungal kingdom (Koufopanou et al., 2001; Dettman et al., 2003a; Fournier et al., 2005; Johnson et al., 2005; Pringle et al., 2005; Le Gac et al., 2007a).

\section{s0150 4.8.2 Fungal Speciation}

p0450 How new species arise in nature is still a highly active field of research. It has long been believed that species originate mostly through allopatric divergence (Mayr, 1963), because extrinsic geographic barriers seemed obvious impediments to gene flow. Fungi could appear as exceptions because eukaryotic microorganisms have long been considered to have global geographic ranges (ubiquitous dispersal hypothesis; Finlay, 2002), at least for those not dependent on a host having a restricted range. This was in particular true for airborne fungal pathogens because their spores can be dispersed over a very long distance (Brown and Hovmoller, 2002). Among the numerous complexes of sibling species recently uncovered using the GCPSR criterion, many however appear consistent with allopatric divergence because the cryptic species occupy nonoverlapping areas separated by geographic barriers (Taylor et al., 2006). This is the case for the species complexes of the model organism Neurospora crassa (Dettman et al., 2003a), the yeast Saccharomyces paradoxus (Kuehne et al., 2007), the plant pathogen Fusarium graminearum (O'Donnell et al., 2004), and the mushrooms Schizophyllum commune (James et al., 1999) and Armillaria mellea (Anderson et al., 1980, 1989). 
In contrast to the wide acceptance of allopatric speciation, the possibility of sympatric speciation in sexual populations had long been dismissed. This is because recombination between different subsets of a population that are adapting to different resources or habitats counteracts natural selection for locally adapted gene combinations (Felsensein, 1981; Rice, 1984). Recombination indeed prevents both the building of linkage disequilibrium between adaptive alleles at different loci and divergence at loci not under disruptive selection.

p0460 Theoretical models have shown that the simplest way to eliminate the role of recombination in breaking down the effects of selection, and thereby allow sympatric speciation, is to have the same gene(s) controlling pleiotropically both enhanced fitness in a specialized habitat and assortative mating (mate choice, i.e., prezygotic isolation) or both fitness and habitat choice if mating takes place within habitats (Rice, 1984). Such "magic traits" (Gavrilets, 2004) have, however, proved difficult to find in nature. Another way to reduce recombination between two populations specialized on different niches is to build up an association (linkage disequilibrium) between habitat-based fitness genes and either assortative mating genes and/or habitat choice genes if mating is restricted within habitats (Dickinson and Antonovics, 1973; Johnson et al., 1996). Theoretical models have shown that this is plausible under certain conditions, although the limitations to the process are far from trivial.

p0465 Fungi are passively dispersed and cannot actively choose the habitat in which they will grow, but for many fungal species sex must occur in the habitat after mycelial development (e.g., on or within the host for fungal parasites). A recent model has shown that, due to this important characteristic of the lifestyle (inability to disperse between development on the host or habitat and mating), mutations providing adaptation on a new habitat can affect pleiotropically both the fitness on the habitat and the ability to mate in this habitat. Adaptation to a new habitat can thus be sufficient to restrict gene flow in sympatry in fungi for which mating occurs within their specialized host or habitat, without requiring active assortative mating (i.e., prezygotic intersterility) (Giraud, 2006; Giraud et al., 2006). Specialization would act in these fungi as a "magic trait" (Gavrilets, 2004), pleiotropically allowing both adaptation to the new host or habitat and reproductive isolation, thus facilitating sympatric speciation (Giraud et al., 2010). This mechanism where a single gene controls both host adaptation and assortative mating is different from that seen in phytophagous insects mating onto their host plants, and where a linkage disequilibrium has to evolve between a gene controlling host choice and a gene controlling host adaptation (Johnson et al., 1996). The mechanism of speciation by host adaptation causing pleiotropically assortative mating is closer to the recently proposed "reduced viability of immigrants" barrier to gene flow (Nosil et al., 2005; Giraud, 2006; Giraud et al., 2006).

p0470 Sympatry is often said to be difficult to define for microorganisms and parasites. For instance, parasites specialized on different sympatric hosts are sometimes considered allopatric (Huyse et al., 2005). A simple, widely applicable definition of sympatry is available: "In sympatry, the probability of mating between two individuals depends only on their genotypes," (Kondrashov, 1986) and not on extrinsic barriers. Two populations of pathogens adapted to different hosts but able to 
disperse to both hosts are therefore truly in sympatry: only their genes responsible for host adaptation will prevent them meeting within their respective hosts to mate (Giraud et al., 2006).

p0475 Compelling evidence for the sympatric divergence is extremely difficult to provide because excluding a past period of allopatry is almost always impossible (Coyne and Orr, 2004, p. 142). Even the most famous candidate cases are still debated, such as the phytophagous insect Rhagoletis pomonella (Coyne and Orr, 2004; Feder et al., 2005, pp. 159-162) or the cichlid fishes in African lakes (Coyne and Orr, 2004, pp. 145-154). Evidence consistent with sympatric divergence of fungal populations driven by parasitic adaptation to different hosts has, however, been reported.

p0480 An example is provided by Ascochyta pathogens, where recent multilocus phylogenetic analyses of a worldwide sample of Ascochyta fungi causing blights of chickpea, faba bean, lentil, and pea have revealed that fungi causing disease on each of these hosts form distinct species (Peever, 2007). Experimental inoculations demonstrated that infection was highly host-specific, yet in vitro crosses showed that the species were completely interfertile. The host specificity of these fungi may therefore constitute a strong reproductive barrier, and the sole one (Peever, 2007), following a mechanism of sympatric divergence by host usage (Giraud, 2006; Giraud et al., 2006). More generally, there exist many close species of ascomycete pathogens that are sympatric but isolated by weak intersterility barriers (Le Gac and Giraud, 2008). The coexistence in sympatry of interfertile populations, specialized on different hosts, and that remain genetically differentiated cannot indeed be explained currently by models other than the reduced viability of immigrants (Nosil et al., 2005; Giraud, 2006; Giraud et al., 2006). This mechanism seems to be able to maintain the species differentiated in sympatry and could similarly have created the divergence in sympatry. It is difficult to exclude a period of allopatry in the past that would have facilitated specialization, such as the accumulation of different alleles beneficial on alternate hosts, as has been proposed for the well-studied case of the phytophagous insect $R$. pomonella (Coyne and Orr, 2004, pp. 159-162).

p0485 An elegant way to demonstrate the sympatric occurrence of speciation is to show that gene flow has occurred after initial divergence using approaches based on coalescence (Wu and Ting, 2004). Such approaches appear very promising and have been used in the fungal plant pathogen Mycosphaerella graminicola, showing that this wheat pathogen arose recently, most probably during wheat domestication in the fertile crescent, by differentiation from Mycosphaerella species pathogens of natural grasses in the face of gene flow (Stukenbrock et al., 2007).

p0490 Many examples exist in fungi of divergence of sibling pathogen species on different hosts. In disagreement with the long-prevailing view that coevolution between host and parasites should lead to cospeciation, these radiations of different hosts most often involved hosts' shifts (Roy, 1998; Refrégier et al., 2008; Tellier et al., 2010). This also seems the case for some fungi causing diseases on crop plants, having arisen from shifts from natural plants (Couch et al., 2005; Brunner et al., 2007; Stukenbrock and McDonald, 2008; Zaffarano et al., 2008). 
As seen earlier, a sine qua non of speciation in sexually reproducing organisms is the decrease of gene flow between incipient species due to the development of reproductive barriers. Two types of reproductive barriers are usually distinguished, premating and postmating. Premating isolation has been shown to prevent gene flow in fungi, with different types of barriers: (1) for organisms depending on biotic vectors, specialization of these vectors can prevent contact between two populations even if they lie close to one another, yielding ecological isolation. For example, the endophyte Epichloë typhina is preferentially chosen by its fly vectors Botanophila as opposed to Epichloë clarkia (Bultman and Leuchtmann, 2003), which may promote a certain degree of reproductive isolation. Another example is the complex Microbotryum violaceum, where the insect vectors are different to some extent between host species, leading to a reduction in mating opportunities among strains from different plants, although the barrier is not complete (van Putten et al., 2007); (2) specialization may also allow for ecological premating isolation if mating occurs within habitats (hosts for parasites), as discussed earlier (Giraud, 2006; Giraud et al., 2006); (3) allochrony, or differences in the time of reproduction, may also be efficient to promote premating isolation. The sister species Saccharomyces cerevisiae and $S$. paradoxus exhibit different cell growth kinetics; this allows most individuals of one species to undergo homospecific crosses before or after reproduction of the individuals of the other species. Proportion of interspecific matings can therefore be significantly reduced without the need of incompatibility factors (Murphy et al., 2006); (4) as has been invoked in plants (Fishman and Wyatt, 1999), a high rate of selfing may be efficient in limiting interspecific matings. Selfing has been suggested to act as a reproductive barrier in the anther smut fungus M. violaceum (Giraud et al., 2008c); and (5) assortative mating due to mate recognition occurs if individuals or gametes are able to discriminate between conspecifics and heterospecifics. Assortative mating seems to be especially important in the reproductive isolation of Homobasidiomycota, where clamp connections between mycelia of opposite types are almost exclusively observed when the tested mycelia belong to the same species when in sympatry (Le Gac and Giraud, 2008).

p0500 Postmating isolation refers to barriers associated with hybrid inviability and sterility and is expected to arise as a result of the divergence of incipient species. In the case of postmating isolation, heterospecific crosses occur and lead to the production of unfit offspring. Hybrids may be inviable or sterile due to genetic incompatibilities if mutations fixed independently in the diverging lineages display negative epistatic interactions when brought together in the same individual, a phenomenon known as Dobzhansky-Müller incompatibilities (Orr and Turelli, 2001). This kind of intrinsic postmating reproductive isolation is responsible for the numerous reported cases in fungi of crosses that initiate and subsequently abort during in vitro experiments. For instance, heterospecific crosses among Microbotryum species produce in vitro fewer viable mycelia than conspecific ones (Le Gac et al., 2007b), and hybrids are sterile (Sloan et al., 2008; de Vienne et al., 2009); crosses among Neurospora species lead to few or abnormal perithecia or to few viable ascospores (Dettman et al., 2003b). Dobzhansky-Müller incompatibilities have been identified between a nuclear gene and a mitochondrial gene as 
causing sterility in hybrids between two yeast species (Lee et al., 2008). Chromosomal rearrangements have also been proposed as mechanisms generating sterility in fungi given their high genomic fluidity (Zolan, 1995; Poggeler et al., 2000; Delneri et al., 2003; de Vienne et al., 2009). However, the karyotypically differentiated strains may also have differed in their genic content, and showing that the rearrangements were a cause of the divergence and not only its consequence remains a challenging task.

p0505 Speciation in fungi can also occur by hybridization between species (see Brasier, 2001; Olson and Stenlid, 2002; Schardl and Craven, 2003; Giraud et al., 2008b; Aguileta et al., 2009 for extensive reviews). Allopolyploid hybrids (with higher ploidy level than the parental lines) have been identified in diverse genera. Examples include Botrytis allii, the agent of gray mold neck rot of onion and garlic (Staats et al., 2005), several Neotyphodium species, symbiotic endophytes of grasses (Moon et al., 2004), and several Saccharomyces species empirically selected for brewing (Masneuf et al., 1998). Homoploid speciation (with no change in chromosome number) has also been described in fungi. A well-known case is that of the rust Melampsora $\times$ columbiana that emerged from hybridization of M. medusa, parasite of Populus deltoides, and M. occidentalis, parasite of P. trichocarpa (Newcombe et al., 2000), and that is able to parasitize the hybrid trees.

p0510 In conclusion, important advances have been made recently on the speciation in fungi, and they have proved tractable biologic models for the general study of speciation. Fungi also exhibit some specific and interesting modes of speciation, and many open questions remain which will be fascinating to explore.

\section{s0155 4.9 Mating and Pathogenesis}

p0515 Within the fungal kingdom, the ability to undergo sexual reproduction is linked to pathogenesis from a number of different aspects. The four major links to pathogenesis include the ability to form infectious spores, the production of invasive hyphae, the generation of genetic diversity through meiotic recombination, and in some species an association of mating type with virulence.

p0520 Sexual reproduction in many fungal pathogens leads to the formation of infectious spores. Spores are one of the likely routes of infection for human pathogens, including Cryptococcus, and have recently been documented to be infectious like yeast cells (Giles et al., 2009; Velagapudi et al., 2009). In representative plant pathogens including the Ustilago and Microbotryum genera, sexual reproduction is stimulated in association with the host plant and the dikaryotic hyphae produced by mating are the infectious form, thus requiring sexual reproduction for successful infections (Bakkeren et al., 2008). In Cryptococcus (Xue, 2010), it has been shown that a full sexual cycle, leading to the production of infectious spores, can be completed in association with plants, in some cases triggering hyphal penetration and disease in leaves and triggering jasmonate-mediated plant defenses, further linking the animal and plant fungal pathogens (Xue et al., 2007). Following these studies, 
recent work has shown that the inositol permease family is expanded in Cryptococcus (Xue et al., 2010), and inositol stimulates mating and can be supplied by the plant. These findings in a plant-associated human pathogen complement analogous mechanisms defined in well-characterized plant pathogens. For example, a recent study described a novel sucrose transporter in $U$. maydis that is required for virulence, which allows the pathogen to scavenge sucrose from the host while avoiding immune recognition by enabling direct carbon source utilization without the production of extracellular monosaccharides (Wahl et al., 2010). In contrast to the plant pathogenic basidiomycetes, the infectious form of Cryptococcus in animals is the yeast cells, and hyphal forms are only rarely observed in tissue sections from infected patients and animals.

p0525 Sex can create diversity by enabling genetic exchange within a population of a given species, but can also impact the evolution of virulence via introgression of more limited genomic regions between closely related species (Kavanaugh et al., 2006) or hybridization between two different species (Cogliati et al., 2001; Lengeler et al., 2001). There are a series of reports on hybridization events, likely that occurred via sexual reproduction between distinct species, which have resulted in isolates with altered virulence properties in plant and insect pathogens, including both fungi and oomycetes (Viaud et al., 1998; Olson and Stenlid, 2002; Schardl and Craven, 2003). In these cases, hybrid vigor may be the cause of altered host range, environmental niche, or virulence properties. Studies in plant pathogens have also found that hybridizations between species can lead to mitochondrial transfer, impacting virulence (Olson and Stenlid, 2001). These mitochondrial findings have garnered interest from the Cryptococcus field, as recent studies of the $C$. gattii outbreak genotypes indicate a strong association between the mitochondrial genome and virulence, although studies in $C$. neoformans found no link associated with the exchange of serotype A and D mitochondrial genomes and virulence (Toffaletti et al., 2004; Ma et al., 2009).

p0530 While the mammalian fungal pathogens do not require sex for infections, sexual reproduction has been retained, and in a number of cases, shown to be critical for aspects of successful infections. A recent seminal discovery of sexual reproduction in Aspergillus fumigatus reported that sex occurred only after 6 months of incubation on oatmeal supplemented agar, and may lead to the production of aerosolized resistant infectious spores (O'Gorman et al., 2009). Through whole genome analysis, it was revealed that the dandruff causing basidiomycete Malassezia has retained many of the genes related to mating and meiosis, including the mating-type locus, leading to the current hypothesis that this organism may complete a sexual cycle in association with human skin (Xu et al., 2007). Similar bioinformatics studies in the ascomycete dermatophytes, the dimorphic pathogens, and an examination of Pneumocystis also found evidence for mating-type loci and meiotic genes, indicating likely roles of sexual reproduction in these human pathogens and possibly occurring with a commensal or infectious state in humans (Smulian et al., 2001; Bubnick and Smulian, 2007; Fraser et al., 2007; Mandel et al., 2007; Burgess et al., 2008, 2009; Li et al., 2010). In the case of Pneumocystis, a group of obligate pathogenic species that only proliferate in the lungs of their infected hosts and which are 
highly species-specific, pathologic studies have suggested that sexual reproduction may be occurring in the lung of the infected host. Genomic studies have revealed genes encoding meiotic gene homologs, and when heterologously expressed in the closely related fission yeast Schizosaccharomyces pombe, these genes can complement to restore meiotic function in mutants lacking the $S$. pombe ortholog (Burgess et al., 2008). This suggests the potential capacity for an extant sexual cycle that may remain to be defined in the Pneumocystis sp. Additionally, mating has been observed to occur in vivo during infections with $C$. albicans, with reports documenting mating on the skin, in the GI tract, and other regions, and might therefore influence the evolutionary trajectory in response to, for example, antifungal drug therapy (Hull et al., 2000; Lachke et al., 2003; Dumitru et al., 2007).

p0535 Phylogenetic studies reveal that the Malassezia species, which are specialized to survive as commensals on human skin and associated with a myriad of inflammatory skin disorders, are basidiomycetes closely related to the plant pathogen of corn, Ustilago maydis. Although no extant sexual cycle has been defined for the Malassezia species, as discussed earlier, the genome reveals a mating-type locus similar to that of the bipolar species Ustilago hordei that infects barley (Bakkeren et al., 2008), and the machinery for mating and meiosis. Thus, like $U$. maydis, this raises the possibility that sexual reproduction might occur in conjunction with and even be stimulated by the host, and could be associated with infection. It further raises the possibility that the infectious form in humans could be a filamentous dikaryon produced by mating, rather than the yeast form. Further studies to address this interesting hypothesis are clearly warranted, and might reveal that sex produces novel antigens associated with disease manifestations.

p0540 Another distinct way in which the sexual cycle of fungi is linked to virulence involves roles for the mating-type locus itself in promoting pathogenesis. This has been most clearly established in $C$. neoformans, in which the serotype D variety neoformans lineage strains of the $\alpha$ mating type are more pathogenic than congenic strains of the a mating type (Kwon-Chung et al., 1992; Nielsen et al., 2005a). There appears to be an influence of genetic background, and thus the $\alpha$ locus contributes to virulence to a greater extant compared to the a locus in some serotype D genetic backgrounds but not others (Nielsen et al., 2005b), consistent with models in which virulence is a quantitative trait and the mating-type locus represents one of several genomic loci that contribute to infection. In contrast to these findings in serotype D, in the serotype A variety grubii lineage congenic strains of the $\alpha$ and a mating type were found to be of equivalent virulence in several different animal models, including heterologous model hosts (Nielsen et al., 2003). Thus far this has only been addressed in congenic strains derived from the sequence reference strain H99, and whether there might be a virulence difference for strains of opposite mating type during solo infections of the host remains to be explored in other serotype A strain backgrounds. Thus, it may emerge that this is a serotype/variety-specific difference, or it may emerge that in both serotype D and A that the mating-type locus contributes to virulence but that the impact is dependent on the strain background. Construction of additional serotype A congenic strain pairs will be necessary to examine this question in further detail. 
Interestingly, during co-infections of the serotype A congenic strains of opposite mating type, the $\alpha$ strain has a greater predilection to penetrate and infect the central nervous system (CNS) compared to a co-infecting strain of a mating type (Nielsen et al., 2005a). This involves crossing the blood-brain barrier, as there is no apparent difference in colonization of the lung, or dissemination to the spleen, but fewer a cells are observed in the CNS compared to $\alpha$ cells in most infected animals. When the inocula was directly delivered to the CNS rather than to the lung, there was no difference in survival of the $\alpha$ and a strains, providing evidence that their interaction occurs at the level of crossing the blood-brain barrier (Nielsen et al., 2005a). Recent findings provide evidence that the Ste3 pheromone receptor is involved in the interaction between $\alpha$ and a cells, in that a strains lacking the ste3a receptor are enabled to compete with $\alpha$ cells for CNS penetration, suggesting that a form of pheromone-based quorum sensing may occur between the two mating types during co-infection (Okagaki et al., 2010).

p0550 Similar types of interactions may occur with other fungal pathogens during infection of the host, and which may involve a dialog between cells in the population involving mating machinery but which does not actually lead to sexual reproduction. For example, Soll and colleagues have presented evidence that longdistance communication occurs between $\mathbf{a} / \mathbf{a}$ and $\alpha / \alpha M T L$ homozygous strains of C. albicans in the context of a biofilm, and that this pheromone communication alters the formation and adhesiveness of the resulting biofilm (Daniels et al., 2006).

p0555 Sexual reproduction among eukaryotes is pervasive and a major driving force in evolution. Among the fungi, sexual reproduction often occurs at a lower frequency than asexual propagation, although all species examined thus far appear to retain genes encoding meiotic machinery. Thus, there may be few if any true asexual fungi but many that are cryptically or covertly sexual, enabling recombination and increasing genetic diversity. Among the fungal pathogens, sexual reproduction also leads to the production of infectious spores and invasive hyphae. While sex is not yet known to be directly necessary for successful animal infections, it is in several examples linked to aspects of pathogenicity. In the plant pathogens the links between pathogenicity and sex are often obligatory, illustrating a requirement of sex for infection. Overall, sexual reproduction remains a central aspect of fungal virulence in both the plant and animal kingdoms, and whether sex plays a more intimate role in fungal infection of animals remains a provocative hypothesis to be explored in future investigations, as in fungi infecting plants.

\section{s0160 4.10 Genomics of Fungi: What Makes a Fungus Pathogenic?}

\section{s0165 4.10.1 Comparative Genomics of Plant Pathogens}

p0560 In this section, we are interested in exploring the genomic characteristics that allow some fungi to infect plants and, more rarely, animals (for a thorough review see Aguileta et al., 2009). The pathogenic fungi are most often opportunistic (Richardson, 1991; Pfaller and Diekema, 2004). Their capacity to derive nutrients from a large range of plant hosts appears to rely on a battery of genomic resources 
that are the result of different evolutionary processes. Perhaps the most important source of new genes and gene functions that are specific of fungal pathogens are derived via expansions of gene families that facilitate the infection of the host (Sidhu, 2002; Keller et al., 2005). Typically, these gene families include cell surface receptors such as the G-protein-coupled receptors (GPCRs), which bind exogenous ligands and participate in signaling cascades (Dean et al., 2005; Cuomo et al., 2007); secreted proteins, which constitute a diverse group of small peptides such as toxins, proteinaceous effectors, hydrolytic and degrading enzymes (Machida et al., 2005; Hane et al., 2007; Xu et al., 2007); protein effectors that suppress plant defenses and alter cellular metabolism (Kamper et al., 2006; Hane et al., 2007); and secondary metabolites such as nonspecific and host-specific toxins (Soanes et al., 2007). Key gene families involved in the biosynthesis of toxins include polyketide synthases (PKS) (Hopwood, 1997; Shen, 2000), nonribosomal peptide synthesis genes (NRPS) (Yuen et al., 2003), hybrid PKS-NRPSs (Kroken et al., 2003; Bohnert et al., 2004), and cytochrome P450 (Deng et al., 2007). Other genomic elements that have expanded include genes that trigger regulatory cascades (Martin et al., 2007; Martin et al., 2008). Gene families typically expand by gene duplication, which in fungal genomes range from whole-genome duplications (Dujon et al., 2004; Kellis et al., 2004; Scannell et al., 2006) to several instances of tandem duplications, such as events involving pathogenicity-related gene families including adhesins (Verstrepen and Fink, 2009), cellular motors called kinesins (Schoch et al., 2003), the ABC transporters and MFS drug efflux systems that help fungi detoxify products from the plants defenses (Howlett, 2006), the multidrug resistance transporter families (Gbelska et al., 2006), major surface glycoproteins, hexose uptake (Dulermo et al., 2009), TRK potassium transporters (Miranda et al., 2009), related proteins, and proteases (Keely et al., 2005). Gene duplications related to adaptations to the pathogenic lifestyle have also been documented, as in the case of the oxidative phosphorylation pathway, whose components have evolved by functional divergence with several instances of gene loss and duplication (Marcet-Houben et al., 2009). Following duplication, rapid rates of evolution and positive selection can give rise to novel gene functions that allow the fungus to coevolve with its host or to infect new hosts. In fungal genomes, positive selection has been found to act in the evolution of functionally important gene families, in particular those that confer an adaptation to a pathogenic lifestyle. These include genes coding for defense systems or for evading host resistance mechanisms, toxic protein genes, and other virulence-related genes (Staats et al., 2007). Particular examples of genes under positive selection that have been identified in fungal genomes include the mycotoxin gene cluster in Fusarium (Ward et al., 2002; Cuomo et al., 2007), various phytotoxin genes in Botrytis (Staats et al., 2007) and Phytophthora infestans (Liu et al., 2005), the aflatoxin gene cluster in Aspergillus (Carbone et al., 2007), host-specific toxin the wheat pathogen Phaeosphaeria nodorum (Stukenbrock and McDonald, 2007), antigens in Coccidioides human pathogens (Johannesson et al., 2004), and serine proteases in 10 fungal species $(\mathrm{Hu}$ and Leger, 2004). Positive selection in the plant defense R-genes is frequently followed by coevolution in the avirulence genes of the fungal parasite (Jones and Jones, 1997; Parniske et al., 1997; Meyers et al., 1998). This gene-for-gene 
interaction with corresponding responses in both the host and the parasite genomes is referred to as an "arms-race" process (Dawkins and Krebs, 1979).

p0565 In terms of the structure of fungal genomes, it has been shown that genes encoding biochemical products aiding in infection are often clustered together (Jargeat et al., 2003). Clustering of important gene families appears to offer several advantages for pathogenicity (Sidhu, 2002; Keller et al., 2005). Indeed, evidence shows that fungal genes interacting in the same metabolic pathway tend to be clustered together (Keller and Hohn, 1997). Another mechanism linking genes in the genome is the suppression of recombination that occurs surrounding the genes that determine mating compatibility, which are clustered at the mating-type loci (Herskowitz, 1989). Protein products of mating-type loci additionally may serve functions for mating and virulence through common G-protein-mediated environmental sensing and response pathways (Bolker, 1998). Interestingly, and in contrast with gene clustering, genetic variation created by chromosomal rearrangements has been reported to favor the adaptation to novel hosts or nutritional environments (Larriba, 2004), thus contributing to pathogenicity. Transposable elements are another class of genomic elements that have also been shown to play a significant role in enhancing the pathogenic capacities of fungi (Wostemeyer and Kreibich, 2002). In several pathogenic fungi, including Leptosphaeria maculans and Magnaporthe grisea, sequences coding for avirulence genes are found in genomic regions dense with transposable elements (Kang et al., 2001; Gout et al., 2006; Rehmeyer et al., 2006; Fudal et al., 2007), potentially contributing to the extreme variability of avirulence genes that are associated with host-pathogen coevolution. Telomeres are rapidly evolving genomic regions particularly prone to the accumulation of transposable elements, and they sometimes contain avirulence genes, thereby playing a role in host adaptation (Rehmeyer et al., 2006; Chen et al., 2007; Sánchez-Alonso and Guzman, 2008). Sometimes the genes that confer pathogenicity to fungi come from other species, either via HGT or hybridization. Although HGT is not as pervasive in fungal genomes as it is in bacteria, it appears to have occurred multiple independent times (Penalva et al., 1990, Kavanaugh et al., 2006). Occasionally, complete clusters are speculated to have been horizontally transferred (Walton, 2000). Finally, hybridization is another way to mix genes and produce new crosses with increased pathogenic capacities. There has been growing concern during the past decade over the number of reported hybridizations in fungi, particularly among pathogenic species (see Olson and Stenlid, 2002, for a review). Several hybridization events have thus been identified among parasites and mutualists from all clades of fungi. Some have been related to an increase in virulence or host range, a shift in host spectrum or even a switch toward mutualism (Olson and Stenlid, 2002).

p0570 Fungal genomes are extremely plastic. This is highlighted by the different genomic processes that have generated a versatile repertoire of biochemical functions that allow fungi to colonize a diverse range of environments and to also establish relationships with other species, either by infection or symbiosis, with an extensive array of partners. New genomic data will continue to fascinate us with examples of amazing potentials for adaptation. 


\section{s0170 4.10.2 Comparing Animal and Plant Pathogens}

p0575 Pathogenic fungi are mostly intracellular pathogens, indicating that at some point during the interaction between the host and the invading species the pathogen lives inside the host cell. Despite the variety of intracellular fungal pathogens infecting both plant and animal cells in seemingly unique ways, there are only a few general solutions to the challenge of penetrating and surviving inside host cells (Casadevall, 2008). Indeed, the problem represented by intracellular infection has been tackled by convergent solutions that have evolved in parallel in the different fungal lineages (Morris et al., 2009) of both plant and animal pathogens. It is interesting to note that among fungi there appear to be many more species that parasitize plants than animals (Desprez-Loustau et al., 2010). The reasons for this imbalance are not very clear and deserve further attention. Typically, fungi maintain closer relationships with plants and have evolved many biochemical functions to take advantage of their plant hosts to obtain nutrients (Pallen and Wren, 2007; Boller and He, 2009; Burdon and Thrall, 2009; Pringle et al., 2009). An intriguing hypothesis posits that fungi became pathogenic through the evolution of dual-use traits. It is hypothesized that this first appeared as a mechanism to defend from environmental aggressions, such as predation by amoebae, and later allowed invasion of plant and animal cells alike (Morris et al., 2009). C. neoformans provides a good example of dual-use traits that have helped this species to defend itself from amoebal predation and infect animal cells. Dual-use traits include, but are not limited to, capsule formation, and the production of melanin, laccase, phospholipase, proteases, and ureases (Casadevall et al., 2003). Also, according to this thesis, originally saprophytic interactions existed among plants, animals, and fungi that allowed the evolution of interkingdom biochemical exchanges by different strategies (Dodds et al., 2009; Oldroyd et al., 2009). Later on, these innovations were exploited to invade plant and animal cells and derive benefits (Brun et al., 2009; Grant and Jones, 2009). Examples of the new uses of previous adaptations to saprophytic lifestyles abound, and include toxin production, adhesins to adhere to host cells, injectors to penetrate the cell, interaction of fungal cells with host effector cells, and microbial efflux pumps for managing toxic environmental compounds that also help detoxify the fungal cell from defense plant products (Morris et al., 2009; Panstruga and Dodds, 2009).

p0580 The genomes of fungal animal pathogens have not been as extensively studied as phytopathogens. However, work has been published on a few of the best known infect animals. These include Aphanomyces astaci (Bangyeekhun et al., 2001; Oidtmann et al., 2004), which causes the crayfish plague; Cordyceps tuberculata (Sung et al., 2007) and Beauveria bassiana (Coates et al., 2002), both of which are entomopathogens; Batrachochytrium dendrobatidis (Kilpatrick et al., 2010), a chytridiomycete fungus that is suspected to have caused the demise of many frog species; and recently an emergent disease of bats resulting in a population decline in excess of $75 \%$ has been associated with the pathogenic fungus Geomyces destructans (Blehert et al., 2008; Puechmaille et al., 2010). Also, there are the documented cases of Malassezia globosa (Xu et al., 2007), the causative agent of dandruff; the 
infamous species A. fumigatus (Nierman et al., 2005; O'Gorman et al., 2009), which is responsible for aspergillosis in immunosuppressed human patients; and the well-known infections caused by C. albicans (http://www.candidagenome.org/), C. neoformans (Loftus et al., 2005), Coccidioides immitis (Johannesson et al., 2004), and Histoplasma capsulatum (Magrini et al., 2004). In all of these examples, lineagespecific gene family expansions have played a significant role in pathogenicity.

p0585

More research needs to be conducted and more animal pathogens need to be sequenced before we have a comprehensive view of the genetic basis, if any, of the differences between the fungal genomes of plant and animal pathogens. Most mechanisms and gene functions may be shared, as has been shown by a study of the NLP toxin whose fold is conserved and shows similarities with that of bacteria (Ottmann et al., 2009), so we can speculate about lineage- and host-specific genes and gene functions in each case.

\section{s0175 4.11 Conclusion}

p0590 Comparative genomic studies in plant pathogenic and symbiotic fungi, although still in the early stages and limited to a few pathogens, have already brought many insights into the evolution of the pathogenic lifestyle, in particular into the mechanisms of virulence and host adaptations. There is a marked bias in the sequencing efforts toward pathogenic fungi, but current projects are covering the fungal genomes of species with very diverse lifestyles, that will hopefully allow us to gain further insights into the genomics of pathogenicity.

p0595 Regarding epidemiology, molecular methods have much to offer to the study of fungal pathogens, allowing elucidation of ecological and microevolutionary processes. Population genetic approaches have provided important insights for some fungal pathogens on their mating systems, dispersal, and population structure. However, much wider employment of these methods is warranted to study fungal pathogens, where it is still too restricted, although much progress has been made recently. Microsatellite markers in particular are very powerful tools (Jarne and Lagoda, 1996) and should be more widely used for population studies in fungi, despite the technical challenges of their isolation in this kingdom (Dutech et al., 2007). Further, new methods to analyze data are being developed at a rapid pace, some using the Bayesian or coalescence frameworks, or coupling geography and genetics to unravel migration and speciation histories, which should allow even more powerful inferences on the evolutionary processes. However, further theoretical development is badly needed to apply the extant molecular methods to the variety and specificities of the fungal life cycles, such as pervasive clonality and alternation between haplo- and diploid phases (Balloux and Lugon-Moulin, 2002; Halkett et al., 2005).

p0600 Important advances have also been made recently on the speciation in fungi. Recently developed analytical methods for studying past gene flow and differentiation should be useful to determine in which cases fungal speciation by specialization onto novel hosts has occurred in sympatry (Hey and Nielsen, 2004; Hey et al., 2004). Deciphering the genetics of speciation should also prove to be 
fascinating; for instance, by finding markers segregating with inviability or sterility in interspecific progeny.

\section{s0180 Acknowledgements}

p0605 We thank Michel Tibayrenc for his cordial invitation to write this review. We acknowledge the grants ANR 06-BLAN-0201, ANR 07-BDIV-003, ANR-09-0064-01, and NIH/NIAID AI39115. Parts of this chapter are derivatives of articles previously published (Giraud et al., 2008a, 2008b, 2010; Aguileta et al., 2009). We thank the Emerfundis group. We apologize to all those colleagues whose work we might have missed to cite in this chapter.

\section{References}

Achtman, M., 1996. A surfeit of YATMs? J. Clin. Microbiol. 34, 1870.

Agapow, P.-M., Burt, A., 2001. Indices of multilocus linkage disequilibrium. Mol. Ecol. Notes $1,101-102$.

Aguileta, G., Hood, M., Refrégier, G., Giraud, T., 2009. Genome evolution in pathogenic and symbiotic fungi. Adv. Bot. Res. 49, 151-193.

Anagnostakis, S., 2001. The effect of multiple importations of pets and pathogens on a native tree. Biol. Invasions 3, 245-254.

Anderson, E.C., Thompson, E.A., 2002. A model-based method for identifying species hybrids using multilocus genetic data. Genetics 160, 1217-1229.

Anderson, J.B., Ullrich, R.C., 1978. Biological species of Armillaria mellea in North America. Mycologia 71, 402-414.

Anderson, J.B., Korhonen, K., Ullrich, R.C., 1980. Relationships between European and North American biological species of Armillaria mellea. Exp. Mycol. 4, 87-95.

Anderson, J.B., Bailey, S.S., Pukkila, P.J., 1989. Variation in ribosomal DNA among biological species of Armillaria, a genus of root-infecting fungi. Evolution 43, 1652-1662.

Anderson, P.K., Cunningham, A.A., Patel, N.G., Morales, F.J., Epstein, P.R., Daszak, P., 2004. Emerging infectious diseases of plants: pathogen pollution, climate change and agrotechnology drivers. Trends Ecol. Evol. 19, 535-544.

Arnaud-Haond, S., Belkhir, K., 2007. GENCLONE: a computer program to analyse genotypic data, test for clonality and describe spatial clonal organization. Mol. Ecol. Notes $7,15-17$.

Atallah, Z.K., Maruthachalam, K., Toit, L.d., Koike, S.T., Michael Davis, R., Klosterman, S.J., et al., 2010. Population analyses of the vascular plant pathogen Verticillium dahliae detect recombination and transcontinental gene flow. Fungal Genet. Biol. Vol. 47. pp. 416-422.

Austerlitz, F., Jung-Muller, B., Godelle, B., Gouyon, P.-H., 1997. Evolution of coalescence times, genetic diversity and structure during colonization. Theor. Popul. Biol. 51, $148-164$.

Bain, J.M., Tavanti, A., Davidson, A.D., Jacobsen, M.D., Shaw, D., Gow, N.A.R., et al., 2007. Multilocus sequence typing of the pathogenic fungus Aspergillus fumigatus. J. Clin. Microbiol. 45, 1469-1477.

Bakkeren, G., Kamper, J., Schirawski, J., 2008. Sex in smut fungi: structure, function and evolution of mating-type complexes. Fungal Genet. Biol. 45 (Suppl. 1), S15-21.

Balloux, F., Lugon-Moulin, N., 2002. The estimation of population differentiation with microsatellite markers. Mol. Ecol. 11, 155-165. 
Bangyeekhun, E., Cerenius, L., Soderhall, K., 2001. Molecular cloning and characterization of two serine proteinase genes from the crayfish plague fungus, Aphanomyces astaci. J. Invertebr. Pathol. 77, 206-216.

Banke, S., McDonald, B.A., 2005. Migration patterns among global populations of the pathogenic fungus Mycosphaerella graminicola. Mol. Ecol. 14, 1881-1896.

Barres, B., Halkett, F., Dutech, C., Andrieux, A., Pinon, J., Frey, P., 2008. Genetic structure of the poplar rust fungus Melampsora larici-populina: evidence for isolation by distance in Europe and recent founder effects overseas. Infect. Genet. Evol. 8, 577-587.

Bartlett, K.H., Kidd, S.E., Kronstad, J.W., 2008. The emergence of Cryptococcus gattii in British Columbia and the Pacific Northwest. Curr. Infect. Dis. Rep. 10, 58-65.

Beaumont, M.A., Zhang, W.Y., Balding, D.J., 2002. Approximate Bayesian computation in population genetics. Genetics 162, 2025-2035.

Beerli, P., Felsenstein, J., 1999. Maximum-likelihood estimation of migration rates and effective population numbers in two populations using a coalescent approach. Genetics 152, 763-773.

Beerli, P., Felsenstein, J., 2001. Maximum likelihood estimation of a migration matrix and effective population sizes in $n$ subpopulations by using a coalescent approach. Proc. Natl. Acad. Sci. U.S.A. 98, 4563-4568.

Bell, G., 1982. The Masterpiece of Nature: The Evolution and Genetics of Sexuality. University of California Press, Berkeley, CA.

Berbee, M.L., 2001. The phylogeny of plant and animal pathogens in the Ascomycota. Physiol. Mol. Plant Pathol. 59, 165-187.

Berbee, M.L., Taylor, J.W., 2001. Fungal molecular evolution. Gene Trees and Geologic Time The Mycota: A Comprehensive Treatise on Fungi as Experimental Systems for Basic and Applied Research. New York, Springer-Verlag, Volume VII: Systematics and Evolution Part B. pp. 229-245.

Berger, L., Speare, R., Daszak, P., Green, D., Cunningham, A., Goggin, C.L., et al., 1998. Chytridiomycosis causes amphibian mortality associated with population declines in the rain forests of Australia and Central America. Proc. Natl. Acad. Sci. U.S.A. 95, 9031-9036.

Billiard, S., López-Villavicencio, M., Devier, B., Hood, M.E., Fairhead, C., Giraud, T., 2010. Having sex, yes, but with whom? Inferences from fungi on the evolution of anisogamy and mating types. Biol. Rev. DOI: 10.1111/j.1469-185X.2010.00153.x.

Birch, P.R.J., Whisson, S.C., 2001. Phytophthora infestans enters the genomics era. Mol. Plant Pathol. 2, 257-263.

Birky, C.W., 1996. Heterozygosity, heteromorphy, and phylogenetic trees in asexual eukaryotes. Genetics 144, 427-437.

Blankenship, J.R., Singh, N., Alexander, B.D., Heitman, J., 2005. Cryptococcus neoformans isolates from transplant recipients are not selected for resistance to calcineurin inhibitors by current immunosuppressive regimens. J. Clin. Microbiol. 43, 464-467.

Blehert, D.S., Hicks, A.C., Behr, M., Meteyer, C.U., Berlowski-Zier, B.M., Buckles, E.L., et al., 2008. Bat white-nose syndrome: an emerging fungal pathogen? Science 323, 227.

Bohnert, H.U., Fudal, I., Dioh, W., Tharreau, D., Notteghem, J.L., Lebrun, M.H., 2004. A putative polyketide synthase peptide synthetase from Magnaporthe grisea signals pathogen attack to resistant rice. Plant Cell 16, 2499-2513.

Bolker, M., 1998. Sex and crime: heterotrimeric G-proteins in fungal mating and pathogenesis. Fungal Genet. Biol 25, 143-156.

Boller, T., He, S.Y., 2009. Innate immunity in plants: an arms race between pattern recognition receptors in plants and effectors in microbial pathogens. Science 324, 742-744. 
Bossart, J.L., Prowell, D.P., 1998. Genetic estimates of population structure and gene flow: limitations, lessons and new directions. Trends Ecol. Evol. 13, 202-206.

Bovers, M., Hagen, F., Kuramae, E.E., Boekhout, T., 2008. Six monophyletic lineages identified within Cryptococcus neoformans and Cryptococcus gattii by multi-locus sequence typing. Fungal Genet. Biol. 45, 400-421.

Brasier, C.M., 2001. Rapid evolution of introduced plant pathogens via interspecific hybridization. BioScience 51, 123-133.

Broquet, T., Petit, E.J., 2009. Molecular estimation of dispersal for ecology and population genetics. Annu. Rev. Ecol. Evol. Syst. 40, 193-216.

Brown, J.K.M., 1994. Chance and selection in the evolution of barley mildew. Trends Microbiol. 2, 461-501.

Brown, J.K.M., Hovmoller, M.S., 2002. Aerial dispersal of pathogens on the global and continental scales and its impact on plant disease. Science 297, 537-541.

Brun, S., Malagnac, F., Bidard, F., Lalucque, H., Silar, P., 2009. Functions and regulation of the Nox family in the filamentous fungus Podospora anserina: a new role in cellulose degradation. Mol. Microbiol. 74, 480-496.

Brunner, P.C., Schurch, S., McDonald, B.A., 2007. The origin and colonization history of the barley scald pathogen Rhynchosporium secalis. J. Evol. Biol. 20, 1311-1321.

Bubnick, M., Smulian, A.G., 2007. The MAT1 locus of Histoplasma capsulatum is responsive in a mating type-specific manner. Eukaryot. Cell 6, 616-621.

Bultman, T.L., Leuchtmann, A., 2003. A test of host specialization by insect vectors as a mechanism for reproductive isolation among entomophilous fungal species. Oikos 103, 681-687.

Burdon, J.J., Thrall, P.H., 2009. Coevolution of plants and their pathogens in natural habitats. Science 324, 755-756.

Burgess, J.W., Kottom, T.J., Limper, A.H., 2008. Pneumocystis carinii exhibits a conserved meiotic control pathway. Infect. Immun. 76, 417-425.

Burgess, J.W., Kottom, T.J., Villegas, L.R., Lamont, J.D., Baden, E.M., Ramirez-Alvarado, M., et al., 2009. The Pneumocystis meiotic PCRan1p kinase exhibits unique temperature-regulated activity. Am. J. Respir. Cell Mol. Biol. 41, 714-721.

Burt, A., Carter, D.A., Koenig, G.L., White, T.J., Taylor, J.W., 1996. Molecular markers reveal cryptic sex in the human pathogen Coccidioides immitis. Proc. Natl. Acad. Sci. U.S.A. 93, 770-773.

Byrnes 3rd, E.J., Heitman, J., 2009. Cryptococcus gattii outbreak expands into the Northwestern United States with fatal consequences. F1000 Biol. Rep. 1, 62.

Byrnes 3rd, E.J., Bildfell, R.J., Dearing, P.L., Valentine, B.A., Heitman, J., 2009a. Cryptococcus gattii with bimorphic colony types in a dog in western Oregon: additional evidence for expansion of the Vancouver Island outbreak. J. Vet. Diagn. Invest. 21, 133-136.

Byrnes 3rd, E.J., Bildfell, R.J., Frank, S.A., Mitchell, T.G., Marr, K.A., Heitman, J., 2009b. Molecular evidence that the range of the Vancouver Island outbreak of Cryptococcus gattii infection has expanded into the Pacific Northwest in the United States. J. Infect. Dis. 199, 1081-1086.

Byrnes 3rd, E.J., Li, W., Lewit, Y., Ma, H., Voelz, K., et al., 2010. Emergence and pathogenicity of highly virulent Cryptococcus gattii genotypes in the northwest United States. PLoS Pathog 6, e1000850.

Byrnes 3rd, E.J., Li, W., Lewit, Y., Perfect, J.R., Carter, D.A., Cox, G.M., et al., 2009c. First reported case of Cryptococcus gattii in the Southeastern USA: implications for travelassociated acquisition of an emerging pathogen. PLoS One 4, e5851. 
Calderon, E.J., 2010. Pneumocystis infection: seeing beyond the tip of the iceberg. Clin. Infect. Dis. 50, 354-356.

Carbone, I., Ramirez-Prado, J.H., Jakobek, J.L., Horn, B.W., 2007. Gene duplication, modularity and adaptation in the evolution of the aflatoxin gene cluster. BMC Evol. Biol. 7, 111.

Carlile, M., Watkinson, S., Gooday, G., 2001. The Fungi. second ed. Academic Press, London.

Casadevall, A., 2008. Evolution of intracellular pathogens. Annu. Rev. Microbiol. 62, $19-33$.

Casadevall, A., Perfect, J., 1998. Cryptococcus Neoformans. ASM Press, Washington DC.

Casadevall, A., Steenbergen, J.N., Nosanchuk, J.D., 2003. ""Ready made" virulence and "dual use" virulence factors in pathogenic environmental fungi-the Cryptococcus neoformans paradigm. Curr. Opin. Microbiol. 6, 332-337.

Cavalli-Sforza, L.L., 1966. Population structure and human evolution. Proc. R. Soc. Lond. B. Biol. Sci. 164, 362-379.

Chen, Q.H., Wang, Y.C., Li, A.N., Zhang, Z.G., Zheng, X.B., 2007. Molecular mapping of two cultivar-specific avirulence genes in the rice blast fungus Magnaporthe grisea. Mol. Genet. Genomics 277, 139-148.

Chen, R.S., McDonald, B.A., 1996. Sexual reproduction plays a major role in the genetic structure of populations of the fungus Mycosphaerella graminicola. Genetics 142, $1119-1127$.

Chen, S., Sorrell, T., Nimmo, G., Speed, B., Currie, B., Ellis, D., et al., 2000. Epidemiology and host- and variety-dependent characteristics of infection due to Cryptococcus neoformans in Australia and New Zealand. Australasian Cryptococcal Study Group. Clin. Infect. Dis. 31, 499-508.

Cheng, P.Y., Sham, A., Kronstad, J.W., 2009. Cryptococcus gattii isolates from the British Columbia cryptococcosis outbreak induce less protective inflammation in a murine model of infection than Cryptococcus neoformans. Infect. Immun. 77, 4284-4294.

Cleaveland, S., Laurenson, M.K., Taylor, L.H., 2001. Diseases of humans and their domestic mammals: pathogen characteristics, host range and the risk of emergence. Philos. Trans. R. Soc. Lond. B. Biol. Sci. 356, 991-999.

Clement, M., Posada, D., Crandall, K.A., 2000. TCS: a computer program to estimate gene genealogies. Mol. Ecol. 9, 1657-1659.

Coates, B.S., Hellmich, R.L., Lewis, L.C., 2002. Allelic variation of a Beauveria bassiana (Ascomycota : Hypocreales) minisatellite is independent of host range and geographic origin. Genome 45, 125-132.

Cockerham, C.C., 1969. Variance of gene frequencies. Evolution 23, 72-83.

Cockerham, C.C., 1973. Analyses of gene frequencies. Genetics 74, 679-700.

Cogliati, M., Esposto, M.C., Clarke, D.L., Wickes, B.L., Viviani, M.A., 2001. Origin of Cryptococcus neoformans var. neoformans diploid strains. J. Clin. Microbiol. 39, 3889-3894.

Cooke, D.E.L., 2007. Tracking the sudden oak death pathogen. Mol. Ecol. 16, 3735-3736.

Corander, J., Tang, J., 2007. Bayesian analysis of population structure based on linked molecular information. Math. Biosci. 205, 19-31.

Cornuet, J.M., Piry, S., Luikart, G., Estoup, A., Solignac, M., 1999. New methods employing multilocus genotypes to select or exclude populations as origins of individuals. Genetics 153, 1989-2000.

Cornuet, J.M., Santos, F., Beaumont, M.A., Robert, C.P., Marin, J.M., Balding, D.J., et al., 2008. Inferring population history with DIY ABC: a user-friendly approach to approximate Bayesian computation. Bioinformatics 24, 2713-2719. 
Couch, B.C., Fudal, I., Lebrun, M.-H., Tharreau, D., Valent, B., van Kim, P., et al., 2005. Origins of host-specific populations of the blast pathogen, Magnaporthe oryzae, in crop domestication with subsequent expansion of pandemic clones on rice and weeds of rice. Genetics 170, 613-630.

Coyne, J.A., Orr, H.A., 2004. Speciation. Sinauer Associates, Sunderland, MA.

Criscione, C.D., Poulin, R., Blouin, M.S., 2005. Molecular ecology of parasites: elucidating ecological and microevolutionary processes. Mol. Ecol. 14, 2247-2257.

Cuomo, C.A., Gueldener, U., Xu, J.R., Trail, F., Turgeon, B.G., Di Pietro, A., et al., 2007. The Fusarium graminearum genome reveals a link between localized polymorphism and pathogen specialization. Science 317, 1400-1402.

Cushion, M.T., 2004. Pneumocystis: unraveling the cloak of obscurity. Trends Microbiol. 12, $243-249$.

Cushion, M.T., Walzer, P.D., 1984a. Cultivation of Pneumocystis carinii in lung-derived cell lines. J. Infect. Dis. 149, 644.

Cushion, M.T., Walzer, P.D., 1984b. Growth and serial passage of Pneumocystis carinii in the A549 cell line. Infect. Immun. 44, 245-251.

Daniels, K.J., Srikantha, T., Lockhart, S.R., Pujol, C., Soll, D.R., 2006. Opaque cells signal white cells to form biofilms in Candida albicans. Embo J. 25, 2240-2252.

Dasbach, E.J., Davies, G.M., Teutsch, S.M., 2000. Burden of aspergillosis-related hospitalizations in the United States. Clin. Infect. Dis. 31, 1524-1528.

Daszak, P., Cunningham, A.A., Hyatt, A.D., 2000. Emerging infectious diseases of wildlife-threats to biodiversity and human health. Science 287, 443-449 .

Datta, K., Bartlett, K.H., Baer, R., Byrnes, E., Galanis, E., Heitman, J., et al., 2009. Spread of Cryptococcus gattii into Pacific Northwest region of the United States. Emerg. Infect. Dis. 15, 1185-1191.

Davison, D., Pritchard, J.K., Coop, G., 2009. An approximate likelihood for genetic data under a model with recombination and population splitting. Theor. Popul. Biol. 75, $331-345$.

Dawkins, R., Krebs, J.R., 1979. Arms race between and within species. Proc. R. Soc. Lond. B 205, 489-511.

Dawson, K.J., Belkhir, K., 2001. A Bayesian approach to the identification of panmictic populations and the assignment of individuals. Genet. Res. 78, 59-77.

De Meeus, T., Lehmann, L., Balloux, F., 2006. Molecular epidemiology of clonal diploids: a quick overview and a short DIY (do it yourself) notice. Infect. Genet. Evol. 6, $163-170$.

de Queiroz, K., 1998. The general lineage concept of species, and the process of speciation. In: Howard, D.J., Belocher, S.H. (Eds.), Endless Forms: Species and Speciation. Oxford University Press, Oxford, pp. 57-75.

de Queiroz, K., 2007. Species Concepts and Species Delimitation. Systematic Biology 56, 879-886.

de Vienne, D.M., Refrégier, G., Hood, M., Guigue, A., Devier, B., Vercken, E., et al., 2009. Hybrid sterility and inviability in the parasitic fungal species complex Microbotryum. J. Evol. Biol. 22, 683-698.

Dean, R.A., et al., 2005. The genome sequence of the rice blast fungus Magnaporthe grisea. Nature 434, 980-986.

Delmotte, F., Giresse, X., Richard-Cervera, S., M'Baya, J., Vear, F., Tourvieille, J., et al., 2008. Single nucleotide polymorphisms reveal multiple introductions into France of Plasmopara halstedii, the plant pathogen causing sunflower downy mildew. Infect. Genet. Evol. 8, 534-540. 
Delneri, D., Colson, I., Grammenoudi, S., Roberts, I.N., Louis, E.J., Oliver, S.G., 2003. Engineering evolution to study speciation in yeasts. Nature 422, 68-72.

Deng, J.X., Carbone, I., Dean, R.A., 2007. The evolutionary history of Cytochrome P450 genes in four filamentous Ascomycetes. BMC Evol. Biol. 7, 30.

Desjardins, A.E., Hohn, T.M., McCormick, S.P., 1993. Trichothecene biosynthesis in Fusarium species: chemistry, genetics and significance. Microbiol. Rev. 57, 595-604.

Desprez-Loustau, M., Robin, C., Buee, M., Courtecuisse, R., Garbaye2, J., Suffert, F., et al., 2007. The fungal dimension of biological invasions. Trends Ecol. Evol. 22, 472-480.

Desprez-Loustau, M.L., Courtecuisse, R., Robin, C., Husson, C., Moreau, P.A., Blancard, D., et al., 2010. Species diversity and drivers of spread of alien fungi (sensu lato) in Europe with a particular focus on France. Biol. Invasions 12, 157-172.

Dettman, J.R., Jacobson, D.J., Taylor, J.W., 2003a. A multilocus genealogical approach to phylogenetic species recognition in the model eukaryote Neurospora. Evolution 57, $2703-2720$.

Dettman, J.R., Jacobson, D.J., Turner, E., Pringle, A., Taylor, J.W., 2003b. Reproductive isolation and phylogenetic divergence in Neurospora: comparing methods of species recognition in a model eukaryote. Evolution 57, 2721-2741.

Dickinson, H., Antonovics, J., 1973. Theoretical considerations of sympatric divergence. Am. Nat. 107, 256-274.

Dodds, P.N., Rafiqi, M., Gan, P.H.P., Hardham, A.R., Jones, D.A., Ellis, J.G., 2009. Effectors of biotrophic fungi and oomycetes: pathogenicity factors and triggers of host resistance. New Phytol. 183, 993-999.

Douhan, G.W., Peever, T.L., Murray, T.D., 2002. Multilocus population structure of Tapesia yallundae in Washington State. Mol. Ecol. 11, 2229-2239.

Dujon, B., Sherman, D., Fischer, G., Durrens, P., Casaregola, S., Lafontaine, I., et al., 2004. Genome evolution in yeasts. Nature 430, 35-44.

Dulermo, T., Rascle, C., Chinnici, G., Gout, E., Bligny, R., Cotton, P., 2009. Dynamic carbon transfer during pathogenesis of sunflower by the necrotrophic fungus Botrytis cinerea: from plant hexoses to mannitol. New Phytol. 183, 1149-1162.

Dumitru, R., Navarathna, D.H., Semighini, C.P., Elowsky, C.G., Dumitru, R.V., Dignard, D., et al., 2007. In vivo and in vitro anaerobic mating in Candida albicans. Eukaryot Cell $6,465-472$.

Durand, E., Chen, C., Francois, O., 2009. Comment on "On the inference of spatial structure from population genetics data". Bioinformatics 25, 1802-1804.

Dutech, C., Enjalbert, E., Fournier, E., Delmotte, F., Barrès, B., Carlier, J., et al., 2007. Challenges of microsatellite isolation in fungi. Fungal Genet. Biol. 44, 933-949.

Dutech, C., Rossi, J.P., Fabreguettes, O., Robin, C., 2008. Geostatistical genetic analysis for inferring the dispersal pattern of a partially clonal species: example of the chestnut blight fungus. Mol. Ecol. 17, 4597-4607.

Dutech, C., Fabreguettes, O., Capdevielle, X., Robin, C., 2010. Multiple introductions of divergent genetic lineages in an invasive fungal pathogen, Cryphonectria parasitica, in France. Heredity 105 (2), 220-228.

Dyer, R.J., 2009. GeneticStudio: a suite of programs for spatial analysis of genetic-marker data. Mol. Ecol. Resour. 9, 110-113.

Dyer, R.J., Nason, J.D., 2004. Population graphs: the graph theoretic shape of genetic structure. Mol. Ecol. 1713-1727.

Engelbrecht, C.J.B., Harrington, T.C., Steimel, J., Capretti, P., 2004. Genetic variation in eastern North American and putatively introduced populations of Ceratocystis fimbriata f. platani. Mol. Ecol. 13, 2995-3005. 
Enjalbert, J., Duan, X., Giraud, T., Vautrin, D., de Vallavieille-Pope, C., Solignac, M., 2002. Isolation of twelve microsatellite loci, using an enrichment protocol, in the phytopathogenic fungus Puccinia striiformis f.sp. tritici. Mol. Ecol. Notes 2, 563-565.

Ergin, C., Ilkit, M., Kaftanoglu, O., 2004. Detection of Cryptococcus neoformans var. grubii in honeybee (Apis mellifera) colonies. Mycoses 47, 431-434.

Evanno, G., Regnaut, S., Goudet, J., 2005. Detecting the number of clusters of individuals using the software structure: a simulation study. Mol. Ecol. 14, 2611-2620.

Excoffier, L., 2007. Analysis of population subdivision. In: Balding, D., Bishop, M., Cannings, C. (Eds.), Handbook of Statistical Genetics, third ed. John Wiley \& Sons, Ltd, Chichester, pp. 980-1020.

Excoffier, L., Smouse, P.E., Quattro, J.M., 1992. Analysis of molecular variance inferred from metric distances among DNA haplotypes: application to human mitochondrial DNA restriction data. Genetics 131, 479-491.

Excoffier, L., Laval, G., Schneider, S., 2005. Arlequin (version 3.0): an integrated software package for population genetics data analysis. Evol. Bioinform. Online 1, $47-50$.

Falush, D., Stephens, M., Pritchard, J.K., 2003. Inference of population structure using multilocus genotype data: linked loci and correlated allele frequencies. Genetics 164, $1567-1587$.

Farris, J.S., Kallersjo, M., Kluge, A.G., Bult, C., 1994. Testing significance of incongruence. Cladistics 10, 315-319.

Fearnhead, P., Donnelly, P., 2001. Estimating recombination rates from population genetic data. Genetics 159, 1299-1318.

Fearnhead, P., Donnelly, P., 2002. Approximate likelihood methods for estimating local recombination rates. J. R. Stat. Soc. Series B Stat. Methodol. 64, 657-680.

Feder, J.L., Xie, X., Rull, J., Velez, S., Forbes, A., Leung, B., et al., 2005. Mayr, Dobzhansky, and Bush and the complexities of sympatric speciation in Rhagoletis. PNAS 102, 6573-6580.

Feil, E.J., Li, B.C., Aanensen, D.M., Hanage, W.P., Spratt, B.G., 2004. eBURST: inferring patterns of evolutionary descent among clusters of related bacterial genotypes from multilocus sequence typing data. J. Bacteriol. 186, 1518-1530.

Felsenstein, J., 1981. Skepticism towards Santa Rosalia, or why are there so few kinds of animals? Evolution 35, 124-138.

Felsenstein, J., 2007. Trees of genes in populations. In: Gascuel, O., Steel, M. (Eds.), Reconstructing Evolution. Oxford University Press, New York, NY, pp. 3-29.

Findley, K., Rodriguez-Carres, M., Metin, B., Kroiss, J., Fonseca, A., Vilgalys, R., et al., 2009. Phylogeny and phenotypic characterization of pathogenic Cryptococcus species and closely related saprobic taxa in the Tremellales. Eukaryot Cell 8, 353-361.

Finlay, B., 2002. Global dispersal of free-living microbial eukaryote species. Science 296, 1061-1063.

Fisher, D., Burrow, J., Lo, D., Currie, B., 1993. Cryptococcus neoformans in tropical northern Australia: predominantly variant gattii with good outcomes. Aust. N. Z. J. Med. 23, $678-682$.

Fisher, M., Garner, T., 2007. The relationship between the introduction of Batrachochytrium dendrobatidis, the international trade in amphibians and introduced amphibian species. Fungal Biol. Rev. 21, 2-9.

Fisher, M., Bosch, J., Yin, Z., Stead, D., Walker, J., et al., 2010. Proteomic and phenotypic profiling of an emerging pathogen of amphibians, Batrachochytrium dendrobatidis, shows that genotype is linked to virulence. Mol. Ecol. (2009) 18: 415-429. 
Fisher, M.C., Koenig, G.L., White, T.J., Taylor, J.W., 2000. Pathogenic clones versus environmentally driven population increase: analysis of an epidemic of the human fungal pathogen Coccidioides immitis. J. Clin. Microbiol. 38, 807-813.

Fisher, M.C., Koenig, G.L., White, T.J., San-Blas, G., Negroni, R., Alvarez, I.G., et al., 2001. Biogeographic range expansion into South America by Coccidioides immitis mirrors New World patterns of human migration. Proc. Natl. Acad. Sci. U.S.A. 98, $4558-4562$.

Fisher, M.C., Koenig, G.L., White, T.J., Taylor, J.W., 2002. Molecular and phenotypic description of Coccidioides posadasii sp nov., previously recognized as the nonCalifornia population of Coccidioides immitis. Mycologia 94, 73-84.

Fisher, M.C., De Hoog, S., Vanittanakom, N., 2004. A highly discriminatory multilocus microsatellite typing (MLMT) system for Penicillium marneffei. Mol. Ecol. Notes 4, $515-518$.

Fisher, M.C., Hanage, W.P., de Hoog, S., Johnson, E., Smith, M.D., White, N.J., et al., 2005. Low effective dispersal of asexual genotypes in heterogeneous landscapes by the endemic pathogen Penicillium marneffei. Plos Pathog. 1, 159-165.

Fisher, M.C., Garner, T.W.J., Walker, S.F., 2009. Global emergence of Batrachochytrium dendrobatidis and amphibian chytridiomycosis in space, time, and host. Annu. Rev. Microbiol. 63, 291-310.

Fishman, L., Wyatt, R., 1999. Pollinator-mediated competition, reproductive character displacement, and the evolution of selfing in Arenaria uniflora (Caryophyllaceae). Evolution 53, 1723-1733.

Fournier, E., Giraud, T., 2008. Sympatric genetic differentiation of a generalist pathogenic fungus, Botrytis cinerea, on two different host plants, grapevine and bramble. J. Evol. Biol. 21, 122-132.

Fournier, E., Giraud, T., Albertini, C., Brygoo, Y., 2005. Partition of the Botrytis cinerea complex in France using multiple gene genealogies. Mycologia 97, 1251-1267.

Fraser, J.A., Subaran, R.L., Nichols, C.B., Heitman, J., 2003. Recapitulation of the sexual cycle of the primary fungal pathogen Cryptococcus neoformans var. gattii: implications for an outbreak on Vancouver Island, Canada. Eukaryot. Cell 2, 1036-1045.

Fraser, J.A., Giles, S.S., Wenink, E.C., Geunes-Boyer, S.G., Wright, J.R., Diezmann, S., et al., 2005. Same-sex mating and the origin of the Vancouver Island Cryptococcus gattii outbreak. Nature 437, 1360-1364.

Fraser, J.A., Stajich, J.E., Tarcha, E.J., Cole, G.T., Inglis, D.O., Sil, A., et al., 2007. Evolution of the mating type locus: insights gained from the dimorphic primary fungal pathogens Histoplasma capsulatum, Coccidioides immitis, and Coccidioides posadasii. Eukaryot Cell 6, 622-629.

Frenkel, O., Peever, T.L., Chilvers, M.I., Ozkilinc, H., Can, C., Abbo, S., et al., 2010. Ecological genetic divergence of the fungal pathogen Didymella rabiei on sympatric wild and domesticated Cicer spp. (Chickpea). Appl. Environ. Microbiol. 76, 30-39.

Friesen, T.L., Stukenbrock, E.H., Liu, Z.H., Meinhardt, S., Ling, H., Faris, J.D., et al., 2006. Emergence of a new disease as a result of interspecific virulence gene transfer. Nature Genet. 38, 953-956.

Fuchs, B.B., Mylonakis, E., 2006. Using non-mammalian hosts to study fungal virulence and host defense. Curr. Opin. Microbiol. 9, 346-351.

Fudal, I., Ross, S., Gout, L., Blaise, F., Kuhn, M.L., Eckert, M.R., et al., 2007. Heterochromatin-like regions as ecological niches for avirulence genes in the Leptosphaeria maculans genome: map-based cloning of AvrLm6. Mol. Plant Microbe Interact. 20, 459-470. 
Gaggiotti, O.E., Jones, F., Lee, W.M., Amos, W., Harwood, J., Nichols, R.A., 2002. Patterns of colonization in a metapopulation of grey seals. Nature 416, 424-427.

Galagan, J.E., Henn, M.R., Ma, L.J., Cuomo, C.A., Birren, B., 2005. Genomics of the fungal kingdom: Insights into eukaryotic biology. Genome Res. 15, 1620-1631.

Galanis, E., MacDougall, L., 2010. Epidemiology of Cryptococcus gattii, British Columbia, Canada, 1999-2007. Emerg. Infect Dis. 16, 251-257.

Gao, H., Williamson, S., Bustamante, C.D., 2007. A Markov chain Monte Carlo approach for joint inference of population structure and inbreeding rates from multilocus genotype data. Genetics 176, 1635-1651.

Garner, T.W.J., Perkins, M.W., Govindarajulu, P., Seglie, D., Walker, S., Cunningham, A.A., Fisher, M.C., 2006. The emerging amphibian pathogen Batrachochytrium dendrobatidis globally infects introduced populations of the North American bullfrog, Rana catesbeiana. BIOLOGY LETTERS. Genetics 2, 455-459.

Gavrilets, S., 2004. Fitness Landscapes and the Origin of Species. Princeton University Press, Princeton.

Gbelska, Y., Krijger, J.J., Breunig, K.D., 2006. Evolution of gene families: the multidrug resistance transporter genes in five related yeast species. FEMS Yeast Res. 6, 345-355.

Geiser, D.M., Pitt, J.I., Taylor, J.W., 1998. Cryptic speciation and recombination in the aflatoxin-producing fungus Aspergillus flavus. Proc. Natl. Acad. Sci. U.S.A. 95, 388-393.

Gezuele, E., Calegari, L., Sanabría, D., Davel, G., Civila, E., 1993. Isolation in uruguay of Cryptococcus neoformans var. gattii from nest of the wasp Polybia occidentalis. Rev. Iberoam. Micol. 10, 5-6.

Giles, S.S., Dagenais, T.R., Botts, M.R., Keller, N.P., Hull, C.M., 2009. Elucidating the pathogenesis of spores from the human fungal pathogen Cryptococcus neoformans. Infect. Immun. 77, 3491-3500.

Giraud, T., 2004. Patterns of within population dispersal and mating of the fungus Microbotryum violaceum parasitising the plant Silene latifolia. Heredity 93, 559-565.

Giraud, T., 2006. Speciation: selection against migrant pathogens: the immigrant inviability barrier in pathogens. Heredity 97, 316-318.

Giraud, T., Fortini, D., Levis, C., Leroux, P., Brygoo, Y., 1997. RFLP markers show genetic recombination in Botryotinia fuckeliana (Botrytis cinerea) and transposable elements reveal two sympatric species. Mol. Biol. Evol. 14, 1177-1185.

Giraud, T., Villareal, L.M.M.A., Austerlitz, F., Le Gac, M., Lavigne, C., 2006. Importance of the Life Cycle in Sympatric Host Race Formation and Speciation of Pathogens. Phytopathology 96, 280-287.

Giraud, T., Enjalbert, J., Fournier, E., Delmotte, F., Dutech, C., 2008a. Population genetics of fungal diseases of plants. Parasite 15, 449-454.

Giraud, T., Refregier, G., de Vienne, D.M., Le Gac, M.a., Hood, M.E., 2008b. Speciation in fungi. Fungal Genet. Biol. 45, 791-802.

Giraud, T., Yockteng, R., Lopez-Villavicencio, M., Refregier, G., Hood, M.E., 2008c. Mating system of the anther smut fungus Microbotryum violaceum: selfing under heterothallism. Eukaryot Cell 7, 765-775.

Giraud, T., Gladieux, P., Gavrilets, S., 2010. Linking emergence of fungal plant diseases and ecological speciation. Trends Ecol. Evol. 25, 387-395.

Gladieux, P., Zhang, X.-G., Afoufa-Bastien, D., Valdebenito Sanhueza, R.-M., Sbaghi, M., Le Cam, B., 2008. On the origin and spread of the scab disease of apple: out of central Asia. PLoS ONE 3, e1455. 
Gladieux, P., Caffier, V., Devaux, M., Le Cam, B., 2010a. Host-specific differentiation among populations of Venturia inaequalis causing scab on apple, pyracantha and loquat. Fungal Genet. Biol. 47, 511-521.

Gladieux P., Vercken E., Fontaine M.C., Hood, M.E., Jonot O., Couloux A., Giraud T. 2010b. Maintenance of fungal pathogen species that are specialized to different hosts: allopatric divergence and introgression through secondary contact. Molecular Biology and Evolution in press. doi:10.1093/molbev/msq235.

Gladieux, P., Zhang, X.G., Roldan-Ruiz, I., Caffier, V., Leroy, T., Devaux, M., et al., 2010c. Evolution of the population structure of Venturia inaequalis, the apple scab fungus, associated with the domestication of its host. Mol. Ecol. 19, 658-674.

Gleason, F., Kagami, M., Lefevre, E., Sime-Ngando, T., 2008. The ecology of chytrids in aquatic ecosystems: roles in food web dynamics. Fungal Biol. Rev. 17-25.

Goka, K., Yokoyama, J., Une, Y., Kuroki, T., Suzuki, K., Nakahara, M., et al., 2009. Amphibian chytridiomycosis in Japan: distribution, haplotypes and possible route of entry into Japan. Mol. Ecol. 18, 4757-4774.

Goudet, J., 1995. FSTAT (Version 1.2): a computer program to calculate F-statistics. J. Hered. 86, 485-486.

Gout, L., Fudal, I., Kuhn, M.L., Blaise, F., Eckert, M., Cattolico, L., et al., 2006. Lost in the middle of nowhere: the AvrLm1 avirulence gene of the Dothideomycete Leptosphaeria maculans. Mol. Microbiol. 60, 67-80.

Goyeau, H., Halkett, F., Zapater, M.F., Carlier, J., Lannou, C., 2007. Clonality and host selection in the wheat pathogenic fungus Puccinia triticina. Fungal Genet. Biol. 44, 474-483.

Grant, M.R., Jones, J.D.G., 2009. Hormone (dis)harmony moulds plant health and disease. Science 324, 750-752.

Greene, D.R., Koenig, G., Fisher, M.C., Taylor, J.W., 2000. Soil isolation and molecular identification of Coccidioides immitis. Mycologia 92, 406-410.

Griffiths, R.C., Marjoram, P., 1996. Ancestral inference from samples of DNA sequences with recombination. J. Comput. Biol. 3, 479-502.

Griffiths, R.C., Tavare, S., 1994. Sampling theory for neutral alleles in a varying environment. Philos. Trans. R. Soc. Lond. B Biol. Sci. 344, 403-410.

Gudlaugsson, O., Gillespie, S., Lee, K., Vande Berg, J., Hu, J., Messer, S., et al., 2003. Attributable mortality of nosocomial candidemia, revisited. Clin. Infect. Dis. 37, $1172-1177$.

Guérin, F., Gladieux, P., Le Cam, B., 2007. Origin and colonization history of newly virulent strains of the phytopathogenic fungus Venturia inaequalis. Fungal Genet. Biol. 44, 284-292.

Guillemaud, T., Beaumont, M.A., Ciosi, M., Cornuet, J.M., Estoup, A., 2010. Inferring introduction routes of invasive species using approximate Bayesian computation on microsatellite data. Heredity 104, 88-99.

Guillot, G., 2009a. On the inference of spatial structure from population genetics data. Bioinformatics 25, 1796-1801.

Guillot, G., 2009b. Response to comment on "On the inference of spatial structure from population genetics data". Bioinformatics 25, 1805-1806.

Guillot, G., Leblois, R., Coulon, A., Frantz, A.C., 2009. Statistical methods in spatial genetics. Mol. Ecol. 18, 4734-4756.

Halkett, F., Simon, J.-C., Balloux, F., 2005. Tackling the population genetics of clonal and partially clonal organisms. Trends Ecol. Evol. 20, 194-201. 
Hane, J.K., Lowe, R.G.T., Solomon, P.S., Tan, K.-C., Schoch, C.L., Spatafora, J.W., et al., 2007. Dothideomycete plant interactions illuminated by genome sequencing and EST analysis of the wheat pathogen Stagonospora nodorum. Plant Cell 19, 3347-3368.

Hardham, A.R., 2005. Phytophthora cinnamomi. Mol. Plant Pathol. 6, 589-604.

Hawksworth, D.L., 1991. The fungal dimension of biodiversity: magnitude, significance, and conservation. Mycol. Res. 95, 641-655.

Heitman, J., Kronstad, J.W., Taylor, J.W., Casselton, L.A., 2007. Sex in Fungi: Molecular Determination and Evolutionary Implications. American Society for Microbiology Press, Washington DC.

Herskowitz, I., 1989. A regulatory hierarchy for cell specialization in yeast. Nature 342, $749-757$.

Hey, J., 2006. On the failure of modern species concepts. Trends Ecol. Evol. 21, 447-450.

Hey, J., Machado, C.A., 2003. The study of structured populations-new hope for a difficult and divided science. Nat. Rev. Genet. 4, 535-543.

Hey, J., Nielsen, R., 2004. Multilocus methods for estimating population sizes, migration rates and divergence time, with applications to the divergence of Drosophila pseudoobscura and D. persimilis. Genetics 167, 747-760.

Hey, J., Nielsen, R., 2007. Integration within the Felsenstein equation for improved Markov chain Monte Carlo methods in population genetics. Proc. Natl. Acad. Sci. U.S.A. 104, 2785-2790.

Hey, J., Won, Y.-J., Sivasundar, A., Nielsen, R., Markert, J., 2004. Using nuclear haplotypes with microsatellites to study gene flow between recently separated Cichlid species. Mol. Ecol. 13, 909-919.

Hogenhout, S.A., Van der Hoorn, R.A.L., Terauchi, R., Kamoun, S., 2009. Emerging concepts in effector biology of plant-associated organisms. Mol. Plant Microbe Interact. 22, $115-122$.

Holder, M., Lewis, P.O., 2003. Phylogeny estimation: traditional and Bayesian approaches. Nat. Rev. Genet. 4, 275-284.

Hopwood, D.A., 1997. Genetic contributions to understanding polyketide synthases. Chem. Rev. 97, 2465-2497.

Horsfall, J., 1983. Impact of introduced pests on man. In: Wilson, C., Graham, CL (Eds.), Exotic Plant Pests and North American Agriculture. Academic Press, New York, NY, pp. $1-13$.

Hovmoller, M.S., Yahyaoui, A.H., Milus, E.A., Justesen, A.F., 2008. Rapid global spread of two aggressive strains of a wheat rust fungus. Mol. Ecol. 17, 3818-3826.

Howlett, B.J., 2006. Secondary metabolite toxins and nutrition of plant pathogenic fungi. Curr. Opin. Plant Biol. 9, 371-375.

Hsueh, Y.P., Fraser, J.A., Heitman, J., 2008. Transitions in sexuality: recapitulation of an ancestral tri- and tetrapolar mating system in Cryptococcus neoformans. Eukaryotic Cell 7, 1847-1855.

Hu, G., Leger, R.J.S., 2004. A phylogenomic approach to reconstructing the diversification of serine proteases in fungi. J. Evol. Biol. 17, 1204-1214.

Hubisz, M.J., Falush, D., Stephens, M., Pritchard, J.K., 2009. Inferring weak population structure with the assistance of sample group information. Mol. Ecol. Resour. 9, 1322-1332.

Hudson, R.R., 1987. Estimating the recombination parameter of a finite population-model without selection. Genet. Res. 50, 245-250.

Hudson, R.R., 2001. Two-locus sampling distributions and their application. Genetics 159, $1805-1817$. 
Hudson, R.R., Kaplan, N.L., 1985. Statistical properties of the number of recombination events in the history of a sample of DNA-sequences. Genetics 111, 147-164.

Huelsenbeck, J.P., Andolfatto, P., 2007. Inference of population structure under a Dirichlet process model. Genetics 175, 1787-1802.

Hull, C.M., Raisner, R.M., Johnson, A.D., 2000. Evidence for mating of the "asexual" yeast Candida albicans in a mammalian host. Science 289, 307-310.

Huson, D.H., Bryant, D., 2006. Application of phylogenetic networks in evolutionary studies. Mol. Biol. Evol. 23, 254-267.

Huyse, T., Poulin, R., Théron, A., 2005. Speciation in parasites: a population genetics approach. Trends Parasitol. 21, 469-475.

Idnurm, A., Walton, F., Floyd, A., Heitman, J., 2008. Identification of the sex genes in an early diverged fungus. Nature 451, 193-198.

Ioos, R., Andrieux, A., Marçais, B., Frey, P., 2006. Genetic characterization of the natural hybrid species Phytophtora alni as inferred from nuclear and mitochondrial analyses. Fungal Genet. Biol 43, 511-529.

Ivors, K., Garbelotto, M., Vries, I., Ruyter-Spira, C., Hekkert, B., Rosenzweig, N., et al., 2006. Microsatellite markers identify three lineages of Phytophthora ramorum in US nurseries, yet single lineages in US forest and European nursery populations. Mol. Ecol. $15,1493-1505$.

Ivors, K.L., Hayden, K.J., Bonants, P.J.M., Rizzo, D.M., Garbelotto, M., 2004. AFLP and phylogenetic analyses of North American and European populations of Phytophthora ramorum. Mycol. Res. 108, 378-392.

James, T., et al., 2006. Reconstructing the early evolution of fungi using a six-gene phylogeny. Nature 443, 818-822.

James, T.Y., Porter, D., Hamrick, J.L., Vilgalys, R., 1999. Evidence for limited intercontinental gene flow in the cosmopolitan mushroom, Schizophyllum commune. Evolution $53,1665-1677$.

James, T.Y., Litvintseva, A.P., Vilgalys, R., Morgan, J.A.T., Taylor, J.W., Fisher, M.C., et al., 2009. Rapid global expansion of the fungal disease chytridiomycosis into declining and healthy amphibian populations. Plos Pathog. 5, e1000458.

Jargeat, P., Rekangalt, D., Verner, M.C., Gay, G., Debaud, J.C., Marmeisse, R., et al., 2003. Characterisation and expression analysis of a nitrate transporter and nitrite reductase genes, two members of a gene cluster for nitrate assimilation from the symbiotic basidiomycete Hebeloma cylindrosporum. Curr. Genet. 43, 199-205.

Jarne, P., Lagoda, P.J.L., 1996. Microsatellites, from molecules to populations and back. Trends Ecol. Evol. 11, 424-429.

Ji, Z.-H., Jia, J.H., Bai, F.-Y., 2009. Four novel Candida species in the Candida albicans/ Lodderomyces elongisporus clade isolated from the gut of flower beetles. Antonie Van Leeuwenhoek Int. J. Gen. Mol. Microbiol. 95, 23-32.

Johannesson, H., Vidal, P., Guarro, J., Herr, R.A., Cole, G.T., Taylor, J.W., 2004. Positive directional selection in the proline-rich antigen (PRA) gene among the human pathogenic fungi Coccidioides immitis, C. posadasii and their closest relatives. Mol. Biol. Evol. 21, 1134-1145.

Johnson, J.A., Harrington, T.C., Engelbrecht, C.J.B., 2005. Phylogeny and taxonomy of the North American clade of the Ceratocystis fimbriata complex. Mycologia 97, 1067-1092.

Johnson, P.A., Hoppensteadt, F.C., Smith, J.J., Bush, G.L., 1996. Conditions for sympatric speciation: a diploid model incorporating habitat fidelity and non-habitat assortative mating. Evol. Ecol. 10, 187-205. 
Jombart, T., 2008. adegenet: a $\mathrm{R}$ package for the multivariate analysis of genetic markers. Bioinformatics 24, 1403-1405.

Jombart, T., Pontier, D., Dufour, A.B., 2009. Genetic markers in the playground of multivariate analysis. Heredity 102, 330-341.

Jones, D.A., Jones, J.D.G., 1997. The role of leucine-rich repeat proteins in plant defences. Advances in Botanical Research Incorporating Advances in Plant Pathology 24, 89-167.

Kalinowski, S.T., 2002. Evolutionary and statistical properties of three genetic distances. Mol. Ecol. 11, 1263-1273.

Kamper, J., Kahmann, R., Bolker, M., Ma, L.-J., Brefort, T., Saville, B.J., et al., 2006. Insights from the genome of the biotrophic fungal plant pathogen Ustilago maydis. Nature 444, 97-101.

Kang, S., Lebrun, M.H., Farrall, L., Valent, B., 2001. Gain of virulence caused by insertion of a Pot3 transposon in a Magnaporthe grisea avirulence gene. Mol. Plant Microbe Interact. 14, 671-674.

Kareiva, P., Watts, S., McDonald, R., Boucher, T., 2007. Domesticated nature: shaping landscapes and ecosystems for human welfare. Science 316, 1866-1869.

Kasuga, T., White, T.J., Koenig, G., McEwen, J., Restrepo, A., Castaneda, E., et al., 2003. Phylogeography of the fungal pathogen Histoplasma capsulatum. Mol. Ecol. 12, 3383-3401.

Kauserud, H., Svegarden, I.B., Saetre, G.P., Knudsen, H., Stensrud, O., Schmidt, O., et al., 2007. Asian origin and rapid global spread of the destructive dry rot fungus Serpula lacrymans. Mol. Ecol. 16, 3350-3360.

Kavanaugh, L.A., Fraser, J.A., Dietrich, F.S., 2006. Recent evolution of the human pathogen Cryptococcus neoformans by intervarietal transfer of a 14-gene fragment. Mol. Biol. Evol. 23, 1879-1890.

Keeling, P.J., Burger, G., Durnford, D.G., Lang, B.F., Lee, R.W., Pearlman, R.E., et al., 2005. The tree of eukaryotes. Trends Ecol. Evol. 20, 670-676.

Keely, S.P., Renauld, H., Wakefield, A.E., Cushion, M.T., Smulian, A.G., Fosker, N., et al., 2005. Gene arrays at Pneumocystis carinii telomeres. Genetics 170, 1589-1600.

Keller, N.P., Hohn, T.M., 1997. Metabolic pathway gene clusters in filamentous fungi. Fungal Genet. Biol. 21, 17-29.

Keller, N.P., Turner, G., Bennett, J.W., 2005. Fungal secondary metabolism-from biochemistry to genomics. Nat. Rev. Micro. 3, 937-947.

Keller, S.M., McDermott, J.M., Pettway, R.E., Wolfe, M.S., McDonald, B.A., 1997. Gene flow and sexual reproduction in the wheat glume blotch pathogen Phaeosphaeria nodorum (Anamorph Stagonospora nodorum). Phytopathology 87, 353-358.

Kellis, M., Birren, B.W., Lander, E.S., 2004. Proof and evolutionary analysis of ancient genome duplication in the yeast Saccharomyces cerevisiae. Nature 428, $617-624$.

Kidd, S.E., Sorrell, T.C., Meyer, W., 2003. Isolation of two molecular types of Cryptococcus neoformans var. gattii from insect frass. Med. Mycol. 41, 171-176.

Kidd, S.E., Hagen, F., Tscharke, R.L., Huynh, M., Bartlett, K.H., Fyfe, M., et al., 2004. A rare genotype of Cryptococcus gattii caused the cryptococcosis outbreak on Vancouver Island (British Columbia, Canada). Proc. Natl. Acad. Sci. U.S.A. 101, $17258-17263$.

Kidd, S.E., Guo, H., Bartlett, K.H., Xu, J., Kronstad, J.W., 2005. Comparative gene genealogies indicate that two clonal lineages of Cryptococcus gattii in British Columbia resemble strains from other geographical areas. Eukaryot. Cell 4, 1629-1638. 
Kidd, S.E., Bach, P.J., Hingston, A.O., Mak, S., Chow, Y., MacDougall, L., et al., 2007a. Cryptococcus gattii dispersal mechanisms, British Columbia, Canada. Emerg. Infect. Dis. 13, 51-57.

Kidd, S.E., Chow, Y., Mak, S., Bach, P.J., Chen, H., Hingston, A.O., et al., 2007b. Characterization of environmental sources of the human and animal pathogen Cryptococcus gattii in British Columbia, Canada, and the Pacific Northwest of the United States. Appl. Environ. Microbiol. 73, 1433-1443.

Kilpatrick, A.M., Briggs, C.J., Daszak, P., 2010. The ecology and impact of chytridiomycosis: an emerging disease of amphibians. Trends Ecol. Evol. 25, 109-118.

Kimura, M., 1953. "Stepping stone" model of population structure and the decrease of genetic correlation with distance. Annu. Rep. Natl. Inst. Genet., 3, 62-63, Japan.

Kingman, J.F.C., 1982. The coalescent. Stochastic process. Appl 13, 235-248.

Kiss, L., 2005. Powdery mildew as invasive plant pathogens: new epidemics caused by two North American species in Europe. Mycol. Res. 109, 259-260.

Klee, J., Besana, A.M., Genersch, E., Gisder, S., Nanetti, A., Tam, D.Q., et al., 2007. Widespread dispersal of the microsporidium Nosema ceranae, an emergent pathogen of the western honey bee, Apis mellifera. J. Invertebr. Pathol. 96, 1-10.

Kohn, L.M., 2005. Mechanisms of fungal speciation. Annu. Rev. Phytopathol. 43, 279-308.

Kolar, C.S., Lodge, D.M., 2001. Progress in invasion biology: predicting invaders. Trends Ecol. Evol. 16, 199-204.

Kondrashov, A., 1986. Sympatric speciation: when is it possible? Biol. J. Linn. Soc. 27, 201-223.

Koufopanou, V., Burt, A., Szaro, T., Taylor, J.W., 2001. Gene genealogies, cryptic species, and molecular evolution in the human pathogen Coccidioides immitis and relatives (Ascomycota, Onygenales). Mol. Biol. Evol. 18, 1246-1258.

Kroken, S., Glass, N.L., Taylor, J.W., Yoder, O.C., Turgeon, B.G., 2003. Phylogenomic analysis of type I polyketide synthase genes in pathogenic and saprobic ascomycetes. Proc. Natl. Acad. Sci. U.S.A. 100, 15670-15675.

Kuehne, H.A., Murphy, H.A., Francis, C.A., Sniegowski, P.D., 2007. Allopatric divergence, secondary contact and genetic isolation in wild yeast populations. Curr. Biol. 17, 407-411.

Kuhn, G., Hijri, M., Sanders, I.R., 2001. Evidence for the evolution of multiple genomes in arbuscular mycorrhizal fungi. Nature 414, 745-748.

Kuhner, M.K., 2009. Coalescent genealogy samplers: windows into population history. Trends Ecol. Evol. 24, 86-93.

Kuhner, M.K., Yamato, J., Felsenstein, J., 2000. Maximum likelihood estimation of recombination rates from population data. Genetics 156, 1393-1401.

Kwon-Chung, K.J., Bennett, J.E., 1984a. Epidemiologic differences between the two varieties of Cryptococcus neoformans. Am. J. Epidemiol. 120, 123-130.

Kwon-Chung, K.J., Bennett, J.E., 1984b. High prevalence of Cryptococcus neoformans var. gattii in tropical and subtropical regions. Zentralbl. Bakteriol. Mikrobiol. Hyg. A. 257, 213-218.

Kwon-Chung, K.J., Varma, A., 2006. Do major species concepts support one, two or more species within Cryptococcus neoformans? FEMS Yeast Res. 6, 574-587.

Kwon-Chung, K.J., Edman, J.C., Wickes, B.L., 1992. Genetic association of mating types and virulence in Cryptococcus neoformans. Infect. Immun. 60, 602-605.

Kwon-Chung, K.J., Boekhout, T., Fell, J.W., Diaz, M., 2002. Proposal to conserve the name Cryptococcus gattii against $C$. hondurianus and C. bacillisporus (Basidiomycota, Hymenomycetes, Tremellomycetidae). Taxon 51, 804-806. 
Lachke, S.A., Lockhart, S.R., Daniels, K.J., Soll, D.R., 2003. Skin facilitates Candida albicans mating. Infect. Immun. 71, 4970-4976.

Larriba, G., 2004. Genome instability, recombination, and adaptation in Candida albicans. In: San-Blas, G., Calderone, R. (Eds.), Pathogenic Fungi: Host Interactions and Emerging Strategies for Control. Horizon Press, UK, pp. 285-334.

Latter, B.D.H., 1973. Island model of population differentiation—general solution. Genetics 73, $147-157$.

Le Gac, M., Giraud, T., 2008. Existence of a pattern of reproductive character displacement in Basidiomycota but not in Ascomycota. J. Evol. Biol. 21, 761-772.

Le Gac, M., Hood, M.E., Fournier, E., Giraud, T., 2007a. Phylogenetic evidence of host-specific cryptic species in the anther smut fungus. Evolution 61, 15-26.

Le Gac, M., Hood, M.E., Giraud, T., 2007b. Evolution of reproductive isolation within a parasitic fungal complex. Evolution 61, 1781-1787.

Lee, H.-Y., Chou, J.-Y., Cheong, L., Chang, N.-H., Yang, S.-Y., Leu1, J.-Y., 2008. Incompatibility of nuclear and mitochondrial genomes causes hybrid sterility between two yeast species. Cell 135, 1065-1073.

Lengeler, K.B., Cox, G.M., Heitman, J., 2001. Serotype AD strains of Cryptococcus neoformans are diploid or aneuploid and are heterozygous at the mating-type locus. Infect. Immun. 69, 115-122.

Li, N., Stephens, M., 2003. Modeling linkage disequilibrium and identifying recombination hotspots using single-nucleotide polymorphism data. Genetics 165, 2213-2233.

Li, W., Metin, B., White, T.C., Heitman, J., 2010. Organization and evolutionary trajectory of the mating type (MAT) locus in dermatophyte and dimorphic fungal pathogens. Eukaryot Cell 9, 46-58.

Li, W.H., Fu, Y.X., 1999. Coalescent theory and its application in population genetics. In: Halloran, M.E., Geiser, S. (Eds.), Statistics in Genetics. Springer, Berlin, pp. 45-80.

Linde, C.C., Zhan, J., McDonald, B.A., 2002. Population structure of Mycosphaerella graminicola: from lesions to continents. Phytopathology 92, 946-955.

Linz, B., Balloux, F., Moodley, Y., Manica, A., Liu, H., Roumagnac, P., et al., 2007. An African origin for the intimate association between humans and Helicobacter pylori. Nature 445, 915-918.

Lips, K., Brem, F., Brenes, R., Reeve, J., Alford, R., Voyles, J., et al., 2006. Emerging infectious disease and the loss of biodiversity in a neotropical amphibian community. Proc. Natl. Acad. Sci. U.S.A. 103, 3165-3170.

Lips, K., Diffendorfer, J., Mendelson, I.J., Sears, M., 2008. Riding the wave: reconciling the roles of disease and climate change in amphibian declines. PLoS Biol. 6, 441-454.

Liu, Z., Bos, J.I.B., Armstrong, M., Whisson, S.C., da Cunha, L., Torto-Alalibo, T., et al., 2005. Patterns of diversifying selection in the phytotoxin-like scr74 gene family of Phytophthora infestans. Mol. Biol. Evol. 22, 659-672.

Lizarazo, J., Linares, M., de Bedout, C., Restrepo, A., Agudelo, C.I., Castaneda, E., 2007. [Results of nine years of the clinical and epidemiological survey on cryptococcosis in Colombia, 1997-2005]. Biomedica 27, 94-109.

Loftus, B.J., Fung, E., Roncaglia, P., Rowley, D., Amedeo, P., Bruno, D., et al., 2005. The genome of the basidiomycetous yeast and human pathogen Cryptococcus neoformans. Science 307, 1321-1324.

London, R., Orozco, B.S., Mylonakis, E., 2006. The pursuit of cryptococcal pathogenesis: heterologous hosts and the study of cryptococcal host-pathogen interactions. FEMS Yeast Res. 6, 567-573. 
Longcore, J., Pessier, A., Nichols, D., 1999. Batrachochytrium dendrobatidis gen et sp nov, a chytrid pathogenic to amphibians. Mycologia 91, 219-227.

Lutzoni, F., Kauff, F., Cox, C.J., McLaughlin, D., Celio, G., Dentinger, B., et al., 2004. Where are we in assembling the fungal tree of life, classifying the fungi, and understanding the evolution of their subcellular traits? Am. J. Bot. 91, 1446-1480.

Ma, H., Hagen, F., Stekel, D.J., Johnston, S.A., Sionov, E., Falk, R., et al., 2009. The fatal fungal outbreak on Vancouver Island is characterized by enhanced intracellular parasitism driven by mitochondrial regulation. Proc. Natl. Acad. Sci. U.S.A. 106, 12980-12985.

MacDougall, L., Fyfe, M., 2006. Emergence of Cryptococcus gattii in a novel environment provides clues to its incubation period. J. Clin. Microbiol. 44, 1851-1852.

MacDougall, L., Kidd, S.E., Galanis, E., Mak, S., Leslie, M.J., Cieslak, P.R., et al., 2007. Spread of Cryptococcus gattii in British Columbia, Canada, and detection in the Pacific Northwest, USA. Emerg. Infect. Dis. 13, 42-50.

Machida, M., Asai, K., Sano, M., Tanaka, T., Kumagai, T., Terai, G., et al., 2005. Genome sequencing and analysis of Aspergillus oryzae. Nature 438, 1157-1161.

Magrini, V., Warren, W.C., Wallis, J., Goldman, W.E., Xu, J., Mardis, E.R., et al., 2004. Fosmid-based physical mapping of the Histoplasma capsulatum genomne. Genome Res. 14, 1603-1609.

Maiden, M.C.J., Bygraves, J.A., Feil, E., Morelli, G., Russell, J.E., Urwin, R., et al., 1998. Multilocus sequence typing: a portable approach to the identification of clones within populations of pathogenic microorganisms. Proc. Natl. Acad. Sci. U.S.A. 95, $3140-3145$.

Malécot, G., 1951. Un traitement stochastique des problèmes linéaires (mutation, linkage, migration) en génétique des populations. Annales de l'Université de Lyon A 14, 79-117.

Mandel, M.A., Barker, B.M., Kroken, S., Rounsley, S.D., Orbach, M.J., 2007. Genomic and population analyses of the mating type loci in Coccidioides species reveal evidence for sexual reproduction and gene acquisition. Eukaryot. Cell 6, 1189-1199.

Marcet-Houben, M., Marceddu, G., Gabaldon, T., 2009. Phylogenomics of the oxidative phosphorylation in fungi reveals extensive gene duplication followed by functional divergence. BMC Evol. Biol. 9, 295.

Marjoram, P., Tavare, S., 2006. Modern computational approaches for analysing molecular genetic variation data. Nat. Rev. Genet. 7, 759-770.

Marr, K.A., Carter, R.A., Boeckh, M., Martin, P., Corey, L., 2002a. Invasive aspergillosis in allogeneic stem cell transplant recipients: changes in epidemiology and risk factors. Blood 100, 4358-4366.

Marr, K.A., Patterson, T., Denning, D., 2002b. Aspergillosis. Pathogenesis, clinical manifestations, and therapy. Infect. Dis. Clin. North Am. 16, 875-894, vi.

Martin, F., Kohler, A., Duplessis, S., 2007. Living in harmony in the wood underground: ectomycorrhizal genomics. Curr. Opin. Plant Biol. 10, 204-210.

Martin, F., Aerts, A., Ahren, D., Brun, A., Danchin, E.G.J., Duchaussoy, F., et al., 2008. The genome of Laccaria bicolor provides insights into mycorrhizal symbiosis. Nature 452, $88-92$.

Mascheretti, S., Croucher, P.J.P., Vettraino, A., Prospero, S., Garbelotto, M., 2008. Reconstruction of the sudden oak death epidemic in California through microsatellite analysis of the pathogen Phytophthora ramorum. Mol. Ecol. 17, 2755-2768.

Masneuf, I., Hansen, J., Groth, C., Piskur, J., Dubourdieu, D., 1998. New hybrids between Saccharomyces sensu stricto yeast species found among wine and cider production strains. App. Environ. Microbiol. 64, 3887-3892. 
Matute, D., McEwen, J., Puccia, R., Montes, B., San-Blas, G., Bagagli, E., et al., 2005. Cryptic speciation and recombination in the fungus Paracoccidioides brasiliensis as revealed by gene genealogies. Mol. Biol. Evol. 23, 65-73.

Matute, D.R., Sepulveda, V.E., Quesada, L.M., Goldman, G.H., Taylor, J.W., Restrepo, A., et al., 2006. Microsatellite analysis of three phylogenetic species of Paracoccidioides brasiliensis. J. Clin. Microbiol. 44, 2153-2157.

Maynard-Smith, J., 1999. The detection and measurement of recombination from sequence data. Genetics 153, 1021-1027.

Maynard-Smith, J., Smith, N.H., 1998. Detecting recombination from gene trees. Mol. Biol. Evol. 15, 590-599.

Maynard-Smith, J., Smith, N.H., O’Rourke, M., Spratt, B.G., 1993. How clonal are bacteria? Proc. Natl. Acad. Sci. U.S.A. 90, 4384-4388.

Mayr, E., 1963. Animal Species and Evolution. Harvard University Press, Cambridge, MA.

Mboup, M., Leconte, M., Gautier, A., Wan, A.M., Chen, W., de Vallavieille-Pope, C., et al., 2009. Evidence of genetic recombination in wheat yellow rust populations of a Chinese oversummering area. Fungal Genet. Biol. 46, 299-307.

McDonald, B.A., Linde, C., 2002. Pathogen population genetics, evolutionary potential, and durable resistance. Annu. Rev. Phytopathol. 40, 349-379.

McVean, G., Awadalla, P., Fearnhead, P., 2002. A coalescent-based method for detecting and estimating recombination from gene sequences. Genetics 160, 1231-1241.

Meirmans, P.G., Van Tienderen, P.H., 2004. GENOTYPE and GENODIVE: two programs for the analysis of genetic diversity of asexual organisms. Mol. Ecol. Notes 4, 792-794.

Meteyer, C., Buckles, E., Blehert, D., Hicks, A., Green, D., Shearn-Bochsler, V., et al., 2009. Histopathologic criteria to confirm white-nose syndrome in bats. J. Vet. Diagn. Invest. 21, 411-414.

Meyer, W., Aanensen, D.M., Boekhout, T., Cogliati, M., Diaz, M.R., Esposto, M.C., et al., 2009. Consensus multi-locus sequence typing scheme for Cryptococcus neoformans and Cryptococcus gattii. Med. Mycol. 47, 561-570.

Meyers, B.C., Chin, D.B., Shen, K.A., Sivaramakrishnan, S., Lavelle, D.O., Zhang, Z., et al., 1998. The major resistance gene cluster in lettuce is highly duplicated and spans several megabases. Plant Cell 10, 1817-1832.

Milgroom, M.G., 1996. Recombination and the multilocus structure of fungal populations. Annu. Rev. Phytopathol. 34, 457-477.

Milgroom, M.G., Peever, T.L., 2003. Population biology of plant pathogens-the synthesis of plant disease epidemiology and population genetics. Plant Dis. 87, 608-617.

Milgroom, M.G., Sotirovski, K., Risteski, M., Brewer, M.T., 2009. Heterokaryons and parasexual recombinants of Cryphonectria parasitica in two clonal populations in southeastern Europe. Fungal Genet. Biol. 46, 849-854.

Miller, N., Estoup, A., Toepfer, S., Bourguet, D., Lapchin, L., Derridj, S., et al., 2005. Multiple transatlantic introductions of the western corn rootworm. Science 310, 992.

Miranda, M., Bashi, E., Vylkova, S., Edgerton, M., Slayman, C., Rivetta, A., 2009. Conservation and dispersion of sequence and function in fungal TRK potassium transporters: focus on Candida albicans. FEMS Yeast Res. 9, 278-292.

Moon, C.D., Craven, K.D., Leuchtmann, A., Clement, S.L., Schardl, C.L., 2004. Prevalence of interspecific hybrids amongst asexual fungal endophytes of grasses. Mol. Ecol. 13, $1455-1467$.

Morehouse, E.A., James, T.Y., Ganley, A.R.D., Vilgalys, R., Berger, L., Murphy, P.J., et al., 2003. Multilocus sequence typing suggests the chytrid pathogen of amphibians is a recently emerged clone. Mol. Ecol. 12, 395-403. 
Morgan, J., Meltzer, M.I., Plikaytis, B.D., Sofair, A.N., Huie-White, S., Wilcox, S., et al., 2005. Excess mortality, hospital stay, and cost due to candidemia: a case-control study using data from population-based candidemia surveillance. Infect. Control Hosp. Epidemiol. 26, 540-547.

Morgan, J.A.T., Vredenburg, V.T., Rachowicz, L.J., Knapp, R.A., Stice, M.J., Tunstall, T., et al., 2007. Population genetics of the frog-killing fungus Batrachochytrium dendrobatidis. Proc. Natl. Acad. Sci. U.S.A. 104, 13845-13850.

Morris, C.E., Bardin, M., Kinkel, L.L., Moury, B., Nicot, P.C., Sands, D.C., 2009. Expanding the paradigms of plant pathogen life history and evolution of parasitic fitness beyond agricultural boundaries. PLoS Pathog 5, e1000693.

Murphy, H.A., Kuehne, H.A., Francis, C.A., Sniegowski, P.D., 2006. Mate choice assays and mating propensity differences in natural yeast populations. Biol. Lett 2, 553-556.

Mylonakis, E., Moreno, R., El Khoury, J.B., Idnurm, A., Heitman, J., Calderwood, S.B., et al., 2005. Galleria mellonella as a model system to study Cryptococcus neoformans pathogenesis. Infect. Immun. 73, 3842-3850.

Neal, P.R., Anderson, G.J., 2005. Are "mating systems" "breeding systems" of inconsistent and confusing terminology in plant reproductive biology? Or is it the other way around? Plant Syst. Evol. 250, 173-185.

Newcombe, G., Stirling, B., McDonald, S., Vradshaw Jr., H.D., 2000. Melampsora xcolumbiana, a natural hybrid of M. medusae and M. occidentalis. Mycol. Res. 104, 261-274.

Nguyen, N.H., Suh, S.O., Marshall, C.J., Blackwell, M., 2006. Morphological and ecological similarities: wood-boring beetles associated with novel xylose-fermenting yeasts, Spathaspora passalidarum gen. sp. nov. and Candida jeffriesii sp. nov. Mycol. Res. 110, $1232-1241$.

Nguyen, N.H., Suh, S.O., Blackwell, M., 2007. Five novel Candida species in insect-associated yeast clades isolated from Neuroptera and other insects. Mycologia 99, 842-858.

Nielsen, K., Cox, G.M., Wang, P., Toffaletti, D.L., Perfect, J.R., Heitman, J., 2003. Sexual cycle of Cryptococcus neoformans var. grubii and virulence of congenic a and alpha isolates. Infect. Immun. 71, 4831-4841.

Nielsen, K., Cox, G.M., Litvintseva, A.P., Mylonakis, E., Malliaris, S.D., Benjamin Jr., D.K., et al., 2005a. Cryptococcus neoformans a strains preferentially disseminate to the central nervous system during coinfection. Infect. Immun. 73, 4922-4933.

Nielsen, K., Marra, R.E., Hagen, F., Boekhout, T., Mitchell, T.G., Cox, G.M., et al., 2005b. Interaction between genetic background and the mating-type locus in Cryptococcus neoformans virulence potential. Genetics 171, 975-983.

Nielsen, R., 2000. Estimation of population parameters and recombination rates from single nucleotide polymorphisms. Genetics 154, 931-942.

Nielsen, R., Beaumont, M.A., 2009. Statistical inferences in phylogeography. Mol. Ecol. 18, 1034-1047.

Nielsen, R., Wakeley, J., 2001. Distinguishing migration from isolation: a Markov chain Monte Carlo approach. Genetics 158, 885-896.

Nierman, W.C., Pain, A., Anderson, M.J., Wortman, J.R., Kim, H.S., Arroyo, J., et al., 2005. Genomic sequence of the pathogenic and allergenic filamentous fungus Aspergillus fumigatus. Nature 438, 1151-1156.

Nosil, P., Vines, T.H., Funk, D.J., 2005. Perspective: reproductive isolation caused by natural selection against immigrants from divergent habitats. Evolution 59, 705-719.

Nunn, M.A., Schaefer, S.M., Petrou, M.A., Brown, J.R., et al., 2007. Environmental source of Candida dubliniensis. Emerg. Infect. Dis. 13, 747-750.

O’Donnell, K., Ward, T.J., Geiser, D.M., Kistler, H.C., Aoki, T., 2004. Genealogical concordance between the mating type locus and seven other nuclear genes supports formal 
recognition of nine phylogenetically distinct species within the Fusarium graminearum clade. Fungal Genet. Biol. 41, 600-623.

O’Gorman, C.M., Fuller, H.T., Dyer, P.S., 2009. Discovery of a sexual cycle in the opportunistic fungal pathogen Aspergillus fumigatus. Nature 457, 471-474.

Odds, F., Bougnoux, M., Shaw, D., Bain, J., Davidson, A., Diogo, D., et al., 2007. Molecular phylogenetics of Candida albicans. Eukaryot. Cell 6, 1041-1052.

Okagaki, L.H., Strain, A.K., Nielsen, J.N., Charlier, CK., Baltes, N.J., et al., 2010. Cryptococcal cell morphology affects host cell interactions and pathogenicity. PLoS Pathog 6, e1000953.

Oidtmann, B., Schaefers, N., Cerenius, L., Soderhall, K., Hoffmann, R.W., 2004. Detection of genomic DNA of the crayfish plague fungus Aphanomyces astaci (Oomycete) in clinical samples by PCR. Vet. Microbiol. 100, 269-282.

Oldroyd, G.E.D., Harrison, M.J., Paszkowski, U., 2009. Reprogramming plant cells for endosymbiosis. Science 324, 753-754.

Olson, A., Stenlid, J., 2001. Plant pathogens. Mitochondrial control of fungal hybrid virulence. Nature 411, 438.

Olson, A., Stenlid, J., 2002. Pathogenic fungal species hybrids infecting plants. Microbes Infect. 4, 1353-1359.

Ordonez, M.E., Kolmer, J.A., 2007. Simple sequence repeat diversity of a worldwide collection of Puccinia triticina from durum wheat. Phytopathology 97, 574-583.

Orr, H.A., Turelli, M., 2001. The evolution of postzygotic isolation: accumulating Dobzhansky-Muller incompatibilities. Evolution 55, 1085-1094.

Ottmann, C., Luberacki, B., Kufner, I., Koch, W., Brunner, F., Weyand, M., et al., 2009. A common toxin fold mediates microbial attack and plant defense. Proc. Natl. Acad. Sci. U.S.A. 106, 10359-10364.

Otto, S.P., 2009. The evolutionary enigma of sex. Am. Nat. 174, S1-S14.

Paetkau, D., Calvert, W., Stirling, I., Strobeck, C., 1995. Microsatellite analysis of population-structure in canadian polar bears. Mol. Ecol. 4, 347-354.

Pallen, M.J., Wren, B.W., 2007. Bacterial pathogenomics. Nature 449, 835-842.

Palm, M.E., 2001. Systematics and the impact of invasive fungi on agriculture in the United States. BioScience 51, 141-147.

Panstruga, R., Dodds, P.N., 2009. Terrific protein traffic: the mystery of effector protein delivery by filamentous plant pathogens. Science 324, 748-750.

Pappas, P.G., Rex, J.H., Lee, J., Hamill, R.J., Larsen, R.A., Powderly, W., et al., 2003. A prospective observational study of candidemia: epidemiology, therapy, and influences on mortality in hospitalized adult and pediatric patients. Clin. Infect. Dis. 37, 634-643.

Pappas, P.G., Kauffman, C.A., Andes, D., Benjamin Jr., D.K., Calandra, T.F., Edwards Jr., J.E., et al., 2009. Clinical practice guidelines for the management of candidiasis: 2009 update by the Infectious Diseases Society of America. Clin. Infect. Dis. 48, 503-535.

Park, B.J., Wannemuehler, K.A., Marston, B.J., Govender, N., Pappas, P.G., Chiller, T.M., 2009. Estimation of the current global burden of cryptococcal meningitis among persons living with HIV/AIDS. AIDS 23, 525-530.

Parniske, M., Hammond-Kosack, K.E., Goldstein, C., Thomas, C.M., Jones, D.A., Harrisson, K., et al., 1997. Novel disease resistance specificities result from sequence exchange between tandemly repeated genes at the Cf-4/9 locus of tomato. Cell 91, 821-932.

Paterson, D.L., Singh, N., 1999. Invasive aspergillosis in transplant recipients. Medicine (Baltimore) 78, 123-138.

Patterson, N., Price, A.L., Reich, D., 2006. Population structure and eigenanalysis. Plos Genet. 2, 2074-2093. 
Peever, T., 2007. Role of host specificity in the speciation of Ascochyta pathogens of cool season food legumes. Eur. J. Plant Pathol 119, 119-126.

Peever, T.L., Zeigler, T.S., Dorrance, A.E., Correa-Victoria, F.J., Martin, S.S., 2000. Pathogen Population Genetics and Breeding for Disease Resistance (http://www.apsnet. org/online/feature/PathPopGenetics/). pp.

Peever, T.L., Salimath, S.S., Su, G., Kaiser, W.J., Muehlbauer, F.J., 2004. Historical and contemporary multilocus population structure of Ascochyta rabiei (teleomorph: Didymella rabiei) in the Pacific Northwest of the United States. Mol. Ecol. 13, 291-309.

Pella, J., Masuda, M., 2006. The Gibbs and split-merge sampler for population mixture analysis from genetic data with incomplete baselines. Can. J. Fish. Aquat. Sci. 63, 576-596.

Penalva, M.A., Moya, A., Dopazo, J., Ramon, D., 1990. Sequences of isopenicillin- $N$ synthetase genes suggest horizontal gene-transfer from prokaryotes to eukaryotes. Proc. R. Soc. Lond. B Biol. Sci. 241, 164-169.

Perfect, J.R., 1989. Cryptococcosis. Infect. Dis. Clin. North Am. 3, 77-102.

Pessier, A., Nichols, D., Longcore, J., Fuller, M., 1999. Cutaneous chytridiomycosis in poison dart frogs (Dendrobates spp.) and white's tree frogs (Litoria caerulea). J. Vet. Diagn. Invest. 11, 194-199.

Pfaller, M.A., Diekema, D.J., 2004. Rare and emerging opportunistic fungal pathogens: concern for resistance beyond Candida albicans and Aspergillus fumigatus. J. Clin. Microbiol. 42, 4419-4431.

Pimentel, D., McNair, S., Janecka, J., Wightman, J., Simmonds, C., O'Connell, C., et al., 2001. Economic and environmental threats of alien plant, animal, and microbe invasions. Agric. Ecosyst. Environ. 84, 1-20.

Piotrowski, J., Annis, S., Longcore, J., 2004. Physiology of Batrachochytrium dendrobatidis, a chytrid pathogen of amphibians. Mycologia 96, 9-15.

Piry, S., Alapetite, A., Cornuet, J.M., Paetkau, D., Baudouin, L., Estoup, A., 2004. GENECLASS2: a software for genetic assignment and first-generation migrant detection. J. Hered. 95, 536-539.

Poggeler, D., Masloff, S., Jacobsen, S., Kuck, U., 2000. Karyotype polymorphism correlates with intraspecific infertility in the homothallic ascomycete Sordaria macrospora. J. Evol. Biol. 13, 281-289.

Posada, D., Crandall, K.A., 2001. Intraspecific gene genealogies: trees grafting into networks. Trends Ecol. Evol. 16, 37-45.

Power, A.G., Mitchell, C.E., 2004. Pathogen spillover in disease epidemics. Am. Nat. 164, S79-S89.

Pringle, A., Baker, D., Platt, J., Wares, J., Latgé, J., Taylor, J., 2005. Cryptic speciation in the cosmopolitan and clonal human pathogenic fungus Aspergillus fumigatus. Evolution $59,1886-1899$.

Pringle, A., Bever, J.D., Gardes, M., Parrent, J.L., Rillig, M.C., Klironomos, J.N., 2009. Mycorrhizal symbioses and plant invasions. Annu. Rev. Ecol. Evol. Syst. 40, 699-715.

Pritchard, J.K., Seielstad, M.T., Perez-Lezaun, A., Feldman, M.W., 1999. Population growth of human Y chromosomes: a study of Y chromosome microsatellites. Mol. Biol. Evol. $16,1791-1798$.

Pritchard, J.K., Stephens, M., Donnelly, P., 2000. Inference of population structure using multilocus genotype data. Genetics 155, 945-959.

Pritchard, J.K., Wen, X., Falush, D., 2007. Documentation for structure software: Version 2.2. pp. 
Prospero, S., Black, J.A., Winton, L.M., 2004. Isolation and characterization of microsatellite markers in Phytophthora ramorum, the causal agent of sudden oak death. Mol. Ecol. Notes 4, 672-674.

Prospero, S., Hansen, E.M., Grunwald, N.J., Winton, L.M., 2007. Population dynamics of the sudden oak death pathogen Phytophthora ramorum in Oregon from 2001 to 2004. Mol. Ecol. 16, 2958-2973.

Puechmaille, S.J., Verdeyroux, P., Fuller, H., Gouilh, M., Beckaert, M., Teeling, E.C., 2010. White-nose syndrome fungus (Geomyces destructans) in Bat, France. Emerg. Infect. Dis. 16, 290-293, DOI: 10.3201/eid1602.091391.

Ramachandran, S., Deshpande, O., Roseman, C.C., Rosenberg, N.A., Feldman, M.W., Cavalli-Sforza, L.L., 2005. Support from the relationship of genetic and geographic distance in human populations for a serial founder effect originating in Africa. Proc. Natl. Acad. Sci. U.S.A. 102, 15942-15947.

Rannala, B., Mountain, J.L., 1997. Detecting immigration by using multilocus genotypes. Proc. Natl. Acad. Sci. U.S.A. 94, 9197-9201.

Rappleye, C.A., Goldman, W.E., 2006. Defining virulence genes in the dimorphic fungi. Annu. Rev. Microbiol. 60, 281-303.

Refrégier, G., Le Gac, M., Jabbour, F., Widmer, A., Hood, M., Yockteng, R., et al., 2008. Cophylogeny of the anther smut fungi and their Caryophyllaceous hosts: prevalence of host shifts and importance of delimiting parasite species. BMC Evol. Biol. 8, 100.

Rehmeyer, C., Li, W.X., Kusaba, M., Kim, Y.S., Brown, D., Staben, C., et al., 2006. Organization of chromosome ends in the rice blast fungus, Magnaporthe oryzae. Nucleic Acids Res. 34, 4685-4701.

Reis, R.S., Almeida-Paes, R., Muniz Mde, M., Tavares, P.M., Monteiro, P.C., Schubach, T.M., et al., 2009. Molecular characterisation of Sporothrix schenckii isolates from humans and cats involved in the sporotrichosis epidemic in Rio de Janeiro, Brazil. Mem. Inst. Oswaldo Cruz 104, 769-774.

Reynoso, M., Chulze, S., Zeller, K., Torres, A., Leslie, J., 2009. Genetic structure of Fusarium verticillioides populations isolated from maize in Argentina. Eur. J. Plant Pathol. 123, 207-215.

Rice, W.R., 1984. Disruptive selection on habitat preference and the evolution of reproductive isolation: a simulation study. Evolution 38, 1251-1260.

Richardson, M.D., 1991. Opportunistic and pathogenic fungi. J. Antimicrob. Chemother. 28, $1-11$.

Rimek, D., Haase, G., Luck, A., Casper, J., Podbielski, A., 2004. First report of a case of meningitis caused by Cryptococcus adeliensis in a patient with acute myeloid leukemia. J. Clin. Microbiol. 42, 481-483.

Rippon, J.W., 1988. Medical Mycology. WB Saunders, Philadelphia, PA.

Rivas, G.-G., Zapater, M.-F., Abadie, C., Carlier, J., 2004. Founder effects and stochastic dispersal at the continental scale of the fungal pathogen of bananas Mycosphaerella fijiensis. Mol. Ecol. 13, 471-482.

Rizzo, D.M., Garbelotto, M., Hansen, E.A., 2005. Phytophthora ramorum: integrative research and management of an emerging pathogen in California and Oregon forests. Annu. Rev. Phytopathol. 43, 309-335.

Rousset, F., 1997. Genetic differentiation and estimation of gene flow from F-statistics under isolation by distance. Genetics $145,1219-1228$.

Rousset, F., 2000. Genetic differentiation between individuals. J. Evol. Biol. 13, 58-62.

Rousset, F., 2008a. Dispersal estimation: demystifying Moran's I. Heredity 100, 231-232. 
Rousset, F., 2008b. Genepop'007: a complete re-implementation of the genepop software for Windows and Linux. Mol. Ecol. Res. 8, 103-106.

Roy, B.A., 1998. Cryptic species in the Puccinia monoica complex. Mycologia 90, 846-853.

Rydholm, C., Szakacs, G., Lutzoni, F., 1998. Low genetic variation and no detectable population structure in Aspergillus fumigatus compared to closely related Neosartorya species. Eukaryotic Cell 5, 650-657.

Salamati, S., Zhan, J., Burdon, J.J., McDonald, B.A., 2000. The genetic structure of field populations of Rhynchosporium secalis from three continents suggests moderate gene flow and regular recombination. Phytopathology 90, 901-908.

Sampaio, J.P., Inacio, J., Fonseca, A., Gadanho, M., Spencer-Martins, I., Scorzetti, G., et al., 2004. Auriculibuller fuscus gen. nov., sp. nov. and Bullera japonica sp. nov., novel taxa in the Tremellales. Int. J. Syst. Evol. Microbiol. 54, 987-993.

Sánchez-Alonso, P., Guzman, P., 2008. Predicted elements of telomere organization and function in Ustilago maydis. Fungal Genet. Biol. 45, S54-S62.

Scannell, D.R., Byrne, K.P., Gordon, J.L., Wong, S., Wolfe, K.H., 2006. Multiple rounds of speciation associated with reciprocal gene loss in polyploid yeasts. Nature 440, $341-345$.

Schaffer, R., 1975. The major groups of Basidiomycetes. Mycologia 66, 1-18.

Schardl, C.L., Craven, K.D., 2003. Interspecific hybridization in plant-associated fungi and oomycetes: a review. Mol. Ecol. 12, 2861-2873.

Schoch, C.L., Aist, J.R., Yoder, O.C., Gillian Turgeon, B., 2003. A complete inventory of fungal kinesins in representative filamentous ascomycetes. Fungal Genet. Biol. 39, 1-15.

Schulze, J., Sonnenborn, U., 2009. Yeasts in the gut: from commensals to infectious agents. Dtsch. Arztebl. Int. 106, 837-842.

Schurko, A.M., Neiman, M., Logsdon, J.M., 2009. Signs of sex: what we know and how we know it. Trends Ecol. Evol. 24, 208-217.

Seaton, R.A., 1996. The management of cryptococcal meningitis in Papua New Guinea. P. N. G. Med. J. 39, 67-73.

Sharpton, T.J., Stajich, J.E., Rounsley, S.D., Gardner, M.J., Wortman, J.R., Jordar, V.S., et al., 2009. Comparative genomic analyses of the human fungal pathogens Coccidioides and their relatives. Genome Res. 19, 1722-1731.

Shen, B., 2000. Biosynthesis of aromatic polyketides, Biosynthesis: Aromatic Polyketides, Isoprenoids, Alkaloids, vol. 209. pp. 1-51 Topics in Current Chemistry.

Sidhu, G.S., 2002. Mycotoxin genetics and gene clusters. Eur. J. Plant Pathol. 108, $705-711$.

Singh, N., Alexander, B.D., Lortholary, O., Dromer, F., Gupta, K.L., John, G.T., et al., 2008. Pulmonary cryptococcosis in solid organ transplant recipients: clinical relevance of serum cryptococcal antigen. Clin. Infect. Dis. 46, e12-8.

Slatkin, M., 1985. Gene-flow in natural populations. Annu. Rev. Ecol. Syst. 16, 393-430.

Slatkin, M., 1987. Gene flow and the geographic structure of natural populations. Science 236, 787-792.

Sloan, D., Giraud, T., Hood, M., 2008. Maximized virulence in a sterilizing pathogen: the anther-smut fungus and its co-evolved hosts. J. Evol. Biol. 21, 1544-1554.

Smulian, A.G., Sesterhenn, T., Tanaka, R., Cushion, M.T., 2001. The ste3 pheromone receptor gene of Pneumocystis carinii is surrounded by a cluster of signal transduction genes. Genetics 157, 991-1002.

Soanes, D.M., Richard, T., Talbot, N., 2007. Insights from sequencing fungal and oomycete genomes: what can we learn about plant disease and the evolution of pathogenicity? The Plant Cell 19, 3318-3326. 
Sorrell, T.C., 2001. Cryptococcus neoformans variety gattii. Med. Mycol. 39, 155-168.

Spratt, B.G., Hanage, W.P., Li, B., Aanensen, D.M., Feil, E.J., 2004. Displaying the relatedness among isolates of bacterial species-the eBURST approach. FEMS Microbiol. Lett. 241, 129-134.

Staats, M., van Baarlen, P., van Kan, J.A.L., 2005. Molecular phylogeny of the plant pathogenic genus Botrytis and the evolution of host specificity. Mol. Biol. Evol. 22, 333-346.

Staats, M., van Baarlen, P., Schouten, A., van Kan, J.A.L., Bakker, F.T., 2007. Positive selection in phytotoxic protein-encoding genes of Botrytis species. Fungal Genet. Biol. $44,52-63$.

Staples, R.C., 2000. Research on the rust fungi during the twentieth century. Annu. Rev. Phytopathol. 38, 49-69.

Stenberg, P., Lundmark, M., Saura, A., 2003. MLGsim: a program for detecting clones using a simulation approach. Mol. Ecol. Notes 3, 329-331.

Stephens, M., 2008. Inference under the coalescent. In: Balding, D.J., Bishop, M., Cannings, C. (Eds.), Handbook of Statistical Genetics, third ed. John WIley \& Sons, Ltd, Chichester, pp. 878-908.

Stukenbrock, E., Banke, S., McDonald, B., 2006. Global migration patterns in the fungal wheat pathogen Phaeosphaeria nodorum. Mol. Ecol. 15, 2895-2904.

Stukenbrock, E.H., McDonald, B.A., 2007. Geographical variation and positive diversifying selection in the host-specific toxin SnToxA. Mol. Plant Pathol. 8, 321-332.

Stukenbrock, E.H., McDonald, B.A., 2008. The origins of plant pathogens in agro-ecosystems. Annu. Rev. Phytopathol. 46, 75-100.

Stukenbrock, E.H., Banke, S., Javan-Nikkhah, M., McDonald, B.A., 2007. Origin and domestication of the fungal wheat pathogen Mycosphaerella graminicola via sympatric speciation. Mol. Biol. Evol. 24, 398-411.

Suh, S.O., Blackwell, M., 2004. Three new beetle-associated yeast species in the Pichia guilliermondii clade. FEMS Yeast Res. 5, 87-95.

Suh, S.O., Blackwell, M., 2005. Four new yeasts in the Candida mesenterica clade associated with basidiocarp-feeding beetles. Mycologia 97, 167-177.

Suh, S.O., Marshall, C.J., McHugh, J.V., Blackwell, M., 2003. Wood ingestion by passalid beetles in the presence of xylose-fermenting gut yeasts. Mol. Ecol. 12, 3137-3145.

Suh, S.O., Gibson, C.M., Blackwell, M., 2004a. Metschnikowia chrysoperlae sp. nov., Candida picachoensis sp. nov. and Candida pimensis sp. nov., isolated from the green lacewings Chrysoperla comanche and Chrysoperla carnea (Neuroptera: Chrysopidae). Int. J. Syst. Evol. Microbiol. 54, 1883-1890.

Suh, S.O., McHugh, J.V., Blackwell, M., 2004b. Expansion of the Candida tanzawaensis yeast clade: 16 novel Candida species from basidiocarp-feeding beetles. Int. J. Syst. Evol. Microbiol. 54, 2409-2429.

Suh, S.O., Nguyen, N.H., Blackwell, M., 2005. Nine new Candida species near C. membranifaciens isolated from insects. Mycol. Res. 109, 1045-1056.

Suh, S.O., Nguyen, N.H., Blackwell, M., 2006. A yeast clade near Candida kruisii uncovered: nine novel Candida species associated with basidioma-feeding beetles. Mycol. Res. 110, 1379-1394.

Suh, S.O., Nguyen, N.H., Blackwell, M., 2008. Yeasts isolated from plant-associated beetles and other insects: seven novel Candida species near Candida albicans. FEMS Yeast Res. 8, 88-102.

Sukroongreung, S., Nilakul, C., Ruangsomboon, O., Chuakul, W., Eampokalap, B., 1996. Serotypes of Cryptococcus neoformans isolated from patients prior to and during the AIDS era in Thailand. Mycopathologia 135, 75-78. 
Sung, G.H., Hywel-Jones, N.L., Sung, J.M., Luangsa-Ard, J.J., Shrestha, B., Spatafora, J.W., 2007. Phylogenetic classification of Cordyceps and the clavicipitaceous fungi. Stud. Mycol. 5-59.

Szpiech, Z.A., Jakobsson, M., Rosenberg, N.A., 2008. ADZE: a rarefaction approach for counting alleles private to combinations of populations. Bioinformatics 24, $2498-2504$.

Tampakakis, E., Peleg, A.Y., Mylonakis, E., 2009. Interaction of Candida albicans with an intestinal pathogen, Salmonella enterica serovar typhimurium. Eukaryot Cell 8, $732-737$.

Tatem, A.J., Rogers, D.J., Hay, S.I., 2006. Global transport networks and infectious disease spread. Adv. Parasitol. 62, 293-343.

Tavare, S., Balding, D.J., Griffiths, R.C., Donnelly, P., 1997. Inferring coalescence times from DNA sequence data. Genetics 145, 505-518.

Taylor, J.W., Fisher, M.C., 2003. Fungal multilocus sequence typing-it's not just for bacteria. Curr. Opin. Microbiol. 6, 351-356.

Taylor, J.W., Geiser, D.M., Burt, A., Koufopanou, V., 1999a. The evolutionary biology and population genetics underlying fungal strain typing. Clin. Microbiol. Rev. 12, 126-146.

Taylor, J.W., Jacobson, D., Fisher, M., 1999b. The evolution of asexual fungi: reproduction, speciation and classification. Annu. Rev. Phytopathol. 37, 197-246.

Taylor, J.W., Jacobson, D.J., Kroken, S., Kasuga, T., Geiser, D.M., Hibbett, D.S., et al., 2000. Phylogenetics species recognition and species concepts in fungi. Fungal Genet. Biol. 31, 21-32.

Taylor, J.W., Turner, E., Townsend, J.P., Dettman, J.R., Jacobson, D., 2006. Eukaryotic microbes, species recognition and the geographic limits of species: examples from the kingdom fungi. Philos. Trans. R. Soc. B Biol. Sci. 361, 1947-1963.

Tellier, A., de Vienne, D., Giraud, T., Shykoff, J., Hood, M., Refrégier, G., 2010. Theory and examples of host-parasite reciprocal influence: from short-term to long term interactions, from coevolution to cospeciation and host shifts. Host-Pathogen Interactions: Genetics, Immunology and Physiology. Nova Science Publishers, New York, NY, pp.

Tenzer, I., Gessler, C., 1999. Genetic diversity of Venturia inaequalis across Europe. Eur. J. Plant Pathol. 105, 545-552.

Thrall, P., Hochberg, M., Burdon, J., Bever, J., 2006. Coevolution of symbiotic mutualists and parasites in a community context. Trends in Ecology and Evolution 22, 120-126.

Tibayrenc, M., 1998. Genetic epidemiology of parasitic protozoa and other infectious agents: the need for an integrated approach. Int. J. Parasitol. 28, 85-104.

Tibayrenc, M., 2005. Bridging the gap between molecular epidemiologists and evolutionists. Trends Microbiol. 13, 575-580.

Timms, R., Read, A.F., 1999. What makes a specialist special? Trends Ecol. Evol. 14, 333-334.

Toffaletti, D.L., Nielsen, K., Dietrich, F., Heitman, J., Perfect, J.R., 2004. Cryptococcus neoformans mitochondrial genomes from serotype A and D strains do not influence virulence. Curr. Genet 46, 193-204.

Tsai, I.J., Bensasson, D., Burt, A., Koufopanou, V., 2008. Population genomics of the wild yeast Saccharomyces paradoxus: quantifying the life cycle. Proc. Natl. Acad. Sci. U.S. A. $105,4957-4962$.

Upton, A., Fraser, J.A., Kidd, S.E., Bretz, C., Bartlett, K.H., Heitman, J., et al., 2007. First contemporary case of human infection with Cryptococcus gattii in Puget Sound: evidence for spread of the Vancouver Island outbreak. J. Clin. Microbiol. $45,3086-3088$. 
Urwin, R., Maiden, M.C.J., 2003. Multi-locus sequence typing: a tool for global epidemiology. Trends Microbiol. 11, 479-487.

van Putten, W.F., Elzinga, J.A., Biere, A., 2007. Host fidelity of the pollinator guilds of Silene dioica and Silene latifolia: possible consequences for sympatric host race differentiation of a vectored plant disease. Int. J. Plant Sci 168, 421-434.

Vanittanakom Jr., N., Cooper, C.R., Fisher, M.C., Sirisanthana, T., 2006. Penicillium marneffei infection and recent advances in the epidemiology and molecular biology aspects. Clin. Microbiol. Rev. 19, 95-110.

Vekemans, X., Hardy, O.J., 2004. New insights from fine-scale spatial genetic structure analyses in plant populations. Mol. Ecol. 13, 921-935.

Velagapudi, R., Hsueh, Y.P., Geunes-Boyer, S., Wright, J.R., Heitman, J., 2009. Spores as infectious propagules of Cryptococcus neoformans. Infect. Immun. 77, 4345-4355.

Vercken, E., Fontaine, M.C., Gladieux, P., Hood, M.E., Jonot, O., Giraud, T. Glacial refugia in pathogens: European genetic structure of anther smut pathogens on Silene latifolia and S. dioica. PloS Pathogens in press.

Verstrepen, K.J., Fink, G.R., 2009. Genetic and epigenetic mechanisms underlying cell-surface variability in protozoa and fungi. Annu. Rev. Genet. 43, 1-24.

Viaud, M., Couteaudier, Y., Riba, G., 1998. Molecular analysis of hypervirulent somatic hybrids of the entomopathogenic fungi Beauveria bassiana and Beauveria sulfurescens. Appl. Environ. Microbiol. 64, 88-93.

Voyles, J., Young, S., Berger, L., Campbell, C., Voyles, W., Dinudom, A., et al., 2009. Pathogenesis of chytridiomycosis, a cause of catastrophic amphibian declines. Science $326,582-585$.

Wagner, H.H., Holderegger, R., Werth, S., Gugerli, F., Hoebee, S.E., Scheidegger, C., 2005. Variogram analysis of the spatial genetic structure of continuous populations using multilocus microsatellite data. Genetics 169, 1739-1752.

Wahl, R., Wippel, K., Goos, S., Kamper, J., Sauer, N., 2010. A novel high-affinity sucrose transporter is required for virulence of the plant pathogen Ustilago maydis. PLoS Biol. 8, e1000303.

Wakeley, J., 1997. Using the variance of pairwise differences to estimate the recombination rate. Genet. Res. 69, 45-48.

Wall, J.D., 2000. A comparison of estimators of the population recombination rate. Mol. Biol. Evol. 17, 156-163.

Walsh, T.J., Anaissie, E.J., Denning, D.W., Herbrecht, R., Kontoyiannis, D.P., Marr, K.A., et al., 2008. Treatment of aspergillosis: clinical practice guidelines of the Infectious Diseases Society of America. Clin. Infect. Dis. 46, 327-360.

Walton, J.D., 2000. Horizontal gene transfer and the evolution of secondary metabolite gene clusters in fungi: an hypothesis. Fungal Genet. Biol. 30, 167-171.

Wang, R.L., Wakeley, J., Hey, J., 1997. Gene flow and natural selection in the origin of Drosophila pseudoobscura and close relatives. Genetics 147, 1091-1106.

Ward, T.J., Bielawski, J.P., Kistler, H.C., Sullivan, E., O’Donnell, K., 2002. Ancestral polymorphism and adaptative evolution in the trichothecene mycotoxin gene cluster of phytopathogenic Fusarium. Proc. Natl. Acad. Sci. U.S.A. 99, 9278-9283.

Watterson, G.A., 1975. Number of segregating sites in genetic models without recombination. Theor. Popul. Biol. 7, 256-276.

Welch, D.M., Meselson, M., 2000. Evidence for the evolution of Bdelloid rotifers without sexual reproduction or genetic exchange. Science 288, 1211-1215.

Weldon, C., du Preez, L., Hyatt, A., Muller, R., Speare, R., 2004. Origin of the amphibian chytrid fungus. Emerg. Infect. Dis. 10, 2100-2105. 
Whitlock, M.C., McCauley, D.E., 1999. Indirect measures of gene flow and migration: F-ST not equal $1 /(4 \mathrm{Nm}+1)$. Heredity $82,117-125$.

Williams, P.D., 2009. Darwinian interventions: taming pathogens through evolutionary ecology. Trends Parasitol. 26, 83-92.

Wilson, G.A., Rannala, B., 2003. Bayesian inference of recent migration rates using multilocus genotypes. Genetics 163, 1177-1191.

Wisplinghoff, H., Bischoff, T., Tallent, S.M., Seifert, H., Wenzel, R.P., Edmond, M.B., 2004. Nosocomial bloodstream infections in US hospitals: analysis of 24,179 cases from a prospective nationwide surveillance study. Clin. Infect. Dis. 39, 309-317.

Wostemeyer, J., Kreibich, A., 2002. Repetitive DNA elements in fungi (Mycota): impact on genomic architecture and evolution. Curr. Genet. 41, 189-198.

Wright, S., 1931. Evolution in Mendelian populations. Genetics 16, 0097-0159.

Wright, S., 1943. Isolation by distance. Genetics 28, 114-138.

Wright, S., 1946. Isolation by distance under diverse systems of mating. Genetics 31, $39-59$.

Wu, C., Ting, C., 2004. Genes and speciation. Nat. Rev. Genet. 5, 114-122.

Xu, J., Saunders, C.W., Hu, P., Grant, R.A., Boekhout, T., Kuramae, E.E., et al., 2007. Dandruff-associated Malassezia genomes reveal convergent and divergent virulence traits shared with plant and human fungal pathogens. Proc. Natl. Acad. Sci. U.S.A. 104, 18730-18735.

Xue, C., Tada, Y., Dong, X., Heitman, J., 2007. The human fungal pathogen Cryptococcus can complete its sexual cycle during a pathogenic association with plants. Cell Host Microbe 1, 263-273.

Xue, C., Liu, T., Chen, L., Li, W., Liu, I., Kronstad, J.W., Seyfang, A., Heitman, J., 2010. Role of an Expanded Inositol Transporter Repertoire in Cryptococcus neoformans Sexual Reproduction and Virulence. MBio. 1, e00084-10.

Yarwood, C.E., 1970. Man-made plant diseases. Science 168, 218-220 .

Yuen, K., Pascal, G., Wong, S.S.Y., Glaser, P., Woo, P.C.Y., Kunst, F., et al., 2003. Exploring the Penicillium marneffei genome. Arch. Microbiol. 179, 339-353.

Zaffarano, P.L., McDonald, B.A., Linde, C.C., 2008. Rapid speciation following recent host shifts in the palnt pathogenic fungus Rhynchosporium. Evolution 62, 1418-1436.

Zaffarano, P.L., McDonald, B.A., Linde, C.C., 2009. Phylogeographical analyses reveal global migration patterns of the barley scald pathogen Rhynchosporium secalis. Mol. Ecol. 18, 279-293.

Zaoutis, T.E., Argon, J., Chu, J., Berlin, J.A., Walsh, T.J., Feudtner, C., 2005. The epidemiology and attributable outcomes of candidemia in adults and children hospitalized in the United States: a propensity analysis. Clin. Infect. Dis. 41, 1232-1239.

Zeller, K.A., Bowden, R.L., Leslie, J.F., 2004. Population differentiation and recombination in wheat scab populations of Gibberella zeae from the United States. Mol. Ecol. 13, $563-571$.

Zhan, J., Pettway, R.E., McDonald, B.A., 2003. The global genetic structure of the wheat pathogen Mycosphaerella graminicola is characterized by high nuclear diversity, low mitochondrial diversity, regular recombination, and gene flow. Fungal Genet. Biol. 38, 286-297.

Zhou, X.D., Burgess, T.I., Beer, Z.W., Lieutier, F., Yart, A., Klepzig, K., et al., 2007. High intercontinental migration rates and population admixture in the sapstain fungus Ophiostoma ips. Mol. Ecol. 16, 89-99.

Zolan, M.E., 1995. Chromosome-length polymorphism in fungi. Microbiol. Rev. 59, 686-698. 